Portland State University

PDXScholar

\title{
Heritage and Health: A Political-Economic Analysis of the Foodways of the Paiute Indian Tribe of Utah and the Bishop Paiute Tribe
}

April Hurst Eagan

Portland State University

Follow this and additional works at: https://pdxscholar.library.pdx.edu/open_access_etds

Part of the Agricultural and Resource Economics Commons, Place and Environment Commons, and the Social and Cultural Anthropology Commons

Let us know how access to this document benefits you.

\section{Recommended Citation}

Eagan, April Hurst, "Heritage and Health: A Political-Economic Analysis of the Foodways of the Paiute Indian Tribe of Utah and the Bishop Paiute Tribe" (2013). Dissertations and Theses. Paper 685.

https://doi.org/10.15760/etd.685

This Thesis is brought to you for free and open access. It has been accepted for inclusion in Dissertations and Theses by an authorized administrator of PDXScholar. Please contact us if we can make this document more accessible: pdxscholar@pdx.edu. 
Heritage and Health:

A Political-Economic Analysis of the Foodways of the Paiute Indian Tribe of Utah and the Bishop Paiute Tribe

by

April Hurst Eagan

A thesis submitted in partial fulfillment of the requirements for the degree of

Master of Arts

in

Anthropology

Thesis Committee:

Michele Gamburd, Chair

Karen Seccombe

Jeremy Spoon

Portland State University

2013 


\begin{abstract}
$\underline{\text { Abstract }}$
Funded by Nellis Air Force Base (NAFB), my thesis research and analysis examined Native American knowledge of heritage foods and how diminished access to food resources has affected Native American identity and health. NAFB manages the Nevada Test and Training Range (NTTR), land and air space in southern Nevada, which includes Native American ancestral lands. During a research period of 3 months in the spring/summer of 2012, I interviewed members of Native American nations culturally affiliated with ancestral lands on the NTTR, the Paiute Indian Tribe of Utah (PITU) and the Bishop Paiute Tribe. My research included participant observation and 31 interviews with tribal members considered knowledge holders by tribal leaders. In dialogue with the literature of the anthropology of food, political economy, and Critical Medical Anthropology, my analysis focused on the role of heritage foods in everyday consumption, taking into account the economic, social, environmental, and political factors influencing heritage foods access and diet. My work explored the effects of structural forces and rapid changes in diet and social conditions on Native American health. I found shifts in concepts of food-related identity across ethnic groups, tribes, ages, and genders. I also found evidence of collective efforts to improve diet-related health at tribal and community levels. Through the applied aspects of my research, participants and their families had the opportunity to share recipes and food dishes containing heritage foods as a way to promote human health and knowledge transmission.
\end{abstract}


I dedicate this thesis to Marilyn. 


\section{$\underline{\text { Acknowledgments }}$}

I acknowledge the help and support of my adviser Michele Gamburd and my professors Jeremy Spoon and Karen Seccombe. I would like to thank Michele for her patient explanations and suggestions that greatly improved the work.

I offer special thanks to Jeremy Spoon and my fellow students in the Office of Applied Anthropological Research for their encouragement and inspiration.

I acknowledge the generous financial support of Nellis Air Force Base and its Native American Program that made this research possible. I extend appreciation especially to Lynn Wulf, Richard Arnold, Dorena Martineau, and Gerald Kane for their support and advice. 


\section{$\underline{\text { Table of Contents }}$}

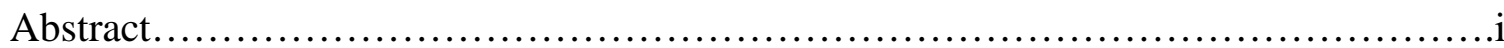

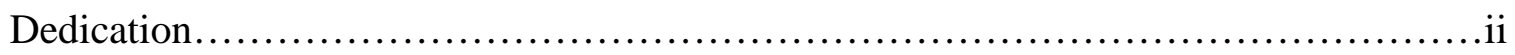

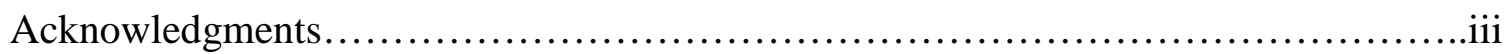

Chapter 1

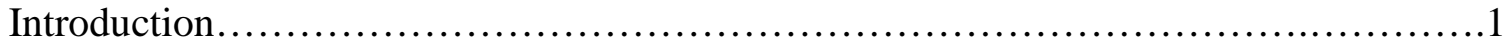

Chapter 2

History and Context......................................................... 14

Chapter 3

Traditional Diet: What is Traditional? .......................................... 33

Chapter 4

Race, Ethnicity, and Food: “The White Diet" .................................54

Chapter 5

Economics, Policy, and Human Health............................................ 76

Chapter 6

Diet-Related Health and Diabetes............................................ 110

Chapter 7

Conclusion................................................................. 138

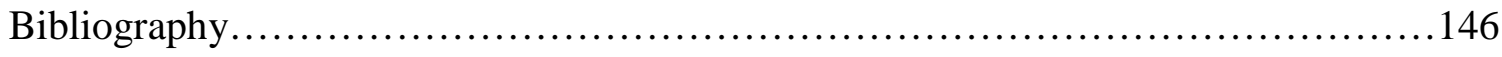

Appendices

A. Interview Schedule for Native American Participants...................... 157

B. Exhaustive List of Heritage Foods................................ 158

C. Participant Demographic Statistics..................................159

D. Map of the Research Area.........................................160

E. Map of Owens Valley............................................ 161 


\section{Chapter 1: Introduction}

As I sit beside Ellen in her home in Cedar City, Utah, during an interview, I am struck by her generosity in sharing candidly with me the rapid changes in conditions that have happened during her lifetime, some of them intensely personal. Ellen has a wonderful, sincere laugh. Her home is beautifully furnished, and photographs of family members adorn the walls. We quickly become comfortable with one another as I ask her questions about her life and about heritage foods and human health. She speaks earnestly about the positive influence of her grandmothers as she was growing up and how with them she lived a healthy, traditional lifestyle. Despite growing up "very poor," she was raised with wild, healthy, heritage foods. Ellen feels fortunate to have been raised by very traditional people and to have learned from generations before her the traditional ways of gathering and preparing food.

At the same time, Ellen is grateful that circumstances changed during her lifetime so that her children had greater educational and economic opportunities than she did. She was very proud of working later in life and helping her children get ahead. Ellen raised her children differently than she had been raised. She brought her children up with both heritage foods and American foods. She values both her integration into the larger society and her Native identity, which she worked to instill in her children.

Many Native American participants in my research project on health and heritage foods described changes during their lifetimes in a similar way: recent social conditions, which included shopping at supermarkets and buying different foods, were seen as better than prior conditions, even if diets were healthier in the past. Participants were more 
likely to have been raised with fresh, local produce from their own gardens or with wild foods families gathered. Participants also saw the perceived benefits of embracing the larger economic system and thus gaining greater economic stability and mobility. As participants experienced greater education and economic opportunity, the structure of daily routines changed to accommodate school schedules and jobs. In addition, participants had greater access to easier, more desirable purchased foods for their children and processed foods that fit into busier lifestyles. For many participants and their families, trends toward more sedentary lifestyles and less healthy diets, due to integration into the economic system and increased purchasing of lower quality foods as opposed to gathering and preparing traditional foods, created negative health outcomes for younger generations.

In the following chapters, I address the structural influences on heritage foods and diet-related health among Native American participants. Nellis Air Force Base manages lands in Nevada, including lands of cultural importance to Southern Paiute and Owens Valley Paiute people, and funded my research in order to better understand Native perspectives. My thesis research and analysis examine Native American knowledge of heritage foods, or traditional foods, and how diminished access to food resources, along with other factors, has affected Native American identity and health. I evaluate the social conditions and social inequalities that contribute to the prevalence of type 2 diabetes among Native American populations. In addition, I investigate the dynamic relationship between heritage foods and food-related identity among participants. My research adds rich data and analysis to the ongoing scholarly discussions about the anthropology of food through revealing what heritage foods mean to Native American participants and 
how Native Americans perform their identity through food. While scholars often discuss food-related problems like obesity and diabetes as individual issues related to individual choices, my research fills a gap in the discussion by using Critical Medical Anthropology/political economy to look at the role of colonial history and ongoing structural influences on diet choices among Native American populations.

\section{Overview of Issues and Theoretical Perspectives}

In dialogue with the literature of the anthropology of food, political economy, and Critical Medical Anthropology, my analysis focuses on the role of heritage foods in everyday consumption at the household level and the economic, social, environmental, and political factors influencing heritage foods and diet (Gamburd 2008; Mintz and DuBois 2002). I examine food-related gendered distinctions as well as food-related elements of identity. I explore what Native Americans of the southern Great Basin from different generations and different places think and say about lack of access to foodgathering places and its effects on heritage food practices, identity, and health.

The anthropology of food is the study of culture and society through the examination of food-related objects, words, and behavior (Tierney and Ohnuki-Tierney 2012:117). In anthropology, foodways focuses on food habits and food practices, including food gathering and food rituals (Jones, Guiliano, and Krell 1983:41). The study of food and foodways has proved valuable in advancing anthropological theory through revealing broad societal processes as well as characteristics of individual cultures and societies (Mintz and Du Bois 2002:99). Numerous scholars have added to the body of theoretical work around food, including Mary Douglas in her research on food 
symbolism and Carole Counihan in her research on food and gender-power relations. Important subtopics in the anthropology of food include food insecurity and eating and identity (Mintz and Du Bois 2002:99). In my research, I add to the anthropological study of food and foodways through investigating the role of food in ethnic and Native American identity.

My analysis explores questions of ethnic identity in its emphasis on symbolic Southern Paiute and Owens Valley Paiute heritage foods such as pine nuts, deer, and rock chuck (the common name for a ground squirrel in the marmot genus). While contemporary Southern Paiute and Owens Valley Paiute people have not had access to ancestral lands on the NTTR except through specialized programs, such as the collaborative efforts among Portland State University, NAFB, and culturally affiliated nations, they have continued to access and manage food-related resources in other areas and still gather and eat heritage foods as a means to maintain identity (Spoon and Arnold 2012).

Political economy refers to a theoretical approach that takes into account interconnected social, political, and economic factors in its analysis of social processes. Political economists seek to analyze the influence of capitalism on all aspects of life. Much of the theoretical work in political economy stems from the writing of Karl Marx. Important voices in political economy in anthropology include Paul Farmer and Merrill Singer, who both use political economy to analyze subtopics in medical anthropology. Critical Medical Anthropology, with its emphasis on the holistic study of human health, including social conditions, fits within this framework. 


\section{Critical Medical Anthropology}

Critical Medical Anthropology is a body of theory and an approach within medical anthropology that has an applied focus and seeks to find solutions in a globalized world (Scheper-Hughes 1994; Singer 1995). An important component of Critical Medical Anthropology is the political economy of health. Beyond political economy and its study of the production and exchange of goods, in this case health services as commodities, Critical Medical Anthropology has a primary goal of understanding differential power relations in social and political systems and thus differential access to health and health services among individuals (Baer, Singer, and Susser 2003; Kleinman 1988). It examines health structures on a macro- and micro-level as well as the dynamic relationship between structures and individuals (Baer, Singer, and Susser 2003; Kleinman 1995; Singer 1995; Singer and Clair 2003). People's wages and their subsequent access to healthy foods and adequate nutrition figure largely into the body of Critical Medical Anthropology work. Through the lenses of the political economy of health and Critical Medical Anthropology, my analysis demonstrates the disparities inherent in social and political systems that affect Native American access to healthy heritage foods and affect their diet-related health.

In addition, Critical Medical Anthropology emphasizes the subjective and individual experience of health and health care. In this way, the theoretical lens of Critical Medical Anthropology encourages a view of the personal as well as social and political bodies (Scheper-Hughes 1994). The individual, physical body serves as more than a cultural or social symbol or as an entity at complete subservience to the State or political body (Scheper-Hughes 1994). The physical body is seen in Critical Medical 
Anthropology as "the terrain where social truths are forged and social contradictions are played out, as well as the locus for personal resistance, activity, and struggle" (ScheperHughes 1994). The interplay between political and social structures and the individual is seen as dynamic and active. My research takes into account individual perceptions while filling in the gap of analyzing structural constraints on diet choices.

Most importantly, Critical Medical Anthropology offers researchers and practitioners a framework within which they may evaluate and critique current conditions and services for the benefit of those they research, usually marginalized or disadvantaged peoples. Within this critical theoretical framework, anthropologists reveal deep social inequities, and they challenge aspects of health systems that disadvantage people (Farmer 2001; Kleinman 1988; Singer 1995). Singer calls this engagement to produce meaningful social change "praxis" (Singer 1995). There is an obvious and close relationship between inequality in society and the living conditions of people. There is also a close relationship between poor living conditions and high rates of disease or social problems within a particular community or region (Kleinman, Das, and Lock 1997; Singer and Clair 2003). Critical Medical Anthropology underlines the idea that an epidemic, for example, does not happen in isolation, but is the consequence of a number of related factors in a society and community (Singer and Clair 2003). In my research, I highlight effective collective efforts at the tribal and community levels that work against structural forces and improve diet-related health.

\section{Research Site and Methodology}


Nellis Air Force Base (NAFB), which funded my research through its Native American Program, manages the Nevada Test and Training Range (NTTR), land and air space in southern Nevada used for military activities, which includes Native American ancestral lands. In 2011, I was an intern on an ethnographic project with Southern Paiute, Western Shoshone, and Owens Valley Paiute knowledge holders in the central and southern Great Basin, which represented collaborative efforts among Portland State University, Native American nations, and NAFB. I narrowed my research to include only 2 tribes representing 2 ethnic groups, Paiute Indian Tribe of Utah (Southern Paiute) and Bishop Paiute Tribe (Owens Valley Paiute). Through my experiences as an NAFB student intern and through discussions with tribal leaders and knowledge holders, I chose to focus my thesis research on knowledge of heritage foods, such as pine nuts and other gathered foods, which are present on Native ancestral lands and the NTTR. I chose to look at the relationships among heritage foods, identity, and human health. The return of my research in the form of this thesis will help NTTR managers understand Native American perspectives and may even help protect food-gathering sites of cultural importance to Native American nations from military activities on the NTTR.

Located within the Great Basin in southern Nevada, the NTTR is comprised of 2.9 million acres of land and air space in southern Nevada restricted for peaceful military operations and managed by NAFB (NAFB 2012). The history of the NTTR is traced back to the $98^{\text {th }}$ Bombardment Wing, which was created in 1947 (NAFB 2012). There are a total of 16 Nations culturally affiliated with the NTTR (Spoon and Arnold 2012), and I consulted knowledge holders from 2 of these nations, including (as federally recognized): Bishop Paiute Tribe in central California and Paiute Indian Tribe of Utah comprised of 
five bands, Cedar Band, Indian Peaks Band, Kanosh Band, Koosharem Band, and Shivwits Band in southwestern Utah (BIA 2013). Through consultation of knowledge holders of these 2 nations, I worked with 2 of the ethnic groups culturally affiliated with the NTTR and located in the central and southern Great Basin region: Southern Paiute and Owens Valley Paiute (Kelly 1934; Liljeblad and Fowler 1986; Spoon et al. 2011; Stoffle and Zedeno 2001).

I utilized a comparative research design that included participants varying by age, nation/tribe, and gender. Comparisons between age groups, between those younger than 60 years old and those older than 60, helped demonstrate whether knowledge of heritage foods has been lost or changed. Gender comparisons helped illustrate differences between what women know about heritage foods and what men know about heritage foods. Finally, gathering information from multiple ethnic groups with cultural ties to the NTTR offered the best representation of Native American perspectives critical to my research analysis. Information gathered in one location was used to confirm or complicate data from another location. The two locations were chosen due to informant availability. I have included maps with locations of reservations and cities, a table with demographic information on my sample, and a list of heritage foods at the end of the document (see Appendices B-E).

My sampling selection of interview consultants included 10 knowledge holders from Bishop Paiute Tribe (Owens Valley Paiute) and 21 knowledge holders from PITU (Southern Paiute). The sample contained individuals from a range of ages, from age 40 to age 80 . Younger informants were not available due to lack of knowledge or lack of experience with heritage foods. Efforts were made to include Southern Paiute and Owens 
Valley Paiute tribal health professionals as part of the sample of Native American knowledge holders as a way to incorporate Native and bio-medical perspectives on health. I selected expert knowledge holders, or consultants, who sometimes were and sometimes were not considered elders, based on information from community leaders.

A convenience sample including both genders was selected to increase understanding of gender-specific information regarding foods and eating practices. While the emphasis of the project is on female perspectives due to the interest of NTTR managers in protecting female-related sites on the NTTR, men were included in the sample in order to cross-check data about gendered beliefs and attitudes.

Interviews were conducted on and off reservations in interviewees' homes, and I utilized an interview schedule and semi-structured interviews. I began interviews with demographic questions, including age, ethnic background, Nation, religion/spiritual affiliation, education, and occupation, as a means to make comparisons between Nations and generations. Later questions gathered knowledge of heritage foods and the cultural importance of particular foods, women's and men's foods/roles, gathering and food preparation practices, eating practices and habits, and access to foods. Finally, concluding questions were focused on consultant perceptions of health in general, human health, and connections among foods and health. During interviews, heritage foods were referred to as "traditional foods" or "traditional diet," in line with the vernacular of the community. The complete list of questions is included at the end of this thesis as Appendix A. The children of consultants interviewed were invited to attend, keeping with Spoon's and Arnold's (2012) methods and promoting the transmission of intergenerational knowledge. 
Depending on consent, interviews were audio recorded, and audio CDs of interviews were returned to participants. Audio recordings were partially transcribed for analysis purposes only. I utilized pseudonyms for all participants mentioned in this paper.

As part of this applied project, I asked participants to share heritage food recipes during interviews, which were then shared with other participants through a traditional foods cookbook and through a community potluck I arranged. Applied anthropology is the part of sociocultural anthropology that focuses on engaging contemporary social issues through policy analysis, applied research, and practice (Ervin 2005:2). My research is applied in that I used research to make a heritage foods cookbook with and for community participants and I gathered data to return to land managers (Ervin 2005:4). PITU leaders and members were interested and actively participated in this part of the research, while key Bishop Paiute Tribe members were not interested in making the cookbook because it was not a project they needed. As an applied anthropologist using a community-based participatory research approach (Perry and Hoffman 2010), I involved the tribal council and research participants in designing the research and the cookbook. Photographs taken during the traditional foods dinner were used in the traditional foods cookbook. Along with tribal leaders, I organized a final gathering of project participants and their families in which participants prepared heritage foods dishes from the cookbook as a way to encourage intergenerational knowledge transmission.

\section{Overview of Chapters}


In the chapters that follow, I introduce the reader to the main issues concerning diet and diet-related health among Native participants and will analyze data on Native foodways in light of identity, heritage, policy, economics, and social conditions.

After a chapter on the recent historical context of the research sites, I outline in Chapter 3 and 4 participants' perspectives on the Native diet, or traditional diet, the current incorporation of heritage foods in Native people's diets, and the importance of heritage foods to participants' identity. I frame questions of food and identity within the larger understandings of social change and dietary change. I use concepts from the anthropology of food, traditional food systems, and foodways to distinguish between wild foods, traditional foods, heritage foods, and familiar foods. I explore how Native people integrate both old and new foods into their lives and into their children's lives through regular heritage foods practices and ceremonial practices and how Native people perform identity through these practices. I define gender identity in terms of heritage food practices that involve being good mothers and eating at home. I address the influence of the dominant culture on diet and food practices over time, as tastes and knowledge changed among Native people and as participants came to see themselves as functioning in multiple worlds. Finally, I use the concepts of self-understanding and groupness to understand what these foods mean to Native people in terms of ethnic identity, through their understanding of self as multicultural and/or Native and their understanding of self as part of a group or tribe.

In Chapter 5, I discuss the effects of larger forces, such as economics, on participants' heritage foods access and heritage foods practices. The theoretical framework of political economy and Critical Medical Anthropology encourages scholars 
to focus on major issues of economics and policy that have consequences for diet and diet-related health, including the expense of heritage foods today and the cost of gas to travel to heritage food-related resources. Social conditions, or modifiable characteristics of the environment such as transportation and access to healthy food, are relevant to the subject of heritage foods and in turn positively or negatively affect Native people's dietrelated health. These wider forces contribute to the toxic food environment. I reveal Native perspectives on the health of the environment as it affects heritage food-related resources. Finally, I outline barriers to Native people's heritage foods access and resulting barriers to heritage foods knowledge transmission.

Chapter 6 narrows the focus from the general toxic food environment to the prevalence of diabetes in particular. Through the framework of political economy, I discuss the politics behind food advertising and the ready availability of delocalized food, or distant food available to individuals and families through commercial channels as a result of an intensified global network of socioeconomic and political interdependency (Pelto and Pelto 1983:507). Participants found it difficult to make healthy food choices in the toxic food environment, especially in the "food desert" where some participants live (Beaulac et al. 2009:1). A food desert is a geographic or socioeconomically disadvantaged area characterized by relatively poor access to healthy and affordable food, which compounds individual disadvantages and contributes to social disparities in diet and diet-related health outcomes (Beaulac et al. 2009:2). I use insights from Critical Medical Anthropology to address the question of optimal social conditions needed for healthy diets. The rapid nature of changing social conditions, including living and working conditions seen as improvements, among Native individuals and families have 
dramatically affected Native American diets and diet-related health due to loss of heritage foods knowledge and incorporation of more processed foods over time. I discuss individual and collective efforts to improve diet-related health and prevent or control diabetes through diet and exercise and through sharing healthy, heritage foods recipes. I discuss the role of individual responsibility versus the role of structural forces in dietrelated health and show the efficacy of collective efforts to improve diet-related health, especially at the levels of the tribe and community. I conclude with a chapter discussing the implications of my research and possible avenues for future research. 


\section{Chapter 2: History and Context}

The topic of my thesis is the concept of heritage foods and their relationship to human health, with a focus on political economy and the effects of large-scale forces on human lives and even human bodies. In order to fully understand this subject, the modern anthropologist, and especially the medical anthropologist, must see beyond the "ethnographically visible" (Farmer 2001:305) and investigate the intersection of the social and biological in space and time. This intersection may be hidden from view through the erasure of key historical events from memory and social consciousness (Farmer 2001:308). The role of the anthropologist is to look deeper than the present, surface state of affairs to understand the continuing influence of history on particular geographic places and people (Farmer 2001:308). It is part of my project to reveal how history continues to shape current systems and to affect human bodies.

The theoretical frameworks of political economy and Critical Medical Anthropology provide a backdrop for my analysis in this chapter and force me to consider the relationship of the individual to society, the dynamics of power in society, and the influence of marginalization, deprivation, and inequality on Native American lives over time. Political economy endeavors to reveal the interrelated structural forces at work in a given society at a particular point in time. Critical Medical Anthropology allows me to examine the social conditions that directly influence the health of individuals.

Although an in-depth discussion of the broad, formative characteristics of the American West are beyond the scope of this thesis, I will endeavor to demonstrate how 
recent historical events affecting Native Americans in general have played out in the particular cases of the Bishop Paiute Tribe and the Paiute Indian Tribe of Utah and in the lives of tribal members.

\section{Desert Diets}

The Paiute Indian Tribe of Utah (PITU) and the Bishop Paiute Tribe are both federally recognized tribes with cultural ties to lands in the Great Basin. PITU is part of the Southern Paiute ethnic group and is one of nine federally and non-federally recognized Southern Paiute nations (Kelly 1934; Spoon and Arnold 2012). Southern Paiute ancestral lands span parts of Nevada, Utah, Arizona, and California (Spoon et al. 2011:9). The Bishop Paiute Tribe is part of the Owens Valley Paiute ethnic group and is one of five Owens Valley Paiute nations (Liljeblad and Fowler 1986). Owens Valley Paiute terrain is situated in a narrow valley in eastern California that includes the headwaters of the Owens River and runs parallel with the eastern slope of the southern Sierra Nevada Mountains (Liljeblad and Fowler 1986:412). Contemporary Southern Paiute and Owens Valley Paiute tribal members live on and off reservations and in both urban and rural areas.

Southern Paiute and Owens Valley Paiute have called the Great Basin home for thousands of years (Spoon et al. 2011). Southern Paiute and Owens Valley Paiute languages are oral, rather than written, and are critical to keeping the land healthy and their culture alive (Spoon et al. 2011:10). Southern Paiute rich oral history tells creation stories and holds lessons that are transmitted from generation to generation, including "how to compatibly live with the land" (Spoon et al 2011:12). Participants in my research 
talked about the connections they see between all features of the landscape, such as rocks, springs, animals, and plants. They discussed how important it is for their Native language to be spoken throughout their lands and how the land is kept in balance through prayers and respectful management.

Southern Paiute oral history explains that Southern Paiute people were created at Nuvagantu, or the Spring Mountains (Spoon et al. 2011:9). For Southern Paiutes, everything in the landscape is sacred and is living (Spoon et al. 2011:9). The land is considered a relative (Spoon et al. 2011:12). This view frames their relationships with all other beings in the landscape and their relationship with animals and plants used for food. Stories are a gift from the Creator and teach Southern Paiutes why things were created and how the land should be treated. Humans are mandated to care for the land, not passive recipients of its gifts. Due to mining, ranching, and development, many powerful cultural sites and the environment have been damaged, deeply affecting Native spiritual traditions and putting the land out of balance (Spoon et al. 2011).

Southern Paiute and Owens Valley Paiute people experienced the fragmentation of their lands and knowledge due to colonialism and their relocation onto reservations (Spoon and Arnold 2012). Mining and ranching along with the settlement of their lands dramatically affected ecological resources (Spoon and Arnold 2012). Numerous political, economic, and ecological factors, in particular the related policies of the reservation and boarding school eras, have affected Southern Paiute and Owens Valley Paiute heritage foods knowledge transmission and also have led to the incorporation of new foods as important heritage foods. 
At the time of contact with Euro-Americans in the mid-1800s, hunting and gathering along with agricultural practices were integral to Southern Paiute and Owens Valley Paiute ways of life and were practiced according to a complementary division of labor, in which women gathered seeds and berries while men hunted (Gutierrez 1991; Knack 1989; Prindeville 2004). Early European explorers noted the sophistication of irrigation and small-scale farming in Southern Paiute and Owens Valley Paiute territories, including the cultivation of corn, melons, and squashes, and later in the historical period, wheat (Bolton 1950; Brooks 1972). In interviews, I discussed with knowledge holders the foods that have been part of their heritage since pre-contact times as well as those that were incorporated later, realizing that heritage foods knowledge continually adapts and changes.

Great Basin anthropologists have built on the cultural ecology work of Julian Steward, which focused on the influences of the arid environment on culture and behavior, including food practices $(1933 ; 1938 ; 1955)$. More recent ethnographic work in the Great Basin, such as the work of Catherine Fowler and the collaborative efforts of Jeremy Spoon and Richard Arnold, has taken into account more than only environmental influences on culture and behavior and has emphasized knowledge change among cultures. For example, Owens Valley Paiute nations relied on seasonal food-gathering activities and were influenced by indigenous California culture, causing Owens Valley Paiute nations to value the acorn as well as the pine nut (Liljeblad and Fowler 1986:416).

Recent impacts on Southern Paiute and Owens Valley Paiute traditional food and knowledge systems are religious conversion, church programs, boarding schools, increasing urbanization and the wage economy, and loss of access to resources and to 
perform management practices (Turner and Turner 2008). Boarding schools, which continued into the 1980s, separated Native American children from their families and forced them to speak English and eat European foods like potatoes, porridge, and bread, as indigenous foods were considered inferior (Turner and Turner 2008). For Southern Paiute and Owens Valley Paiute, access to ancestral lands on the present-day NTTR was lost to U.S. military control more than 60 years ago. All of these factors played a dramatic role in inhibiting heritage foods practices and knowledge transmission over a relatively short amount of time.

My approach is shaped by the work of Nabhan $(1985,1998,2002,2008)$ and Turner and Turner (2008). The notion of promoting tribal health in terms of foodways through cultural revitalization is not a new concept. Nabhan cites Bingham and Bingham (1979) in his discussion of strengthening diversification of food sources through strengthening indigenous food-related practices, such as gathering techniques learned from elders, as part of "cultural revival movements" which include tribal health programs as well as educational outreach (Nabhan 1985:397). Specific to foodways, place-based heritage foods, and human health, Nabhan identifies a change in "diet composition" (1998:175) rather than an increase in dietary intake as implicated in the prevalence of Type 2 diabetes among Native American peoples. In fact, as Nabhan makes clear, desert foods in particular may have protective effects for Native Americans in the face of chronic diseases (Nabhan 2008; Turner and Turner 2008).

Common desert foods of the central and southern Great Basin, such as yucca and prickly pear fruit, are Southern Paiute and Owens Valley Paiute heritage foods (Euler 1966; Nabhan 2008). In Chapter 6, I explore local understandings of the relationship 
between the lack of heritage foods in Native American diets and the prevalence of type 2 diabetes among Native Americans. I also consider the possibility that integration of more heritage foods in Native American diets could promote Native American health.

\section{Paiute Indian Tribe of Utah}

The Paiute Indian Tribe of Utah is part of the Southern Paiute Nation, or Nuwuvi, meaning "the people" (Spoon et al. 2011:9). Southern Paiute speak a Numic language (Spoon et al. 2011:9).

PITU leaders suggested a good source about their history. The source, a book entitled A History of Utah's American Indians (Forrest, ed. 2010), represents collaboration among Native American scholars in Utah and endeavors to offer a history of Native peoples from a Native perspective. A chapter on the Paiute Indian Tribe of Utah appears on the PITU website (Tom and Holt 2010). Gary Tom and Ronald Holt, the authors of this chapter, compiled information on origin stories, religion, politics, folkways, and economic issues of the PITU tribe from a variety of sources, including Holt's 1992 book Beneath These Red Cliffs: A Southern Paiute Ethnohistory, Robert Euler's 1966 book Southern Paiute Ethnohistory, and Isabel Kelly's 1964 paper Southern Paiute Ethnography. I compile information in this section from all of these publications. In addition, I consulted Isabel Kelly and Catherine Fowler's chapter "Southern Paiute" in Handbook of North American Indians: Volume 11, Great Basin and Isabel Kelly's 1934 article Southern Paiute Bands. Catherine Fowler, anthropologist and professor at the University of Nevada, focused her work on the cultures of Native peoples of the Great Basin and contributed significantly to understandings of Northern Paiute, Southern 
Paiute, and Owens Valley Paiute peoples. Likewise, Isabel Kelly contributed to anthropological knowledge of Great Basin peoples, specifically Southern Paiute. In her 1964 paper, she provides a cultural inventory of the Southern Paiute from firsthand accounts of Native individuals who recalled features of pre-contact life.

Mobile groups of Southern Paiutes in Utah had relatively few encounters with Euro-Americans until members of the Church of Jesus Christ of Latter-Day Saints (LDS) became full-time residents in southern Utah in 1851. Traders, trappers, and travelers heading for California had some effect on Southern Paiute life as they passed through Southern Paiute territory prior to 1851, but the permanent settlement of LDS members caused ecological damage and epidemic diseases, which brought about a 90 percent drop in population among some Southern Paiute groups.

After Brigham Young led a group of LDS settlers into the Great Salt Lake area in 1847, he envisioned a corridor of settlement stretching south to the sea, from Salt Lake City to southern California, and identified good sites for settlement for new converts in what were often important Southern Paiute living and foraging areas in southern Utah. The largest concentration of Southern Paiutes in Utah lived along the Santa Clara River, near the present-day Shivwitz Reservation. At the time, independent Paiute groups consisted of three to five households that moved frequently according to the seasons, plant harvests, and animal migrations. A group's movements usually centered on major food or water resources, and groups' areas overlapped. However, with the rapid colonization of Southern Paiute lands by LDS settlers, the loss of the best resources, and ecological changes from livestock and overgrazing, various groups of Paiutes joined to form larger, sedentary groups. By 1858, LDS settlers had established eleven towns, 
taking the best farmlands and sources of water. Southern Paiutes were hired to provide labor such as planting fields and performing domestic tasks for the new settlements. LDS policy concerning Southern Paiute people reflected that "it was better to feed the Indians than to fight them" (Tom and Holt 2010:4). At the same time, LDS settlers eagerly took Indian lands for their own use.

In other areas of the United States, treaties between the US government and Native American tribes began prior to the 1800s and usually involved tribes giving up land in exchange for a trust relationship with the US government, in which the government promised Native Americans a permanent reservation and protection. As part of this trust responsibility, Native American lands were held in trust, a legal agreement, by the federal government. In addition, Congress enacted legislation intended to promote the well-being of Native Americans. However, legislation has not always proven to benefit Native Americans, but has instead fragmented the population and dislocated them from their ancestral lands.

The first attempt, in 1865, to remove Southern Paiutes in Utah from their homelands was unsuccessful for numerous reasons, one being that treaties with the federal government placed them on a reservation with the Utes, who had continued their practice of slave raids on Paiute groups. Subsequent attempts created several reservations for various bands. The bands did not easily fit into the categories the government created. The first reservation removed the Shivwitz Band from northern Arizona in 1891 to the Santa Clara River west of the present-day city of St. George, an area which had contained a dense population of Southern Paiutes but had been vacated due to the effects of colonization. A total of about 200 people occupied the first reservation, and the federal 
government formally established the reservation in 1903. In 1916, President Wilson expanded the size of the reservation, and three other reservations were soon created: Indian Peaks, Koosharem, and Kanosh. The Cedar Band was moved in 1926 to property that the LDS Church purchased for them in present-day Cedar City. Their belongings at their old camp were burned, and in Cedar City, Southern Paiute families lived in oneroom shacks. As a result of the loss of their lands, Southern Paiutes became dependent on both the LDS church and the federal government.

All of the reservations created for Southern Paiutes in Utah were too small and had too few resources, such as irrigable land and water rights, to sustain the Southern Paiute bands in their traditional practices of gathering food. One of the first Indian policies to affect Southern Paiutes in Utah was the Dawes Act (or Indian Homestead Act) of 1887 , which divided tribal lands into individual plots of 160 acres that would become liable to taxation after an initial trust period of 25 years. Surplus lands were then sold to non-Indians. The allotment system, with its emphasis on individual property and its promise of U.S. citizenship, led to further loss of Native American lands and tribal sovereignty and the fragmentation of tribes, as impoverished Native individuals sold their land when they needed money. The systematic theft of Native lands and the erosion of Native sovereignty are economic and political issues with very real consequences for Native American ways of life and health.

The federal policy of termination, which ended federal recognition of tribes and turned federal jurisdiction over to the state, features prominently in the history of Southern Paiutes in Utah. Termination, which was another strategy to incorporate Native Americans into mainstream society, included the withdrawal of services and federal trust 
responsibility. It also led to further loss of lands, as a great portion of trust lands were taken out of protected status. Senator Watkins of Utah championed the policy and encouraged the termination of Southern Paiute tribes in Utah as a model, despite previous reports on their lack of readiness based on criteria such as degree of acculturation, economic resources, education level of tribal members, and willingness of the tribe and the state. In 1954, President Eisenhower signed Public Law 762, terminating the Southern Paiutes in Utah despite the protests of tribal councils and members. Termination is just one example of the disregard of the US government and US leaders for the rights and self-determination of Native Americans. The system put in place by termination directly disadvantaged Native American individuals.

During the termination period, Southern Paiutes in Utah were ineligible for services. Tribes lost sovereignty, and individuals lost tribal affiliation. For almost twenty years, Southern Paiutes experienced social and economic decline, with increased mortality rates, unemployment, and alcoholism. While colonialism in general produced many of these social problems, termination exacerbated the effects of colonialism. Tribes and individuals suffered the loss of federal legal protection, health and education funds, and grants for training, businesses, and housing. Critical Medical Anthropology, my lens for this research, assumes that social problems such as alcoholism do not happen in isolation, but rather occur in conjunction with larger social issues, such as the loss of sovereignty and tribal affiliation for Native Americans (Singer 2001:210).

During the years that the Utah tribes were terminated, there were attempts to relocate individual Indians to urban centers through vocational training and church programs. The LDS Church officially sponsored an Indian placement program in 1954, 
through which young Native Americans in Utah were placed with LDS families. In 1955, the BIA contracted with the University of Utah to include Southern Paiutes and Utes in a relocation/job training program, but the program ended unsuccessfully. Efforts to rehabilitate Native people in Utah did not take into consideration Native selfdetermination, but instead primarily focused on assimilating them, demonstrating the power dynamics of the society and the marginalization of Native Americans.

Beginning early in the 1950s, Southern Paiutes collectively claimed through the Indian Claims Commission compensation for land that had been taken from them. In 1965, Southern Paiutes were awarded 27.3 cents per acre for their ancestral lands. This compensation, however, did not guarantee them a bright future, as they gave up any claim to over 29 million acres in exchange for a small amount of money. Many were soon left with nothing: no land, no trust relationship with the federal government, and no money. Many Southern Paiutes continued to do unskilled labor as seasonal farm workers or as railroad workers. Alcoholism began to affect more Southern Paiutes, disrupting families and leading to a life expectancy of 42 years for adult males in 1984. From 1981 to 1984,95 percent of tribal deaths were alcohol-related. Even into the 1980s, most Southern Paiutes received no more than an eighth grade education. Social and health services were almost nonexistent during the termination period. In 1979, a survey found that Southern Paiute per capita income was $\$ 1,968$, in contrast with the $\$ 7,004$ per capita income of the average Utah resident. This critical period in the history of Southern Paiutes in Utah makes evident the anthropological importance of examining issues, especially social problems, from the holistic view of political economy. Critical Medical Anthropology points toward the relationship between events that dramatically 
disadvantaged Native Americans politically and economically and negative effects on Native American social and physical health.

Restoration of the federal trust relationship with the five bands, reorganized as the Paiute Indian Tribe of Utah (PITU) on April 3, 1980, quickly reversed many of the negative effects on the health of Southern Paiutes in Utah through access to health services and other programs, such as alcohol intervention and economic development. PITU included 880 members in 2009. Through the long legal process toward restoration and reservation selection, the local community voiced their support of restoration of the tribe. However, prejudice and discrimination against Southern Paiutes continued to present problems for PITU members, particularly for those vying for the few jobs available in southern Utah. In 1984, PITU agreed to receive less than 5,000 acres of poor BLM land as part of their reservation lands, less than one-third of the amount legislation allowed them to select. The restoration legislation also authorized a trust fund of $\$ 2.5$ million with interest drawn for economic development projects and tribal government expenses. PITU built new homes, improved health care and education opportunities, and created two sewing factories for economic development. Since restoration, education has become a priority, with a majority of young tribal members receiving some higher education or vocational training. Unemployment and underemployment continued to trouble PITU members, but a core of community leaders and college-educated professionals emerged. With the restoration of federal recognition, the tribal council operated as the tribal authority and contracted most of its services, with little BIA oversight. While PITU, the officially recognized tribe after restoration, is only in its second generation of existence today, strong leadership and organization are lending the 
tribe a new voice and working to improve social conditions and economic opportunities for tribal members.

\section{Bishop Paiute Tribe}

The Bishop Paiute Tribe is part of the Owens Valley Paiute ethnic group located in Owens Valley east of the Sierra Nevada Mountains. Owens Valley Paiute refer to themselves as Numa, or "People" (Pritzker 2000: 227). Owens Valley Paiute speak dialects of the Mono language that are part of the Western Numic branch of the UtoAztecan linguistic family (Liljeblad and Fowler 1986:412). The Bishop Paiute Tribe was formerly known as the Paiute-Shoshone Indians of the Bishop Community of the Bishop Colony (Pritzker 2000:230).

In my research into the history of the Bishop Paiute Tribe, I utilized Catherine Fowler's chapter "Owens Valley Paiute" in Native America in the Twentieth Century: An Encyclopedia (1994), Richard C. Hanes and Laurie Collier Hillstrom's article "Paiutes" (2013), and Dorothy Cragen and Genny Schumacher's chapter "History" in Deepest Valley (1962), which compiles information from local authors on the subject of Owens Valley history. Key to the more recent history of Owens Valley, the story of the land- and water-grabs by city officials from Los Angeles in the early 1900s provide insight into the present environmental and economic conditions of the Bishop, California, area and the Bishop Paiute Tribe. For my investigation of this very controversial aspect of Owens Valley's past and present, I consulted sources favoring the perspective of Owens Valley residents and sources condoning the actions of the City of Los Angeles. In this section, I rely on Marc Reisner's colloquial account of the City's actions in his book Cadillac 
Desert: The American West and Its Disappearing Water (1993) and Remi Nadeau's wellresearched, historical account from the perspective of a Valley resident in his book The Water Seekers (1950). Although I gathered some information from William Kahrl's book Water and Power: The Conflict over Los Angeles Water Supply in Owens Valley, I did not privilege his perspective that the actions of Los Angeles were "merely practical" and not "malicious" (Kahrl 1983:445).

Paiute people living in Owens Valley experienced little contact with EuroAmericans until the mid-1800s. Due to their isolated location and the formidable barrier of the Sierra Nevada Mountains, Owens Valley Paiutes did not come under mission control during the era of Spanish exploration as did many coastal California Indian groups. After the discovery of gold west of the Sierra and then the discovery of silver southeast of Owens Lake, the US government formed a mining district in Owens Valley in 1860. Euro-American ranchers and farmers soon followed to supply the miners, taking the best food and water resources in the valley. Native inhabitants of the valley resisted the settlement taking place in areas of ecological importance, especially along the Owens River. A period of violence between settlers and Native Americans began shortly after the arrival of Euro-American settlers and lasted until 1866. The US government gathered about a thousand Native people at Camp Independence under false promises and relegated them to a reservation south of Bakersfield in 1863. In this case, the US government held more power than the Native people and forced them onto a reservation through both conceit and brute force. The US government and local Owens Valley residents justified this land grab through the politics of representation and through stereotypes of Native people in the area as "savage" (Biolsi 2007). 
Biolsi directs attention to "race technologies" that "situated actors," in this case the US government, use to identify and classify Native American subjects (2007:400). In the case of Camp Independence and in the case of US policy toward Native Americans across the United States, the goal was "spacing," the systematic displacement of Native American groups from their ancestral lands and from one another (Biolsi 2007:414). Through the "checker-boarding of reservations," the US government classified and spaced Native Americans in order to assimilate them because the US operated on the belief that Native Americans could be "civilized and eventually become citizens" (Biolsi 2007:414).

Remaining Owens Valley Paiutes eventually went to work on ranches. Pioneers had settled in the prime locations along the Owens River, and Paiute access to traditional grounds for gathering seeds and plants and hunting deer and rabbits was limited. 67,000 acres of Owens Valley land was set aside in 1912 for indigenous people in Owens Valley. However, in 1932, President Hoover revoked the reservation of these lands and instead placed them in watershed protection for the benefit of the City of Los Angeles. The City of L.A. then claimed the lands in 1936 in exchange for 875 acres for the Bishop Paiute Reservation. While PITU lost and regained federal recognition, Bishop Paiute Tribe never lost recognition. Both tribes lost lands originally set aside for them.

Today, despite being the fifth largest American Indian nation in California with about 2,000 members, the Bishop Paiute Tribe has one of the smallest land bases of any federally-recognized tribe. In 1994, the Bishop Paiute Tribe opened the Paiute Palace Casino to promote economic development. 
With the swift growth of Los Angeles around the turn of the century and intermittent drought years, the City significantly reduced its groundwater supply and began to look for other sources of water to meet the growing demand of domestic uses of water as well as the development of agriculture in the San Fernando Valley. In 1905, the City passed a bond issue and built an aqueduct on the Owens River which siphoned and carried water under pressure 250 miles from an altitude of roughly 4,000 feet in Owens Valley down to Los Angeles, almost at sea level, utilizing the power of gravity. Eventually, Los Angeles also built a dam in Long Valley, north of Bishop, California, on the Owens River, creating the reservoir known as Lake Crowley. Later, the City leased some of its lands back to farmers, but the water supply remained unreliable for them, as Los Angeles maintained appropriative rights over the Owens River and in dry years none was left for valley farmers. Through the clever political maneuvering of Los Angeles city officials and the power plays of city financiers beginning as early as 1904, the City of Los Angeles eventually bought most of the water rights in Owens Valley, owning 95 percent of the farmland and 85 percent of the property in towns by the mid-1930s.

Ultimately, Los Angeles took so much water from the Owens River that Owens Lake at the south end of the valley dried up, causing environmental damage and putting the health of Owens Valley residents at risk. In addition, the City pumped enough groundwater from Owens Valley wells to significantly change the ecological, economic, and social landscape of Owens Valley by mid-century, making it difficult for the few remaining ranches to survive and for the indigenous people of Owens Valley to gather traditional foods. During the 1950s, the economy of Owens Valley shifted to tourism, providing services for skiers and other outdoor enthusiasts traveling, ironically, from Los 
Angeles on Highway 395. The City of Los Angeles, through its Department of Water and Power, owns and manages a significant amount of the land and property in Owens Valley and continues to play a key role in the political and material matters of Owens Valley to the present day, including those pertaining to Bishop Paiute Tribe members.

In sum, American westward expansion and colonization deprived Owens Valley Paiutes of prime access to traditional food sources, gathering sites, water sources, and irrigated fields. Then, as Los Angeles drained the valley, the politics of water appropriation diminished traditional food sources themselves through the loss of Owens Lake and the species it harbored such as migratory fowl, the loss in large part of the Owens River and the irrigation it sustained, and the loss of vast amounts of groundwater which nourished a wealth of desert plants. In line with the theoretical perspectives of political economy and Critical Medical Anthropology, the history of the Bishop Paiute Tribe features prominently in the present-day life of tribal members. Historical factors continue to influence the tribe's access to ecological and monetary resources and tribal members' living and working conditions, with consequences for health outcomes.

\section{Conclusions}

Each present-day federally recognized tribe is situated in a geographic space and within a political and social sphere revealing a particular historical reality. For PITU and the Bishop Paiute Tribe, history affected and continues to affect tribal members differently. PITU experienced a dreadful period of termination during which tribal members lost land, federal recognition, tribal affiliation, economic opportunities, and critical services for the health of its members. In some respects, termination placed PITU 
25 years behind other tribes in terms of economic viability and tribal member services such as education opportunities and health programs. Even during restoration, PITU did not acquire quality land, but instead got a small amount of land with few ecological resources, which adversely affects tribal members' access to heritage food resources. Although the Bishop Paiute Tribe did not experience termination, it did experience the loss of a significant amount of land and still feels the effects of the loss of water and heritage foods resources such as water fowl in Owens Valley due to the actions of the City of Los Angeles. At the same time, Bishop Paiute Tribe members recognize the benefits of Los Angeles Department of Water and Power owning and managing most of the land in the Valley today, inhibiting further settlement and development in the area. In addition, members recognize that the land the Bishop Paiute Tribe gained in the land swap with the City of Los Angeles was at least quality land in terms of access to water and of proximity to Highway 395, where the casino is located. Multiple factors shaping daily life for tribal members, such as tribal sovereignty and autonomy, tribal affiliation, ethnic pride, access to traditional foods, economic development, and visibility in the larger community and society, all operate in some way on the vast loss of their lands and their relegation to a relatively small land base.

The legacies of Euro-American colonization and loss of ancestral lands continue to constrain the political and economic realities of both PITU and the Bishop Paiute Tribe. Both experienced histories that dramatically disadvantaged and marginalized tribal members through interrelated social and political factors such as loss of cultural knowledge due to boarding schools, history of alcohol abuse, lack of access to higher education, and lack of funding for programs and services for tribal members despite the 
trust responsibility of the US government. Through the holistic viewpoint of political economy and Critical Medical Anthropology, my analysis of the history of both tribes takes into account the structural forces and the relationship between social inequalities and health outcomes in systems that have disadvantaged Native American individuals and continue to do so. Through investigating the history of power dynamics between the US government and Native American nations and Native American access to lands and heritage food resources in this chapter, I set the stage for the upcoming chapters, which will address the political, economic, and social factors, including social conditions, that affect Native American lives, identity, and health, particularly diet-related health. 


\section{Chapter 3: Traditional Diet: What is Traditional?}

\section{Introduction: Foodways and Identity}

One of the members of the Bishop Paiute Tribe and I sit outside to do an interview in her beautiful, expansive yard, ringed with fruit trees and flowers. At the back of her yard on the Bishop Paiute Reservation, she shows me a partly shaded vegetable garden. She says she wakes early every morning of the summer, when the air is still highdesert-cool, to water the plants and work in the yard. I am reminded of summers I spent as a child with my mother's parents in West Texas. My grandpa grew up on an arid Texas farm and kept fruit trees alive during his retirement with careful, joyful determination.

The woman whom I am interviewing has the same determined, pleased look in her eye as she shows me her yard and garden, as she tells me about her life and her upbringing. She takes great pride in her history, her Bishop Paiute identity, and the progress her tribe has made during her lifetime. She describes how she ground acorns by hand as a young person and how she prepared food without electricity or running water. She is happy that things have changed and believes that many of the changes have been for the better. Since her childhood, roads and schools have improved, and people have access to different kinds of foods, many of them easier to prepare than what she ate as a girl. She does not see the changes to tribal members' food habits as negative; she views them as inevitable.

In this chapter, I engage with the concepts of ethnicity and identity in foodways research, focusing specifically on traditional food systems and dietary change. In general, the topic of "foodways" includes all the processes that make micronutrients into 
something to eat and how food choices and eating affect bodies and societies.

"Foodways" includes the meanings, use, and nutrition of the food as well as the techniques used to gather and process the food (Jones, Guiliano, and Krell 1983;

Kuhnlein and Receveur 1996:418). "Traditional food system" refers to all food within a particular culture available from local, natural resources (Kuhnlein and Receveur 1996:418). While participants described local, natural traditional foods they gathered and consumed in traditional ways as children such as wild game, nuts and berries, they also described more recently incorporated traditional foods (traditional in the sense of familiar and important) that did not come from local, natural resources such as purchased foods and introduced foods from the dominant culture. I explore how members of PITU and the Bishop Paiute Tribe preserve ethnic identity through traditional foods and foodways, or heritage foods and foodways, and resist the delocalized food system through ethnic identity. I ask how dietary change has affected participants' understandings of self and self in relation to the group, and how tribal members connect through food.

Identity talk and identity politics are important aspects of everyday life (Brubaker and Cooper 2000:5). Brubaker and Cooper caution scholars to use the term identity with care (2000:5). The term identity as representing a category of practice and a category of social analysis is made to do a lot of work (Brubaker and Cooper 2000:8). Brubaker and Cooper argue that the term identity should be used for analytical work in the strong sense of "self-sameness" and "sameness over time" rather than in the weak, clichéd sense of “multiple, fragmented, and fluid" (2000:11).

Brubaker and Cooper offer clusters of terms to differentiate between the multiple, and often confused, meanings of the term identity (2000:14). In contrast with 
"identification," as in the action of the state to identify people through legitimate physical and symbolic force (Brubaker and Cooper 2000:15), "self-understanding" is a term used to describe one's sense of who one is and one's social location, separate from how the state or outside entities may impose identifying categories on a person (Brubaker and Cooper 2000:17). Self-understanding is closely related to the terms "self-representation" and "self-identification," but can also connote understandings of self that are not discursively articulated (Brubaker and Cooper 2000:18). In essence, self-understanding is a soft enough term to allow for intersecting categories and flux and hard enough to capture the stability or sameness of social locatedness and the bounded self (Brubaker and Cooper 2000:18).

Just as "self-understanding" captures the cognitive and emotional senses one has of one's identity, "groupness" is an emotionally laden term used to connote one's sense of belonging to a group (Brubaker and Cooper 2000:19). Key to the discussion in this chapter, the term groupness is used to describe the felt commonality one has with fellow group members and the felt difference from outsiders (Brubaker and Cooper 2000:19). Sharing food within a group is a significant way to maintain social cohesion. Eating and drinking together is an expression of the fact that "all those who share the meal are brethren and that all the duties of friendship and brotherhood are implicitly acknowledged in their common act" (Goody 1982).

A colonial-era legacy of misidentification continues to affect PITU and BPT members today, as Native American peoples are placed into arbitrary categories in which they do not feel they belong. Bourdieu and Foucault view the modern state's identification and classification systems as powerful "identifiers" that use material and 
symbolic resources to impose categories on individuals and aggregate them through both literal classifications, such as passports, and through a classificatory grid, such as that provided by the census (Brubaker and Cooper 2000:15).

In the case of Native American nations and individuals, this governance mentality (or "governmentality," to use Foucault's word) has been evident in the classificatory system of reservations, through which nations and individuals are either recognized or excluded. For example, I spoke with Bishop Paiute Tribe members who viewed all Owens Valley Indian peoples as one group, despite the tribal distinctions placed upon them by the federal government for federal recognition, oversight, and funding. Similarly, PITU members saw themselves differently than federal jurisdiction represents. PITU members saw themselves as part of independent bands in different ecological areas. The bands were brought together to form one tribe for the purpose of restoration and federal recognition.

In his analysis of Indian removal in California, which occurred from 1880 to 1903, Steven Karr highlights the ability of Cupeno and Diegueno bands to accommodate change and adapt to different language, clothing, and foods, maintaining identity and traditional ways through nontraditional means (2009:26). PITU and Bishop Paiute Tribe have been active in similar efforts to adapt and maintain identity through language and craft classes, language preservation, and food gathering in the face of ongoing socioeconomic and political processes (PITU 2012; Bishop Paiute Tribe 2012).

Cultural practices are closely tied to cultural identity, and food practices are of particular relevance to identity. Food and food practices, including the ways people affirm friendship and kinship through sharing food at potlucks and other food gatherings, 
are some of the most important modes of exchange in culture (Humphrey 1988:252).

Anthropologists look for patterns in food practices indicative of gender and ethnic identity. Characteristics of food gatherings reflect social relationships, such as gendered relationships and power dynamics, as well as group membership and values (Mintz and Du Bois 2002). Social changes lead to dietary changes, and adopting different food practices lead to shifts in identity (Kumanyika 2005:132).

Often the construction and maintenance of identity, particularly ethnic identity, involves the use of symbols, such as language, clothing, and food, to claim identity, redefine identity, and assert rights (Brubaker and Cooper 2000; Kuper 2003; Trimble 2000). The diet of an ethnic group or tribe as well as particular foods a group identifies as symbolic and important to identity play a role in how people within that group view themselves and view their belonging in the group (Brubaker and Cooper 2000). People within a group also define who they have been, who they are, and who they will be through food and other key symbols (Trimble 2000).

In the following two chapters, I will use the terms self-understanding and groupness in my analysis of the role of foodways in participants' understanding of self and sense of belonging to a group. I examine how PITU and Bishop Paiute Tribe identities have shifted in light of the historical changes in culture and subsistence practices outlined in the prior chapter. I present ethnographic information from interviews and life histories completed with participants who have lived through social and dietary changes.

\section{Heritage Foods and Social Change: A Matter of Taste}


Wild Foods, Traditional Foods, Heritage Foods

In this discussion, the distinction between wild foods, traditional foods, and heritage foods is an important one. Participants inherently made distinctions between wild foods, or those gathered or hunted in the old days, and traditional foods, which included wild foods as well as cultivated foods, and sometimes purchased foods, cooked the old way. Heritage foods is the term I use to indicate any foods Native participants identified as important to their culture. It includes wild foods, traditional foods, and traditional foods cooked in new ways. Older participants (those older than 60 years of age) tended to believe traditional foods were foods that were gathered and prepared the traditional way, while younger participants tended to believe traditional foods could include traditional foods bought in the store or prepared in new ways.

Some members of PITU and the Bishop Paiute Tribe asserted that certain foods themselves are traditional, regardless of how they are prepared, while others maintained that it is the gathering and preparation that makes the food traditional. "You have to get it and do it the old way," one interviewee said, which begs the question, "Is there a viable way for younger generations to learn and continue to prepare traditional foods the traditional way?" Participants said that the old way of life is gone. "That way is gone. Life is totally different now. There is no going back," one interviewee said, incredulous that anyone would want to return to grinding acorn flour by hand, for example. Romanticizing gendered and classed work in the preparation of food ignores the time contributions, preferences, and changing self-understanding of Native American women, as they may now prefer a career over cooking or grinding flour all day (Massey 1994). Most participants believed that there is a way to blend the old way of preparing heritage 
foods with the new, signifying that there is still a way to possess tribal or ethnic identity even though some gathering and preparation practices have changed or disappeared. Symbols that mark identity, such as food practices, can change.

Some participants responded to questions about the heritage foods Native people consume today with statements that Native people still gather and prepare food the traditional way, while other participants expressed assumptions that mostly traditional ways are not practiced in their communities. Contrasting opinions among participants reflected patterns related to age and tribal affiliation, and the patterns suggest changing concepts of identity over time, as lifestyles and heritage food practices adapted to incorporate modern means of preparing food. "We still gather our traditional foods," asserted Lisa, an older participant and member of the Bishop Paiute Tribe who is very involved in the community and has worked for the tribe for many years. Laura, a Bishop Paiute Tribe elder and older participant, however, appeared confused when I asked about traditional foods, saying: "When you speak of traditional foods, I don't know what they would be except pine nuts." Glenna Jean also described traditional foods as something mostly belonging to the past. "This was before the $20^{\text {th }}$ century," she said, describing what her ancestors ate. "They ate deer, didn't have that fat. Not like eating beef. And rabbits. They used to go out and get these little [ground squirrels]. We ate a lot of berries, mainly buckberries, go out to the places and get buckberries. They're out right now, I was told. Around the lake, you have to go out." Glenna Jean described what Native people in Owens Valley eat now. "They don't eat any of those things anymore," she said. "We ate a lot of meat [when I was growing up], but it was probably from the store, since it was in the 30s or 40s. Fish, we ate a lot of fish [wild caught] since we were near the lake." 
Participants believed Native people were less likely now to prepare foods the traditional way, but all of the participants still consumed some heritage foods, whether prepared the traditional way or not. Both older and younger participants shared that there were a few foods like pine nuts and deer meat that were still gathered or hunted in traditional ways.

Older participants tended to believe traditional foods had to be gathered, cultivated, and prepared the traditional way in order to be traditional, reflecting a sense of self-understanding that developed during their early years when they ate mostly traditional foods and lived "the old way." Jenny and Paul, a PITU couple around 70 years of age, discussed what types of foods were traditional, remembering foods they ate as young people. "Tomatoes, corn, beans, mostly beans, potatoes. It's all we ate, traditional foods," said Jenny. "Corn, it's traditional. We had onions. Mom used to make onion gravy." Paul added to what Jenny said, looking thoughtful: "Traditional food, they didn't have any of that stuff, chemicals in there. Wild animals, they were healthier for you if you could cook it the right way. My mother would dry them, deer meat. Eat that in the winter time...It was from that wild animal, it was probably good grease. Like deer. I ate a lot of rock chuck [marmot] and deer and fish and rabbits, cottontail, dove." Ethel, a pleasant woman in her sixties who seemed happy to share experiences from her life, described similar traditional foods. "Our food is from over in Indian Peak area, was mainly elk and deer and rabbit," she said. "Other place would be rabbit and prairie dog and sage hen and snake. Other part in the north was mainly buffalo and elk and big game like deer." In this quote, Ethel lists the foods symbolic to her area and symbolic to her band (Indian Peaks Band), foods she ate as a girl and foods still important to the identity of her band. When I asked what made foods traditional, she responded: "We ate mostly 
everything on the mountainside. We didn't go hungry or anything. And what we had we shared. If people passed through, we helped those people out. We'd go and give them food and make them feel they were wanted." Paul felt that harvesting techniques created the distinction between modern and traditional foods. "It's commercial. Commercial picking," he said of picking pine nuts with a machine. "You have to go out there and pick it. That's traditional. Commercial they do with a machine...They sell the cow stomach in the store, but they're too clean. I told them to go to the barnyard and get some dirt, put it in the water and boil it." Paul laughed as he talked about the cow stomach. Participants like Paul did not believe heritage foods included commercial-picked pine nuts or purchased foods. Older participants were more likely to be raised with more wild foods and/or traditional foods. As a result, their definition of heritage foods was narrower than that of younger participants.

Younger participants shared a broader definition of heritage foods, demonstrating a shift in concepts of identity in terms of food practices. Renee, an energetic participant, age 50 , spoke very articulately about foods important to her family and culture. She asserted that traditional foods like deer were traditional whether the foods were cooked outside over a fire or inside on a stovetop. "Deer meat is really the biggest one, in our family, and fish," she said. "And as far as traditional foods available to us now, I like to have my Bluebird flour, and that comes from Colorado. And that's just a well-known brand of flour that all Natives like to use because it makes good bread. Now they sell it down in Cedar, and if my family comes up from the reservation, they bring me flour because they know that's what I like. And that's one thing we use because they don't go out and harvest like they used to." For example, she said of what her husband commonly 
eats: "We do it the Paiute way. They can eat that [Indian] bread so many ways. He can take it to work, and the Indian guys will say, what are you eating? And they'll say, your wife knows how to make that? Yes, so he loves to take his Indian food." Renee also recognized certain newer foods, like hamburger and noodles, as "Paiute" or "Indian food." She said, "Potatoes and hamburgers is a lot that they eat. I make hamburger stew, or hamburger with elbow noodles with tomatoes." Younger participants were more likely to believe heritage foods could be prepared in alternate ways and with new foods or even bought from the store. While foodways and concepts of "tradition" have changed, participants of all ages clearly defined themselves as "Paiute" or "Native". Whether or not they still ate deer, for example, they still connected their self-understanding with symbols like deer meat that have persisted over time.

PITU participants talked about the continued use of several different heritage foods on a regular basis, while Bishop Paiute Tribe participants emphasized the use of one type of heritage food, either pine nuts or game or fish, on a regular basis, or the use of heritage foods in ceremonies. "They [my kids] liked the bread and the regular potatoes," Randee, a PITU participant aged 59, said of heritage foods regularly served in her home. "I try to go out and pick some of the native plants," said Carla, a PITU participant in her forties who eats heritage foods on a regular basis. "A lot of Indian food is an acquired taste. I like the Indian spinach; that's one of my favorites. I love that." Carla talked about growing up eating squash, corn, and beans as heritage foods, foods her family still eats today along with other traditional foods like yucca flower, wild onions, and berries. In contrast to the wider view of (and use of) traditional foods among PITU members, Bishop Paiute Tribe participants' use of traditional foods was more narrow. 
"Pine nuts," said Glenna Jean, a Bishop Paiute Tribe participant in her seventies. "That's one of the foods they still go out and get and like, but that's about the only food they go out and eat now. I don't think they eat anything else." Laura, also in Bishop, agreed: "Pine nuts, that's all." PITU and Bishop Paiute Tribe members' responses revealed an emphasis on different aspects of identity and shifts in concepts of heritage foods and identity unique to each tribe.

Differences in the ways participants thought about and defined traditional foods accounted in part for the differences in use. For example, PITU participants spoke of the continued weekly practice of "Indian breakfast", which included Indian bread and bacon. Indian bread, also called pan bread and karate bread, can be cooked in the ashes of a fire or in the oven. It resembles a typical homemade bread with a rising agent. It is baked, not fried. It is different from fry bread, which is fried. Fry bread is a delicious but fattening food made by frying or deep-frying a simple, flat dough, usually consisting of white flour, sugar, salt, and a leavening agent, in oil, lard, or shortening. Fry bread and bacon are good examples of the messiness of history and identity. These foods were a result of colonization, but participants came to value them as part of traditional or heritage food habits and even as symbols of ethnic identity and self-understanding. In contrast, Bishop Paiute Tribe participants did not include bacon in their definitions of a traditional meal. Contrasts between PITU and Bishop Paiute Tribe participants reflect the unique history of each tribe and the differences in their relationships with the dominant culture. While the history of PITU has been one closely tied to LDS political and social influence, the Bishop Paiute Tribe has maintained a measure of separation and independence from the surrounding society in Owens Valley. Due to political circumstances and the rapid loss of 
their lands, some of PITU's five bands (before the recognition of the tribe) were forced to depend heavily on LDS resources. PITU was not restored as a tribe until 1980, while Bishop Paiute Tribe was first recognized as a tribe in 1912. In addition, numerous PITU participants were raised in LDS households through a church or foster program, which affected their self-understanding in terms of food, while Bishop Paiute Tribe participants were raised by parents or relatives identified closely with strictly "Native" foods.

Reflecting changing concepts of identity, PITU members described potatoes, beans, vegetables in stews, canned fruits, and hamburger prepared in traditional ways with traditional ingredients like Indian spinach as traditional foods. "You can fry it [Indian spinach] with hamburger,” said Jenna, a younger PITU participant with high school-aged children at home. Although they spoke of eating some of these foods in the past and in traditional ways, Bishop Paiute Tribe members did not consider them to be traditional foods by themselves. Rather, Bishop Paiute Tribe members focused on traditional foods as those hunted or gathered from the land, such as game, pine nuts, watercress, and piagi, the caterpillar larvae gathered at Mono Lake or Owens Lake (before it dried out). "And they went up to see if the piagi was going," said Laura of current traditional foods use. "But they didn't find any." PITU and Bishop Paiute Tribe members' definitions of heritage foods differed in that Bishop Paiute Tribe members' held a stricter definition of heritage foods, reflecting their diverging histories and selfunderstanding. For some PITU members who were raised in LDS households, their selfunderstanding was entwined with LDS cultural identity, whether they were LDS members of not. While PITU members often identified with multiple aspects of their 
identity, such as both "Paiute" and "LDS" foods, Bishop Paiute Tribe members tended to identify only with "Native" foods.

Participants from both tribes described the use of heritage foods in ceremonies or customs. Bishop Paiute Tribe participants emphasized the continued use of rabbit and deer meat in ceremonies. Glenn of the Bishop Paiute Tribe, age 75, said traditional foods are always used in ceremonies. "We've gotten away from our traditional foods," he said. "But we always have game in our ceremonies." While Bishop Paiute Tribe members may still hunt rabbit and deer and may fish on occasion, similar to the practices of PITU members, the emphasis from their perspective was on its use in ceremonies. "We've learned a lot of things," Renee said of PITU customs. "When we're eating we take some of our food and throw it behind for the old ones. Dad will say, 'Don't forget the old ones." For the sake of identity, participants believed Native people should learn about, observe, and continue heritage food practices in ceremonies. Observing ceremonies with particular foods, whether the foods are regularly consumed or not, ensures a connection to the past and the persistence of key symbols that connote ethnic and tribal identity.

\section{Gendered Relationships with Food}

Anthropologists have found that often there are gendered divisions of labor in the production of food. Food selection, preparation, and consumption play key roles in the preservation of ethnic identity and gender identity, or sense of belonging, for women, displaced and marginalized peoples, and non-white groups (Slocum 2010:305). The selection process of knowledge holders by tribal leaders for my research was based on the fact that female elders held most of the knowledge of preparing traditional foods. 
Although I interviewed both men and women, the majority of those I interviewed were women. Female participants performed their ethnic and gender identity through food. Participants from both tribes described gender divisions in past traditional food practices. With one exception, all participants stated that women did the gathering and cooking and men did the hunting and sometimes the cleaning of the animals. "I remember just the women cooking...the men never...they might have prepared the fire...went out and got the deer, went out and did the hunting, but they just did certain things. For the rabbits, they would do the skinning. They would skin the animals," said Laura. "We had eggs, bacon, porcupine, but you had to be careful with that. Women did all of that [cooking the porcupine]," said Ethel. "Men just went out hunting, getting wood," said Glenna Jean. Catherine, age 62 with a quiet demeanor, confirmed this. “Some of my family, if they think about me, they say, 'Oh, she doesn't have anyone to hunt for her!" Catherine said. "'Cause I don't have any boys, I have all girls." Renee offered an example of men's work in contrast with women's work. "When we first went down and my husband was going to be introduced to my parents, he shot a deer and took half a deer down to my dad and he thought that was the greatest thing on earth," she said. "So that was tradition: you need to take somebody something and respect my family." It was expected of Renee's husband, as a male, to perform that tradition in line with identity.

There was one participant who found an exception in her family to the gender division regarding food: "One time we were asking dad....and he just smiled and said, you know, my mom was the hunter," Renee said. "His mother was the one that went out and shot deer. I was surprised. That's okay. She did it, that's a legacy she's left for all the 
boys in the family. Grandma did it, not so much grandpa, but grandma." Even the exception reinforced the tradition that men do the hunting in that the legacy was for all of the boys in the family, rather than the girls.

Some participants believed that the gender division they described was reflective of past roles and no longer necessarily applied. For example, Randee talked about hunting today and how women may be involved, either by hunting directly or by going out on the land with the one hunting. "I'm sure they [women] do [hunt]. Yeah, they probably do," she said. "But I know when we get deer tags...I might get someone who knows how to shoot. But say like I was married and he wasn't from the Cedar Band of Paiutes, he could hunt for me, but I would have to go out with him, go hunt deer on our land." In this case, only members of the particular band could obtain tags to hunt in that area. Participants also said that now men do some of the cooking, mirroring to some extent the changes in the larger American culture regarding gender roles. "I learned from my first husband—he was a good cook," Kimberly, a younger participant, said. "He used to go out and go camping a lot. There were ten kids, and his mother was the best cook. Really good soups. Could turn anything into something special. They knew how to cook outdoors. I didn't know how to do that, so a lot of it I learned from him." Participants thought that women could hunt now if they desired, and they cited examples of men taking part in preparations of foods now, including cooking. Gender roles have become less strict as subsistence strategies have changed. 


\section{Taste and Food Selection}

Finally, I found similarities between participants from both tribes regarding changes in taste and food selection. Many of the elders of both tribes prefaced the telling of their own story with the statement that they would not be able to eat that way now, would not want to eat rock chuck or cow stomach. They no longer had a taste for that kind of food, or they did not like it very much even back then. "Not too keen about rock chuck. If I don't have to eat it, I don't want to. I've tasted it, but I'd probably lose tons of weight if I had to eat it. New diet: your challenge to eat rock chuck for 3 months. Major diet here," said Renee, with great humor. Jenny and other participants recalled disliking some heritage foods when they were younger and wild foods were plentiful. "Not now, [but] it [traditional food] used to be [what I liked]. It was what they cooked, and we had to eat it," said Jenny. "I didn't like it [porcupine]; too much taste to it. I didn't like rock chuck, but I watched how they used to cook it. It's really greasy. I tasted that; I didn't like it." Randee remembered enjoying the taste of wild foods at the time, but thought she would not care for the taste now. "My grandfather would get squirrels," she said. "I remember going up and getting a squirrel...it tasted like chicken. I don't know, I never tasted anything like it. I liked it when I was small. I could never eat it now. I remember liking it." Paul maintained a great sense of humor over the changes in taste. "A lot of that [cow stomach or rock chuck] would run you out of there if you haven't smelled it in a while. It would probably kill us if we tried to eat it now," he said. Some participants, particularly younger participants, never enjoyed certain wild foods, like rock chuck or porcupine or squirrel. 
Participants did not romanticize the past in their discussion of changing tastes, instead admitting that in the case of some heritage foods they never liked the taste or they would not like it now. Changing tastes hold implications for identity among Native people, as participants came to view wild foods like rock chuck as a symbol of identity rather than a food regularly consumed to maintain identity. The fact that their ancestors ate rock chuck or that they themselves ate rock chuck when they were younger was enough to form identity around that food. In addition, as tastes changed, children of participants were less exposed to heritage foods firsthand and identified less with foods their parents may have recognized as part of their identity.

It became important to participants to navigate multiple worlds with appreciation for all of them and to configure self-understanding in terms of gathering values and traits central to the different cultures with which they were raised as children, which they hoped to preserve in their own children. "My kids never grew up on that [deer meat] because I grew up on it and I didn't really care to carry it on, I guess," Randee said, explaining how she chose to raise her children with some heritage foods and not others. "My oldest now would never go and hunt a deer." Instead, Randy raised her kids with other symbolic foods. "They [kids] liked the bread and the regular potatoes," she said. Depending on their own tastes, values, family, and life experiences, participants gave examples of choices they made concerning foods they did and did not want to pass on to their children.

I found similarities in participants' characterizations of traditional foods as plain and prepared with little seasoning. Multiple participants described drying deer meat or other meat and how they used only salt and pepper. During my compilation of the 
traditional foods cookbook, I asked participants to edit recipes I had collected. The primary feedback, of older participants in particular, was to eliminate most of the seasoning various recipes contained because Native food did not include a lot of seasoning. "They never had seasoning," said Paul of PITU. "When they made the stew, it was just meat, potatoes. Didn't have a variety because they didn't have a refrigerator to keep them.” Laura, of the Bishop Paiute Tribe, said the same: “They don't cook fancy. It's just plain food. Not a lot of seasoning." Taste and value differentially articulate with ethnicity to shape food systems (Wilk 2006). "Taste" is a term signifying palatability, and in this case, like or dislike of the traditional diet as a whole or individual traditional foods.

Participants spoke of an acquired taste for traditional foods, which many of their children did not have. "I try to go out and pick some of the native plants. But in my house, I'm the only one who will eat it...they didn't grow up eating that. They grew up in the city, city Indians, city life, so they don't. A lot of Indian food is an acquired taste," said Carla. Some aspects of the traditional diet persisted regarding a taste for plain food, as in plain, traditional, wholesome, and familiar, like potatoes and stews.

Above all, participants believed themselves to belong to the Indian world, or the Paiute world, in terms of their identity as Native Americans. Participants performed their identity in different ways. Families and tribes continued the regular use of certain heritage foods and the symbolic use of heritage foods in ceremonies and at food gatherings. Individuals in their sense of self-understanding and of groupness as part of the tribe or ethnic group, as in the Paiute world, continued to emphasize the importance of 
heritage foods to ethnic identity, whether or not they continued to eat particular wild foods like game due to changes in taste or availability.

\section{Cook's Thesis on Native Diet in Owens Valley and Conclusions}

Some factors help maintain ethnic identity through reinforcing the traditional or ethnic diet, while other factors operate to cause dietary change. California Indians in Owens Valley, for example, four generations ago were thoroughly accustomed to the "wild diet," and it possessed palatability (Cook 1976:489). Sherburne Cook theorized there was an "inherited" aspect to taste, or "racial taste," with respect to the taste of the group for traditional foods as individuals acquired taste and as taste persisted due to experience and habit (1976:489).

Though dated, Cook's historical work offers a unique perspective on dietary adaptation in particular among California and Nevada Indians (1976). In his PhD thesis, he argued that when free dietary choices exist between two types of diet, indigenous peoples will select a diet in accordance with food availability, inherited or acquired taste, and social usage or custom (1976:450). Further, during adaptation, more available food will become more desirable and in line with taste and will come to be desired socially, while traditional foods will become less popular and palatable (1976:450). Adaptation from one diet to another relies more than anything else on the availability of foods.

Interestingly, Cook's work includes both quantitative and qualitative dietary studies among Paiute peoples of the Carson and Owens Valleys 40 years ago (1976). Through measuring caloric intake of four key wild food categories (acorns, pine nuts, fish and game, and other), he concluded that Paiute peoples at the time gathered and 
consumed roughly 6 percent of their energy requirements from wild foods (1976: 504). Through ethnographic data, he found among interviewees a range of likes and dislikes for particular foodstuffs, but that in general those past middle age preferred traditional food and the younger generations more often preferred "white food" (1976:491). While major changes in overall diet, including taste and social selection, follow availability, taste may also operate independent of availability (1976:496). He predicted that once those he interviewed who were around 40 years of age had passed into old age, traditional ways would be a rarity (1976:487). He also predicted that in one or two generations the transformation process from one diet to another, which began in the mid-nineteenth century for Owens Valley indigenous peoples, would be complete (1976:507).

Although my research sought to complicate Cook's thesis and predictions, I found it instructive to consider his findings. Participants diverged in their responses concerning what constitute traditional foods and whether foods may be processed in modern ways or must be processed in traditional ways in order to be considered traditional. All participants agreed that tastes had changed among tribal members, and that many "couldn't eat those kinds of foods anymore," despite their symbolic connotation, referring to rock chuck, prairie dog, porcupine, and cow stomach. I found that despite the major transformation in the diets of Bishop Paiute Tribe members and PITU members that occurred during their lifetimes, symbolic and regular use of particular foods persist among Native people and are key to Native people's understanding of themselves and their past. Depending on how one views and defines traditional foods and heritage foods, my research could not confirm Cook's prediction that the transformation process is complete. For some participants, traditional ways were a part of their past and not their 
present, and they no longer consumed traditional foods nor raised their children with traditional foods. However, from the point of view of the majority of participants, tribal members continue to value and consume heritage foods and closely relate their ethnic and tribal identity to symbolic foods, even if food practices and concepts of identity have changed. 


\section{Chapter 4: Race, Ethnicity, and Food: "The White Diet"}

Participants live in a hybrid culture and partake of a variety of foods representing ambiguous classifications, including "white," "LDS," traditional in the sense of familiar, and traditional in the sense of ethnic. At times participants used the terminology of "white" to represent the overall American culture, rather than a race or ethnicity. At other times, participants, specifically PITU members, used the terminology to represent the LDS church, which, though multicultural and multi-ethnic, is overwhelmingly white in terms of race in the context of Utah. In part, participants used the term to refer to race.

In the case of referring to the overall American culture, participants used "white" to signify generic American food, from Hamburger Helper to sandwiches and salads to Sloppy Joes. Participants used the term "white" in reference to health education. For example, as a nutrition educator, I worked in northern Utah in 2008 for a nutrition program that operated uniformly in each county in the state, and the official nutrition lessons did not take into account the cultural differences of participants and featured healthy foods from American culture such as vegetable lasagna and tacos (Americanized version). Renee described Americanized foods in a similar class she attended: "The health department will come up and show us how to eat, what's good food. One time we had tacos, and they taught us. It's just if you know what's good for you, in this day and age it shouldn't be hard to figure out. The information's out there, everywhere. It's open to everybody and they come out to each band. I can go up there and get a class." An Americanized version of tacos constituted a healthy, "white" recipe from the Native perspective. 
However, the classes I taught were sometimes combined with the county extension agent's classes and then foods important to LDS participants were included, an example of the unique context of Utah and LDS culture. An overwhelming majority of people in the classes were LDS members, and there was an emphasis on Utah LDS food culture in the classes. Homemade breads and healthy quick mixes or recipes using oatmeal, wheat, beans, and rice, which are part of the food storage LDS members keep on hand in bulk, were integral parts of the classes (Cheney 2012). County classes were also offered on site at LDS church buildings, such as stake houses (a stake is an LDS territorial jurisdiction; stake houses are basically regional church buildings) and at Relief Society meetings (a women's organization in the church). As many PITU participants were LDS members, they had experienced classes such as these, which have an emphasis on LDS food culture. Due to the context of Utah and its demographics, they saw LDS food culture as representing the "white diet." Participants who identified with LDS food culture, whether they were LDS or not, viewed the "white diet" as part of their identity, while participants who did not viewed Native foods alone as part of their identity.

Participants from both tribes discussed the influence of health education on traditional diet, foodways, and their own values concerning food such as choosing plain, wholesome food and cooking at home. PITU members experienced the influences of the dominant culture as well as the uniquely situated LDS culture of southern Utah, as many I interviewed were a part of the LDS church or participated in food aspects of LDS culture. Participants expressed valuing certain foodways in common with LDS culture such as canning and gardening as well as valuing certain foods as traditional foods such as rhubarb pie, beans cooked with ham, ground beef in various dishes, and wholesome 
vegetable dishes like stews. Participants often cited introduced foods, including foods introduced through the commodities program or health education or the church, as "white man" food or the "white diet." The assignment of particular foods into the categories of traditional or "white" helped participants articulate which foods are important to their identity, separating traditional foods (traditional in the sense of familiar and traditional in the sense of ethnic) from "white" foods. From the perspective of PITU and Bishop Paiute Tribe participants, symbols of identity from the dominant culture included "white" foods and most often correlated with perceptions of race difference.

Race and ethnicity are important factors in determining food-related identity. Slocum offers a review of theories that build on the social construction of race and the post-structuralist critique of essential difference to understand performativity and the materiality of racial embodiments, and specific to food, identity (2010:304). In other words, race is a fiction, but concepts of race and racism still affect material lives, which is of particular interest in a discussion of heritage foods and their connection to race and ethnicity. The body not only represents race/ethnicity and reflects discourse, but also actually performs identities, both old and new, to intervene, reinforce, or create (2010:304). Not only ethnicity, but also perceptions of race difference affect the negotiation of multiple identities, such as a participant's "white world" and "Native world" in relation to symbols like food.

Maintaining racial or ethnic identity is dependent in part upon guarding food habits and tastes (Appadurai 1988). For example, eating soul food is of critical importance to preserving identity as African American communities increasingly fragment and stratify (Zafar 1999). It becomes a matter of racial pride as eating soul food 
reclaims foods that formerly were despised, foods that slaves had to eat and owners would not (Bailey 2007). Many people of color have rejected veganism or vegetarianism as a choice of the privileged and the dominant culture, but some examples of decolonized, alternative soul food from within African American communities incorporate veganism and local food by claiming ties to a past in which backyard gardens and bartering were a part of daily life and consumption (Bailey 2007).

Renee in particular was very articulate in her description of her self-understanding as a Native person. I interviewed her and her husband. Although she is originally Navajo, she took on the identity of her husband's tribe, PITU, once they were married. Renee described how she understood herself within multiple contexts:

"Actually I have three worlds. I have my white world, I have my Navajo world, and I have my Paiute world because tribes, none of them are alike. They all have different ways of doing things, and they all have their ceremonies. And sometimes when I go home to the reservation [Navajo Reservation], I have to respect what they want to do down there and how they do it. For example, Paiute way, when someone dies, out of respect for that person they cut their hair. Then they take their hair into the mountains so the animals will nest with it, but you give it to nature out of respect for the person that died. But when I went to my reservation when my brother died, I said I wanted to cut my hair for my brother, but they said we don't do that. Okay, well, it was my sacrifice so when I came home I cut my hair. I cut my hair for my brother because I'm in this world, my husband's world. It's a good tradition, a good sacrifice." 
Descriptions like Renee's of multiple understandings of identity, of multiple worlds, were common among participants, along with appreciation for them all in different ways. In addition, examples of performing identity, both old and new, were evident among participants, from the renewing of food traditions to intervene and re-create or reinforce identity to the creation of new habits and new identity through the mingling of the multiple traditions present in one family, such as Renee absorbing her husband's traditions:

“I was raised as an Anglo. Even though I was Native, I didn't know a lot. I knew some because I would go home and come back, but when I was older, my sistersin-law would teach me how to do my fry bread, flapping of my bread, doing my breads. And when I moved in here, married him and moved into this family, I saw all the ways they do it and how the traditions are different and so I started absorbing that because the last three children [our youngest three children] are all members of the Paiute tribe. I'm in Paiute country, so this makes sense. I'm just absorbed in his world, and they know that and respect that."

Renee's comments point to the idea that not only young children but also adults can learn culture and food traditions, contributing to a person's sense of identity. She continued:

"It's a different world, and I love the world that we live in. And my kids have the best of both worlds. They can be either side and go into both worlds. It's a good mix, they know both sides. My kids used to dance. The only thing they don't have is the language."

With clarity and candor, Renee touched upon several key aspects of ethnic identity, including food, food traditions, familial relations, dance, and language. In many ways, 58 
she recognized the contribution of preserving traditions from both sides of the family and more than one ethnicity to her own and her children's lived experience and selfunderstanding as Native Americans. Renee's story makes distinctions between Native groups and shows that there is more to identity than the simplified labels of "white" or "LDS" or "Native." Revealing the particular stories and traditions around food of individuals, households, families, and tribes adds complexity to encounters between white and non-white and complicates understandings of identity.

\section{Valuing "the White Diet"}

PITU participants commented on the influence of health education and the LDS church on the adoption of certain new food practices. Several participants perceived salads, greens, and vegetable dishes as part of "white people's food," and thus white food as healthy. "White people's food, they say you need to eat that to live a long time," Paul said. "It helps, otherwise I'd be buried by now. The Paiute tribe had a dietician come around and tell us you need to eat this and not eat that old stuff. I told her I was a caveman, born way back, didn't have refrigerator. I finally got to where I could eat the green stuff like a cow." Older participants sometimes resented the new food even though they accepted it as healthy and life-prolonging. For some participants, adopting new food for health reasons hurt their sense of identity.

Racism against marginalized or ethnic foodways in the US has been evident in public policy through public health and urban planning, through emphasis on "whitening" the diet and the health of the "white diet" (Pilcher 2008). Through creating "white food space," which is largely invisible, programming like health education from the dominant 
culture is directed at the "Other," non-white, as "if they were foolishly standing outside" the foodshed (Slocum 2010:314). For example, in East Austin, Texas, Latinos were the targets of fitness programs because of their presumed cultural tendencies toward unhealthy food, despite the fact that there were greater numbers of obese white people than Latinos in Austin (Herrick 2008). Further, Latinos were over-represented as marginalized in public health policy due to spatial separation from whites and definitions of food deserts even though in many of the local communities, Latinos had better access to small independent grocers and stores with local, healthy, and culturally important foods (Herrick 2008). Likewise, PITU and Bishop Paiute Tribe participants reported learning that the white diet was healthier than the Indian diet, despite evidence that at times the white diet, whether generic American or LDS, was less healthy (processed foods, salt, sugars) than the Indian diet (gathered plants, lean meats, no salt or sugar). In cases like these, the emphasis is on changing Native identity rather than improving Native people's health.

Participants perceived the "white diet" as healthy in terms of examples they were shown through health education and so were encouraged to adopt it. However, it was unhealthy in terms of the commodities program and at times church charity, when canned goods and processed foods were given away that added salt and sugars to people's diets. Participants also believed LDS food was healthy because LDS members ate a lot of salads and vegetables, to which Native people were not initially accustomed. Participants talked about LDS members giving away food or introducing them to new foods that they later valued. "The church ladies, from the Relief Society, used to bring peaches, canned goods," Jenny said. Ellen also spoke of her grandmother valuing certain foods from LDS 
culture. "We didn't have no jam either. We had what you call sorghum. That was our jam, our butter and jam. Dump it into your little plate and get your karate bread [Indian bread]," Ellen explained. "My grandma used to say, 'I wish I had some nice, good white man jam.' I think it was Mrs. Will Palmer [LDS leader], she would give my grandma plum jam." Some of the foods and foodways introduced by the LDS church were healthy, such as plentiful amounts of vegetables in the diet, and others were not healthy, such as adding salt to dishes and using jam on bread.

Participants came to value some introduced foods and foodways, both healthy and unhealthy, as traditional and familiar, while still distinguishing those foods from heritage foods that represent their ethnic identity, such as wild foods like game (deer, rock chuck, prairie dog), berries, and watercress. Although prairie dogs (a type of ground squirrel in the genus Cynomys) are federally protected and no longer eaten, this heritage food holds a significant place in the list of symbolic heritage foods representing ethnic identity.

A critical approach to food and self-understanding acknowledges rather than ignores past and present relations of race/ethnicity and gender and takes into account the complexity of encounter. Some participants spent time growing up in LDS households and were more familiar with "white food" and the "white way" of preparing it.

Participants spoke of their appreciation of LDS food culture or "white food" and were glad they learned the foodways of multiple cultures. Participants believed such exchanges enriched their self-understanding and sense of identity.

PITU participants spent time in LDS households or were themselves LDS, but they still clearly thought of themselves as Native American, part of the Indian world and specifically part of the Paiute world. Familial relations as well as personal choices 
contextualized these worlds. Although participants acknowledged some "white food," whether pioneer food, LDS food, or general American food, as traditional and familiar, they were careful to separate key symbolic foods from other traditional foods.

Participants were also careful to articulate their own life history and relationship with multiple identities and thus multiple heritage foods.

\section{Gender and Family}

Questions of ethnic as well as gender identity surface in discourse regarding food and the gendered household. Access to "good food" can be understood in terms of relations and negotiations that constitute how people get things (Ribot and Peluso 2003). Research shows that women provide nearly 95 percent of all domestic care (Clark 1998; Lorber 1994). Women have been characterized as the caretakers of humanity in feminist scholarship, and women's health-related labor shapes health outcomes across generations (Clark 1998). In households, culture mediates the influence of gender in the negotiation of health decisions, including decisions about food or food choices (Clark 1998).

For PITU and Bishop Paiute Tribe female participants, obtaining and cooking foods the "American way" or the "white man way" became an important part of providing for children and taking care of the health and future of their families as women and "good mothers." Renee spoke of the white man way and the Indian way of preparing food and the importance of teaching future generations. "My kids know what fish is," she said. "But it's important that they know how to cook it, white man way too. There's things we've tried to teach them. They know how to hunt deer, know how to fish, know about rock chuck, they've seen it, so if there's a time we need to go and do resources that 
way, my kids are pretty prepared." Renee and other participants referred to white man food and the white man way of cooking, as opposed to Indian food and the Indian way. Participants' use of the term "white" referred in part to general American culture and to foods like hamburgers, apple pie, salads, and processed foods. It also, in the context of southern Utah, referred to "white" LDS culture, which values family, food preservation, and pioneer foodways (Cheney 2012). Participants saw both the white way and the Native way as important to their families.

Participants emphasized the importance of family and the importance of familyinstilled values, particularly related to eating, which is also in common with LDS culture. Ellen talked about being a good mother and how she did that through food and mealtimes. "We were kinda poor, so we raised our children the best way we knew how," she said. "We always had to eat at one time, all my children and me and my husband. So we could talk! Ask how was school, so that's how we communicated. We had to wait for them, too. We'd all eat together. Sometimes one would be late." Passing on heritage foods knowledge depends on the family and what one learns growing up from family or tribe. "What they eat now is a lot different than what they ate a long time ago. I guess it just depends on what you learn," Glenna Jean said. "Probably eat a lot of the wrong foods, don't eat a lot of vegetables...we always did because my mom always provided us with good food. She always cooked. We didn't eat out. It's how you grow up, how your parents, what they ate, what they taught you to eat. You don't learn how to eat good, you stay with what you ate when you were young." Participants, especially mothers, described eating food at home and eating food together as key aspects of traditional foodways, in common with LDS or pioneer foodways. 


\section{Resistance to the Delocalized Food System: Traditional and Familiar}

Participants provided similar commentary on the value of food traditions like gardening that resist the delocalized food system. Delocalized food on average travels 1,600 miles to reach someone's table (Halweil 2004:7). "We canned, preserved a lot of food, apples and pears," said Laura, describing the traditional ways of the past and the resurgence of some food traditions like gardening. "To tell you the truth, I think the people have changed. It's too convenient to go to the store rather than grow it, but I think it's going to be reversed...I can see it. People are talking about little gardens. My mother always gardened. As teenagers, we ate good. Vegetables. She grew everything, cucumbers, tomatoes, squash. We had strawberries over here.” Many participants described gardening as traditional. "My dad used to raise watermelon, tomatoes, peaches," Paul said. "We had a big garden, grew our own potatoes and melons and onions, even had carrots," Glenna Jean said. Many participants described canning, or bottling, as a part of their traditional foodways as well.

Kimberly, the diabetes counselor, talked about bringing food traditions like gardening and canning back for economic, health, and taste reasons. "I hear a lot of people saying it's too expensive to buy fruits and vegetables at the store," she said. "A lot of people have gardens. They used to have gardens. They're trying to bring that back, with canning. They have a canning class that starts tomorrow. I want to have a canning class for my diabetic patients. I remember my grandmother having a root cellar because they had peaches, apples, they canned all their vegetables and fruits." While canning may 
sometimes use a lot of salt and sugar, the benefit is that the person canning knows what is in her food and can control the amount of salt and sugar.

In the renewing of food traditions, numerous examples arise of resistance and alternatives to the delocalized food system. But often alternatives, such as canning classes and Saturday markets, privilege "whiteness" and "white ideals of health and nutrition" (Slocum 2010:314). Kimberly and others provided evidence of resistance to the delocalized food system through revitalizing food traditions in both pioneer and Native foodways.

Gardening, Canning, and Revitalizing Foodways

Interesting overlays to this discussion are ideas about pioneer foodways, gardening, food preservation, reinvigorating food traditions, eating at home, being good mothers, and gender identity. In his book Plain but Wholesome: Foodways of the Mormon Pioneers, educator and historian Brock Cheney ties together many of the values pioneers held through their food traditions, menus, food processes, and recipes that are still seen today and are experiencing a renewal through gardening and canning classes (2012). Participants from both tribes described traditional foodways that reflected the values of pioneers, and PITU participants in particular referred to LDS food culture, which is reflective of Mormon pioneer foodways, as an influence on their own cooking and food habits. Plain or unrefined food and healthy foods gathered from the garden and cooked at home are common attributes of traditional foodways cited by Native participants as well as Cheney in his study of Mormon pioneer foodways (Cheney 2012). 
Although Mormons originally passed down information about food traditions orally, now Mormon efforts to record and share recipes and food processes abound (Cheney 2012). Young Mormon mothers now attend classes to learn food preservation and home cooking from their peers, as many of their mothers did not learn the food traditions, favoring careers over cooking (Cheney 2012).

Likewise, Native female participants expressed their desire to learn from peers or elders of the tribe, because many did not learn about heritage foods and cooking from their mothers or did not remember what they had learned long ago. Margie, in her seventies, talked about elders learning from one another through elders group activities, such as going pine nut picking or making crafts. A few years ago elders gathered and made Native American food together. Some participants did not grow up with heritage foods at all, while others were introduced to heritage foods by grandparents only and now did not have access to their grandparents to ask them questions. Still others simply were not interested in learning the Native foods when they were younger, and wished to learn more now. "She [my mom] never really taught me how to cook," Randee, a female participant, said. “I don’t ever remember preparing food when I was home." Randee spent a significant portion of her school years in the Salt Lake City area living with LDS families as part of the Indian Placement Program and learned to cook from LDS members. "My mom was not a cook," Julia said, adding that her grandma could make anything taste good. "I learned from my grandmother." Kimberly, a younger participant, explained her attitude toward cooking when she was growing up. "My mom showed me how to make tortillas, but now I can't remember how to do it," she said. "I was more of a tomboy, and I should have paid more attention. My mom tried to show us canning, and I 
wasn't interested. I was always outside.” Many participants did not learn heritage practices from their mothers and instead learned cooking from non-Native families or grandmothers or were not interested in cooking, all of which inhibited the continuation of heritage food practices and led to shifts in identity.

Members of both tribes spoke of gardening, canning, home cooking, and eating at home as part of the traditional way of preparing and consuming food, and they spoke of the renewal of food traditions like gardening and canning in their communities. While pioneer or LDS cultural foods were not part of the wild foods category participants defined as traditional and ethnic, pioneer foods and foodways at times blended into traditional foods categories in participants' descriptions of traditional, in the sense of old, familiar, wholesome, and closely aligned with family values.

\section{Romanticization and Identity}

While people from the dominant culture may romanticize Native cultures and map static identities onto Native peoples, Renee and other participants did not romanticize their Native American identity and self-understanding in the sense that they simultaneously discussed the importance of foods symbolic of their ethnic identity and the everyday nature of choices about adopting new traditions, carrying on old traditions, and tossing out others. Often encounters between people with different foodways are ambivalent and complex (Duruz 2005). Participants did not romanticize changes in taste or adoption of introduced foods and foodways, but often perceived newer foods as traditional and even part of their heritage as they came to value them. 
In the racialized encounter of circulating cuisines, foodways of essentialized others are often appropriated with admiration (Slocum 2010:308). This certainly may be true of the emphasis on "traditional foods" and the romanticized past among activists revitalizing Native foodways for "all humankind" (Kuhnlein and Receveur 1996:432). Thinking of the "traditional diet," for example, in terms of being replaced by the "white diet" misses the "messy, mixed-up, interconnected nature of histories, geographies and identities" (Cook and Harrison 2003:310). It also ignores the agency of individuals to resist, adapt, and transform the meaning of foods in different contexts.

Participants also did not romanticize their relationship with the dominant culture. Expressions of difference through food are performed through gender as well as through relations with dominant others (Cook 2008). Participants expressed understanding that while race is a social construction, it still affects Native American lives through prejudice and even blatant racism, as in the perception of race difference.

\section{The Traditional Foods Dinner: What Potlucks, Soup Nights, and Other Food Gatherings Teach Us about Friendship, Kinship, and Groupness}

In the context of community, food is a powerful symbol and binding entity. Often, communities bond together through the sharing of food. Lin T. Humphrey describes "a sense of community and group identity" that grew out of the sharing and consuming of food at "Soup Night" once a week in her particular community (1988:251). Groupness refers to group members' feelings of belonging and connectedness to other members in a group (Brubaker and Cooper 2000). 
As an applied component of my research project, I organized a one-time traditional foods dinner for Paiute Indian Tribe of Utah (PITU) participants, their families, and general community members. The dinner was held at the Paiute Playground, a lovely outdoor venue for food gatherings located alongside the tribal buildings in Cedar City, complete with a large pavilion, picnic tables, grill, and fire pit in addition to an expansive play area for children. Project participants and the tribal council collectively decided the dinner's location, date, and time, conducive to many participants' schedules. However, the storms swirling around Cedar City the afternoon of the event had other plans. Rain did not fall that evening, but dark clouds and ferocious wind gusts were our guests. A plateful of pine nuts lost the battle with the wind, as did multiple loose plates and napkins, which we all scurried to retrieve. Wind notwithstanding, a solid number of around 20 community members arrived on time, chairs in hand, including Eliza, Margaret, and Lenora. Their families, including their husbands and grandchildren, attended the event, along with several tribal leaders and their family members. I had interviewed these participants and had kept in touch with them through thank you cards, additional visits to their homes to remind them of the dinner, and several phone calls. I felt a certain rapport upon seeing them and talking with them again at the dinner. The food gathering brought people together to enjoy foods of cultural significance and one another's company. I learned that the most important part of the gathering for those in attendance was the camaraderie and support of others in their community.

One of the objectives of the PITU traditional foods dinner was to offer participants an opportunity to demonstrate a food recipe tribal members jointly consider traditional and to share with one another. Regrettably, few arrived with food in hand, 
despite the reminders of the "potluck style" of the gathering. I believe this happened for several reasons besides the obvious reasons of physical handicap, busy lifestyle, and burnt beans. Foremost of these is the idea many participants have of what is "traditional": They hoped to sample truly traditional foods prepared the "old way" and perhaps on some level felt they themselves could not provide this. As a result, they did not bring anything, or they brought Diet Coke, which was the subject of much humor during the dinner. ("What traditional food did you bring?" asked one of the tribal leaders.

“Traditional Coke," said Lenora, an older participant, and her husband joked. "This Coke was made the traditional way.") "Nostalgic gastronomy" brings together memory and lived experience, and nostalgia for a past cuisine one never knew "recreates what one imagines" as food important to culture and race difference (Slocum 2010:308). Through nostalgic gastronomy, marginalized people undermine efforts to "whiten" their diets and refute multicultural sentiment that trivializes difference (2010:308). Further, nostalgic gastronomy allows people to live out their self-understanding and groupness and even to make grocery stores serve memory (Mankekar 2005). Every participant at the dinner brought other family members, usually their children, eager to show the younger generation what traditional food is and to let them have a taste for themselves.

Luckily, I brought several foods that participants had listed as traditional during interviews, though I did not prepare them the traditional way. I bought two whole rainbow trout at the store and encouraged one of the family members present, a younger participant at the gathering, to grill them over the fire I had prepared while I attended to the rest of the details of the dinner. I also purchased packages of very expensive pine nuts. This, too, was the subject of jokes. ("Oh, that April, she went out and caught those 
fish this morning!" and "Yes, she went out and gathered those pine nuts earlier. She is putting us to shame!") At the same time, the questioning of the food prompted good community conversation about what is and is not traditional, which foods are and are not significant.

As the humor evidenced, the traditional foods dinner presented participants an informal way to connect and converse with fellow tribal members, friends, and family. The participants most certainly shared with one another and bonded over the questionable traditional food. Despite the thinness of the food itself, the conversation was ample; the rapport, rich. I was floored by how long the participants lingered in the looming storm. They seemed perfectly content to relax in their outdoor chairs and chat for a couple of hours, despite the roar of the wind and the difficulty hearing one another. I noticed how easily the attendees fell into conversation with old friends and even with me, since they made a connection with me. They were happy to talk about old times and to share information about their families, the tribe, their community.

In Food in the Social Order, Mary Douglas writes that the meaning of food can be changed at a gathering depending on both its quality and quantity (1984:15). If a greater quantity of food is offered, the food represents a greater investment in cost, time, thought, and space (1984:15). The food offered at the traditional foods dinner represented a great deal of thought and time on the part of the participants who prepared food. One elder brought Indian bread and traditional gravy. She brought enough to share with everyone. She carefully wrapped both dishes in towels to keep them warm and thought to bring serving utensils to dispense the food properly. She was openly happy to share her recipe 
with other participants, adding meaning to the gathering. On the other hand, the food was not particularly costly.

The inexpensive food and the potluck style served to disperse power in the group and to give a feeling of free access to the food to all. Children were encouraged to step up in line to try the foods. In addition, it lent an informal air to the gathering, so that participants felt comfortable serving themselves and dishing up seconds, coming and going as they pleased. Humphrey lists numerous qualities of the potluck gathering that encourage a division of power among all guests (1988:253). No one is in charge. There is no seating arrangement. There is no dress code. Any lines between host and guest are blurred. Guests freely move from room to room. Status is downplayed. Guests provide parts of the meal. Humphrey writes that contributing to an event "gives participants some power in shaping the event" (1988:254). This was entirely the point in creating the onetime traditional foods dinner. Participants took advantage of an opportunity to share their knowledge and themselves with others, and the power was divided. Sharing food means that one is willing to share oneself (Humphrey 1988:259). In part, family held the gathering together, and a "family feeling" was created among individuals who share friendship and often kinship (Humphrey 1988:256).

The dinner allowed participants to define their community, to appreciate being a part of that community, and to assert their collective identity and groupness, or individual sense of belonging in the group. According to Jones, Giuliano, and Krell concerning foodways, once food is associated with social experience and social identity, food becomes symbolic (1983:41-42). For example, in one-on-one interviews, community conversation, and tribal council meetings, tribal members identified several heritage 
foods as symbolic, namely, pine nuts, deer meat, rock chuck, Indian bread, and sometimes fry bread. Sharing food with others reinforces the experience of preparing or serving food as valuable and meaningful.

Although the traditional foods dinner was open to all tribal members and not just project participants, I sensed some discomfort among the group when a non-Indian woman arrived at the dinner with five kids in tow. She was a friend of one of the participants who could not make it, and the participant encouraged her to attend and sample the traditional foods with her children. It was open to anybody, she said. However, it quickly became evident that the symbolic nature of the food and the sharing of food within a community with a distinct group identity made it difficult for the nonIndian woman to take part in a meaningful way.

Although tribal participants were not unkind to the woman, it was evident that she did not share their group identity or friendship with members of the gathering and therefore was not readily accepted as part of the social experience. In part this could have been related to the necessity for tribal members to protect information they consider important to their collective identity and at risk if exposed to outside groups. Also, the outside guest brought five hungry children to the dinner and could have been seen as someone taking advantage of the generosity of people she did not know. She deviated from the norm in several categories of acceptable social behavior, most importantly by not being a member of the group.

Food can be used to solidify group membership and define group identity (Mintz and Du Bois 2002). Partly the participants and I decided to organize a dinner to build rapport and community among tribal members. The elders requested and received the 
opportunity simply to be together and feel a sense of belonging and commonality, to sit and eat and talk together.

\section{Conclusions}

Through the lens of identity, this chapter has provided an investigation of heritage foods and foodways, along with food values, habits, and taste, complicated understandings of ethnicity and food. Self-understanding and groupness among PITU and Bishop Paiute Tribe members, articulated with gender and ethnic identity through performing identity and using symbols like food, confirmed the material influence of social change on diet and taste. Holding onto food habits and tastes through nostalgic gastronomy was part of maintaining ethnic identity for Native participants.

By performing identity through food, participants adapted, reinforced, or created past, present, and possible future identities. In food habits and choices, female participants performed their gender identity as they sought to be good mothers and to involve their children in multiple identities, including the white world, the Native world, and specifically, the Paiute world. Complex and even ambivalent encounters between multiple identities, both ethnic and racialized, and different types of diet, such as the white diet learned from the dominant culture through health education programs, had a profound effect on participants' definitions of heritage foods, regular use of certain heritage foods, sharing of food and food knowledge, and symbolic use of heritage foods.

Contrary to Cook's prediction (1976), participants' taste at times operated independently of food availability, as in the case of preferences for plain food over highly seasoned food. Taste did change, however, among PITU and Bishop Paiute Tribe 
participants as availability of heritage foods continued to diminish and as availability of "white food" continued to increase. Participants chose to value certain introduced foods as traditional or familiar, both healthy and unhealthy, and rejected others. Some participants defined introduced foods as heritage foods, while others defined only wild foods as heritage foods.

Members of both tribes spoke of gardening, canning, and eating at home as part of the traditional way of preparing and consuming food, and they spoke of the renewal of food traditions like gardening and canning in their communities as resistance to the delocalized food system. Foodways and food values in common with pioneer or LDS foodways helped reinforce, redefine, and create identity and provided resistance to the delocalized food system in PITU and Bishop Paiute Tribe communities. Participants' commentary moved beyond romanticizing Native identity and essentialized differences between white and non-white. Participants reported valuing both traditional foods, in the sense of familiar and wholesome, and heritage foods as representative of ethnic identity. 


\section{Chapter 5: Economics, Policy, and Human Health}

\section{Introduction: The Political Economy of Health}

This chapter discusses the effects of economic status and related political and social factors on the place of heritage foods in everyday life, on food choices and habits, and ultimately, on the health of Paiute Indian Tribe of Utah (PITU) members and Bishop Paiute Tribe members. The two Native American nations experience influences unique to their history and place, while both also experience food conditions common to communities across the US.

One dramatic example of a medical anthropologist using concepts from the political economy of health is the work of Dr. Paul Farmer in Haiti. As an anthropologist and public health enthusiast, Dr. Paul Farmer surveyed households in the central plateau of Haiti to learn why patients adhered or did not adhere to the regimen of medicines (Kidder 2004).

Picture the central plateau of Haiti: A hot, arid climate; dusty roads clogged with trucks struggling to pass one another; families living in huts with dirt floors, without running water or electricity; people lacking the money to travel to see a doctor for even common illnesses. A decade ago, public health statistics revealed that many Haitians were not completing the full cycle of medicines and were not fully recovering from tuberculosis (Kidder 2004).

At the time, most social scientists were of the mind that Haitians believed more in Voodoo and the power of Voodoo priests to cure illness than in modern medical techniques and so they were not motivated to continue taking medications. Surprisingly, 
as Farmer delved deeper into the countryside and listened to people's stories, he found that this was not the case at all. Instead, Haitian families faced multiple obstacles in daily life due to poverty that worked to prevent them from taking all of their medicines. Almost without fail, the people he surveyed responded that they believed in both Voodoo and modern medicine. As a result, Farmer placed all of the at-risk families on a program through which they received all medications from a nurse and were allotted a stipend each month. Farmer's plan worked. As part of their "cure," Haitians with tuberculosis needed affordable access to modern medicines as well as holistic care that included economic assistance and plentiful nutrition. Health depends not only on individual attitudes and bodies, but also on social structures that determine people's access as a group to resources. In the case of Dr. Farmer's work in Haiti, political economy and Critical Medical Anthropology helped reveal the nature of economic status as a larger force influencing people's health in a concrete way.

As Haitians with tuberculosis experienced challenges due to economic and political factors, such as not being able to afford a doctor or not having a doctor available nearby, Native American participants experienced challenges such as not being able to afford heritage foods available for purchase or not owning or having access to lands with plentiful food-related resources or even not being able to purchase a fishing license. These structural factors influenced food conditions for both Haitians and Native Americans.

In this chapter, I will bring key theoretical concepts from the discourses of political economy and Critical Medical Anthropology to bear on the subject of human health in relation to heritage foods and nutrition. The theoretical frameworks of political 
economy and Critical Medical Anthropology, or the political economy of health, emphasize the role of larger, interrelated factors, such as political factors and economic status, in people's lives, and even health outcomes. Through interviews with PITU members in southern Utah and Bishop Paiute Tribe members in eastern California, I found that economic status in part determined people's food choices and thus affected their health in ways both similar to and different from people's experiences in Haiti. The Native American participants in my research and the Haitian participants in Dr. Farmer's program all experienced a history of exploitation, colonization, and discrimination. These forces continue to affect Native Americans and Haitians today in the form of disadvantageous neoliberal economic status and discriminatory stereotypes. While Haitian participants experienced under-nutrition due to economic status that negatively influenced health outcomes, Native American participants I interviewed discussed experiences in their communities of over-nutrition. Native people increasingly chose processed foods over heritage foods, which negatively affected health outcomes.

PITU and Bishop Paiute Tribe members' experiences of food conditions such as over-nutrition and diabetes vary based on the unique social, economic, and political environment of each tribe. As discussed in Chapter 2, property ownership influences heritage foods access, food traditions, and income generating opportunities. Each nation has developed different economic projects, from a sewing factory to a casino. PITU did not gain quality land during the recent restoration of the tribe, but the Bishop Paiute Tribe fared well in a land trade with the Los Angeles Department of Water and Power (LADWP), securing a more valuable land base with access to more water. The Bishop Paiute Tribe now operates a casino that provides the tribe income and a measure of 
independence. PITU has not had an abundance of funding for its own health and nutrition-related programs; the Bishop Paiute Tribe has. In addition, health services for the Bishop Paiute Tribe, under the name of the Toiyabe Indian Health Project, are integrated with those of nearby tribes, such as the Big Pine Paiute Tribe, perhaps improving the quality and diversification of services.

Other keys to the social and political landscape of each nation are the relationship between the tribe and the larger community and the influence of the larger culture on food habits. Each nation has tribal offices and a reservation in or alongside a city, Cedar City and Bishop respectively. While PITU members have long resided on land privately owned by the Church of Jesus Christ of Latter-day Saints (LDS), Bishop Paiute Tribe members live on land held in trust by the federal government (Knack 1997:159). The influence of the LDS Church on PITU people's definitions of heritage foods and their food habits is evident today. For example, several of those I interviewed had voluntarily entered church programs through which they were sent as children to Salt Lake City or another city to live with a church family and thus learned new foods and cooking methods they incorporated into their lifelong menus of important foods to their families and culture. Although many Bishop Paiute Tribe members are also involved with a Christian denomination, there are a number of churches represented in the area, and none of them has as strong a presence in the community as the LDS church has in the Cedar City area. While PITU is literally integrated into the community in terms of location and religious affiliation, the Bishop Paiute Tribe occupies a location completely separate from the city of Bishop. 
The relationship of each tribe with the larger community, along with other social and political factors, strongly influences food habits and food conditions. Economic factors, including income-generating opportunities and land ownership, are interrelated with social and political factors, and all of these are addressed in the framework of political economy. In this chapter, I will investigate the intersections of these factors, from changing economic opportunities to women entering the workforce, and their influences on cultural capital, in the form of heritage foods knowledge and practices, and human health.

Social conditions, a concept public health scholars and professionals often utilize, are modifiable characteristics of social and physical environments at the individual, household, and community levels (Braveman 2010:35). Social conditions include living and working conditions, social networks, education opportunities, family structure, availability of transportation, safety of neighborhoods, and access to nutritious foods (Braveman 2010:35). Modifiable social inequalities in health such as differences in living conditions and access to education, according to Finn Diderichsen of the University of Copenhagen, are produced and exacerbated through social stratification (Braveman 2010). Different levels of social, economic, and political opportunities and resources in part reflect an individual's social class, race, gender, and other factors and their associated levels of wealth, influence, acceptance, and prestige (Braveman 2010). Different positions in social hierarchies directly affect health. For example, a highly educated professional who becomes disabled may still be able to earn a living, while a manual laborer who suffers the same disability may lose his or her livelihood (Braveman 2010:38). 
As previously discussed, scholars and practitioners actively engaged through "system-challenging praxis" (Singer 1995:80) assert that it is most effective to examine social conditions and health status together. Medical anthropologists and public health practitioners alike believe that health problems and societal problems do not occur in isolation and that in fact health problems are considered in part the responsibility of society and are addressed and mediated through the policies of society, such as policies to promote economic development and to promote child development and education (Braveman 2010:37).

I seek to understand historic and present social conditions in combination with the official, categorized health status of Native Americans and their own perception of their health in order to create a project that will hopefully benefit the individuals with whom I worked. Research with Native Americans related to food, nutrition, and the prevalence of type 2 diabetes is not something new. As someone who has worked in public health and in health education, I want to understand perhaps what had or had not resonated with people in past education programs or health interventions and to build on what I learned with the collaboration of participants I interviewed. I hope to reveal what is at stake for participants as individuals and as part of families and tribes in terms of their health and their access to important, healthy foods today.

It is my goal through research to ask the questions of anthropology and history, of production and consumption, within the theoretical frameworks of political economy and Critical Medical Anthropology. How has economic status affected what Native Americans eat over time and which foods they consider important to eat? How does 
economic status affect Native American access to heritage foods today? How does economic status affect Native American access to healthy foods?

\section{Economic Status}

Critical medical anthropologists show that economic status and access to adequate nutrition are closely linked. Dr. Paul Farmer asserts that regardless of cultural values, people desire (and deserve) access to effective healthcare, including not only medicines, but also healthy foods (Kidder 2004: 96). In light of social, political, and economic factors, I will analyze how economic status has affected what Native Americans eat and their access to heritage foods and healthy foods today.

\section{Fry Bread and Commodity Programs}

Both PITU and Bishop Paiute Tribe members recognized that shifts in economic status have had dramatic effects on human health over time. First, some of the foods they value as traditional today, such as fry bread, were recently incorporated and were the result of American Indians in the last century doing as much as they could with ingredients, "staples," that the federal government provided them through commodity programs. Staples included flour, sugar, and lard, and Native people came up with something tasty to eat out of the ingredients. Fry bread is a delicious but fattening food made by frying or deep-frying a simple, flat dough, usually consisting of white flour, sugar, salt, and a leavening agent, in oil, lard, or shortening. While participants acknowledged this particular food as a fairly recent creation, they still value it and eat it 
today. As discussed in the prior chapter, some participants felt that it is a heritage food; others did not.

Most participants had an awareness of the negative health effects of eating lots of fry bread and fatty foods. Fry bread is not healthy and contains high amounts of saturated fats and easily digested carbohydrates due to low fiber content. It is usually made with white flour and lacks whole grain sources. A typical serving of fry bread contains 526 calories, $15.2 \mathrm{~g}$ of total fat, and 1,112 mg of sodium (Calorie Count 2013). "Well, way back when I was growing up, the weight problem! Where does that come from? I don't remember anybody being overly big, fat, obese. Nobody...we'd buy bacon, and we'd also get it from [the commodities program], but not too much," said Laura, a Bishop Paiute Tribe participant in her seventies who stays active and looks much younger than her age. "Course we had the fry bread, but we didn't overdo the fry bread. Kind of like the tortilla, my mother didn't put any shortening in it...it was just a special occasion.” Kimberly, who works for the Bishop Paiute Tribe diabetes prevention program, spoke of fry bread resulting from the commodities program and of its negative effects on health. "Indian taco is not a traditional food. But there is a recipe with whole wheat," she said. Indian tacos are similar to American versions of tacos, but are typically assembled with fry bread in place of a tortilla or taco shell. Participants from both tribes varied in the ways they valued fry bread and foods like bacon that were introduced during the advent of commodities programs. For the majority of participants, introduced foods like fry bread featured prominently in discussions of heritage foods that are still valued and consumed, despite the fact that fry bread was the result of an economic situation that was thrust upon Native people within the last century and despite it being unhealthy. 
Second, due to economic status, many of those I interviewed felt they could not afford or were not willing to pay for the few traditional foods that are available for purchase today. For example, pine nuts are a key heritage food and extremely expensive. I interviewed a PITU couple living on the Shivwitz Reservation, Jenny and Paul, and together they talked about foods they ate in the past and foods now available. "[Pine nuts] cost too much," said Paul, age 70, in a bemused tone. "Once in a while we buy some. Those bags, not enough in there. Once you start eating, you can't stop, so we don't even start." Most participants said that they wanted to eat more heritage foods, particularly healthy heritage foods, but that they felt foods like pine nuts were simply too expensive to buy on a regular basis or at all. Also available in grocery stores in the Cedar City area at the time of research were frog legs, rabbit meat, and cow stomach. PITU members, for example, preferred not to buy these traditional foods in the grocery store for multiple reasons, including the expense of such foods. As a result, most pantries and kitchens of those I interviewed lacked traditional foods, with the exception of relatively affordable commodities such as dried plants for teas, seasonings, beans, and potatoes. Cost alone was a major barrier for participants wanting to include more heritage foods in their diets.

Third, economic status has affected Native people's access to heritage foods and healthy foods over time. Due to their parents' jobs as migrant workers and due to gathering cycles, some of the older participants moved to different areas in cyclical patterns as children, lived with extended family members for periods of time, and at times did not attend school. Later in their lives, some of the older participants continued to move seasonally for jobs until they had access to higher education. Julia, a PITU participant, age 64 , remembered significant changes in her family once she moved to 
town to go to school. "We're from Shivwitz and Moapa... and I grew up with my grandparents. We'd go back and forth," she said. Participants moved as children because the structure of their families changed and because their families were poor and their parents sought employment or education for their children. These factors affected diet and knowledge transmission, at first for the better as participants had access to healthy foods despite low economic status. However, eventually low economic status worked against the health of Native people in the form of ready access to cheaper, processed foods.

Many participants reported living with grandparents or aunts and uncles, spending most of their childhood outdoors, and having no running water or electricity. "We lived at my grandma's and used to go to school, climbed the hills," said Eliza, a PITU participant who moved with her family depending on employment opportunities. "And there was no water and no electric. As a kid, I didn't think of it as a hardship, but I remember taking a bath in a tin tub thing. Warmed the water on the stove. I didn't think anything of it at the time. Half the stuff I did I don't know my kids could even try!" Glennine spoke of living with her aunt and learning from her: "When my dad died when I was born she [my mother] had to go to work, so I went to stay with my aunt in Nevada." Due to economic constraints particular to each family, participants at times endured difficult living conditions, had less access to education, and experienced changes in family structure, such as living with a relative instead of living with parents, which affected diet and knowledge transmission.

How did this affect what they ate? Ironically, despite what they called "being very poor," participants remembered living a very healthy lifestyle, with healthy traditional 
foods and plenty of exercise. Beans, a common food in participants' diets in the past and today, are cheap and have benefits for heart health and are rich sources of soluble fiber, protein, complex carbohydrates, folate, and iron. Many heritage foods such as pine nuts or lean types of meat are deemed healthy by nutritional standards, especially in combination with ample amounts of exercise on a daily basis.

Despite being poor, participants as children ate healthfully through the methods of hunting, gathering, gardening, and trading. "We didn't have that much [when I was growing up], but we ate pretty good because my grandparents had a garden," Mimi said. "And then we had our vegetables," said Ethel, a PITU participant who grew up part of the time in the Indian Peaks area. "We had sparegrass, carrots, onions, potatoes, beets, turnip. Sparegrass. You boil it in soup. Rhubarb. We made pies out of those. We had berries, strawberries, blueberries you make jam with, honey. They said we didn't have flour then, but we did. We ground it. We'd get the top of the berries and ground those...we had salt, pepper, but pepper was like chili." Participants remembered eating vegetables, some of which they obtained through trading with settlers in the area and through gardening, lots of pine nuts, and desert plants, such as cactus pads and hearts.

Participants described preparing and eating deer, rabbits, and other small game, which are an excellent source of protein and tend to be leaner than meat from commercially raised animals. Julia recalled hunting frogs or whatever they could find as children. "We had everything," Ethel said. "Meat-wise, at that time there was deer, rabbit, elk, porcupine, groundhog, prairie dogs. We had dove, sage hen, a lot of stuff." In the case of hunted foods such as deer and elk, the meat is lean and healthier than most cuts of beef, for example. "But we didn't overeat on that [bacon], didn't eat a lot of fat. 
Deer doesn't have a lot of fat," said Laura. "This was before the $20^{\text {th }}$ century, they ate deer, didn't have that fat. Not like eating beef," said Glenna Gene, a Bishop Paiute Tribe participant also in her seventies. Wild foods were more available when participants were young and were cheaper for participants' families to obtain at that time.

Foraged meats such as deer are not only leaner, but they are also untainted by antibiotics, growth hormones, and food additives, except for salt or spices such as pepper added to drying meat. Further, restrictive livestock management practices and breeding select out beneficial compounds contained in wild food sources (Nabhan 2004:179). “Traditional food, they didn't have any of that stuff, chemicals in there," Paul explained. "Wild animals, they were healthier for you if you could cook it the right way. My mother would dry them, deer meat. Eat that in the winter time. I think they were healthier then." Although participants ate healthy diets as children due in part to low economic status, participants ate less healthy as adults due to economic constraints that affected their diets, including less time to hunt and gather due to jobs in the modern economic system. For example, due to the demands of a modern lifestyle and jobs, Native men go out hunting or fishing less often than in the past. Many are able to bring meat or fish home only once or twice a year. They give the meat to their families and other relatives, especially elder women who live alone. While it is not the only source of meat participants have throughout the year, it offers protein with less fat. The meat is kept frozen and used sparingly throughout the year for its protein and its cultural importance.

Participants commonly reported that no food or materials were wasted in traditional food practices. Native people ate parts of the cow, for example, that people "wouldn't eat now" and that were very nutritious. "With the deer, they used everything, 
and nothing went to waste," said Renee. "I don't think the butcher gives that [cow stomach] out anymore.... Some type of dog food company buys all of that," said Paul, explaining the availability of some heritage foods. Participants remembered obtaining parts of an animal that otherwise would have been wasted, such as cow stomach, from a local butcher when they were younger, but diverse uses of such foods in the delocalized economy has decreased the general availability of such foods today.

Partly due to low economic status, participants described being very active as children, which contributed to optimal health status. "Years ago, they had to work, had to walk places, didn't get into a car and drive. You had to either get on a bike or walk. Now everybody's got a car," recalled Glennine. "You go feed the chickens or get a bucket of water or walk to the store, walk to school. That was a long way. Even here, we used to walk to catch the bus. Now the bus comes right here." Kimberly talked about the activity levels and agility of previous generations in her family. "I remember my grandmas being small, and maybe they didn't get the vitamins either," she said. "They were very active, basketmakers, they could sit on the floor and get off the floor. More agile. My mom couldn't do that, couldn't get up from the floor so she would always say that. I remember going out on picnics and sit on the ground and we don't do that anymore." I interviewed a married couple living in Richfield, Utah, Daren and Renee, both middle-aged. Daren was originally part of the Kanosh Band of Paiutes and a member of the Paiute Indian Tribe of Utah. Upon marriage, Renee considered herself a part of his tribe, and their children were PITU members. When asked about human health, Renee said: "I think the activity level is a big deal. I mean, think, if you're out gathering food or chopping wood or getting water every day and cooking and doing to survive, their lifestyle was lot different. I really don't 
think there was a lot of obese people, Natives." Participants believed traditional ways of life and traditional ways of obtaining and preparing food made them healthy in the past and protected them from diseases like obesity and diabetes.

Participants reported consuming very little sugar when they were younger, in contrast to their children's diets. "They didn't have a lot of sweet," said Renee. "So I think that's a real big downfall because they [Native people now] have a lot of pop and candy and you know, they consume it and have it and everybody has it. It's just for us something is different, for Native Americans." Laura described the lack of desserts when she was growing up. "We didn't have many desserts either," she said. "Every now and then she'd [mom] make a pie. We canned, preserved a lot of food, apples and pears. We'd go and get apples, pears, or peaches...went to the Pine Creek area and got these berries...that you can add sugar to...and that was our dessert." Due to less integration into the global economy and less access to delocalized foods in the past, participants had less access to sugar, sugary foods, and processed foods as children, which protected people from obesity and diabetes at the time.

Low economic status eventually worked against the health of Native people, especially in cities, as the cheapest foods were processed ones, which remains true today. Processed foods are high in salt, fat, and sugar, which helps preserve the foods and helps companies sell the food by making the food taste good and by making the food easy to eat in a hurry (Nestle 2002:29). Participants often described growing up poor or raising families with little resources. Native people I interviewed increasingly settled into the larger American way of life during their lifetimes out of economic necessity and due to time constraints. "A [Native] gentleman from this area who left and recently came back 
said he wouldn't drink the water in LA because it tasted so terrible so he just drank sodas," Kimberly said. "And he said you think McDonald's is close to where you live here, there they were even closer and there were two of them! They didn't have a lot of money so they ate Top Ramen® and put a lot of junk in it. He's lost 6 pounds just by stopping the sodas because he likes the water here." In essence, the structure of participants' lives has changed to accommodate the dominance of capitalism in American society. However, individual experiences of these changes and the individual experience of health were not overlooked in discussions with participants.

Although overarching, unseen forces plainly wrought changes in the daily life of individuals over which they had no direct control (Mintz 1997:366), collective resistance to the economic system and the food industry that markets prepared products exists among participants. Tribal members I interviewed emphasized the ways they share knowledge of heritage foods as well as health information, such as nutrition information, within their families and tribes. Individuals felt they had some measure of control over their health and reported that eating and exercise habits vary greatly among people and families in their community. Elders described the responsibility they felt toward the next generation: to personally show them aspects of their heritage, particularly foods, and to help them take care of their health through educating them and encouraging them. Political economists and critical medical anthropologists address the dynamic between individual agency and wider social, political, and economic forces and changes. Participants' emphasis on individual responsibility for health reflects the widespread acceptance of neoliberal capitalist ideology, which places blame for poor health status on individuals rather than society and wider forces (Singer 2007:44). In light of political 
economy and Critical Medical Anthropology, participants, through no fault of their own, were in many ways disadvantaged in working within and against wider systems that directly affected their health.

\section{Education and Economic Development}

As they reached adulthood, participants' socioeconomic status generally improved, and they reported having better jobs, more education, and more opportunities than their parents. Ethel and Victoria, both PITU participants and both 68 years old, went to high school together. "I was one of the first Indian kids to graduate from Cedar High, in '62, and then I went to college for two years. I went to Salt Lake to business college there, and I came back and taught at the elementary," Ethel said. Bishop Paiute Tribe members spoke of similar opportunities. "I graduated from Bishop Union High School," Laura, a Bishop Paiute Tribe participant, said. "My mother, seemed like she left home quite early, quite young, and she went to work for non-Indians...My mother grew up, went to Reno, started working in homes, so she was introduced to non-Indian foods and learning that. She never did learn to read or write. Never went to school. Her first language was her native, Paiute. We lost my dad when we were real young." Another Bishop Paiute Tribe participant said: “My mom didn't go to school, but my other brothers and sisters went to Stewart and Sherman, to boarding school. I graduated from high school here." Although their parents did not finish high school, many participants reported graduating from high school and benefiting economically from obtaining more education than their parents. 
Some participants, their parents, and even their grandparents had the opportunity to go back to school later in life. Paul, a 70-year-old PITU participant, talked about his education: "I just went to where the jobs were at. Went to Enterprise to pick potatoes, lived in the field. Then we went to Brigham City in the fall to pick cherries. Then we came back...state had a program to send us older adults to school, so I went to Dixie College." Randee and Mimi also talked about education opportunities in their families. “The only thing I remember is the education. That's the only way I went to BYU - they paid for our school," Randee said. "I think I had a normal childhood, made sure I went to school. Education was very important to them. My grandfather did - he went back to school," Mimi said. Educational opportunities like these helped participants secure better employment and advanced their economic status.

Several participants cited working in a sewing factory, a PITU economic development project. "I worked in a sewing factory. When I got out of high school, I worked down here. They made coats. Then I went down to Cedar, and I worked in a factory there. They made sleeping bags. I put the zippers on. That was easy. I mostly sewed all the time. I learned," Catherine explained. Jobs like these were key economic opportunities for participants at the time and helped them advance economically. However, factory jobs were low-paying and brought people into the global proletariat. Ellen spoke of the difficulties of securing employment without a formal education and in the face of prejudice. "We'd move down south around April to go get onions. We never stayed in one place, so it was hard to finish a grade. The teachers would say, 'You look like you would go in the second grade.' I never finished a grade, and I would sit way in the back because I never knew what they were talking about. But I was one heck of a 
colorer. I tell my grandkids, 'Grandma didn't go to school so you need to finish your school. You don't want to be like grandma, peanuts for money.' I worked as a maid, that was my employment," she said. Later Ellen explained struggling to obtain employment:

"We were living in Brigham City at that time, and they had a school for all Natives up there. My husband worked there. One day I put my application...my youngest son was in first grade so I figured I could go to work. I took my application, and I did this all the time and I never got hired. I must have done this 3 or 4 years. But one time when I was there, there was a man from Phoenix there, a superintendent. There were all white people, and they hired who they wanted to hire. I talked to this lady, and said, 'You are always overlooking my application. Why is that?' Just at that time he happened to come in, and he went in there and looked through the file and said, 'There isn't any Ellen Tom in here.' And the lady didn't say anything. I guess they just threw them in the trash. He told me, 'Look for it. You're gonna get called to work.' I worked there as a night attendant for 8 years...”

Education opportunities, job availability, and prejudice continue to play a role in the socioeconomic status of Native participants and are central to tribes' concerns. PITU and Bishop Paiute Tribe members were incorporated into the local economy over time, first as ranch hands and then as migrant agricultural workers, factory workers, and maids. None of these opportunities offered them a way into the middle class. While younger participants experienced greater opportunities than their parents, they still did not have secure economic positions relative to the rest of society. Despite integration into the economy, participants were still disadvantaged both by class and by race/ethnicity. 
Integration into the Economic System

Participants reported rapid changes to a sedentary lifestyle and ready access to processed foods as they grew older and increasingly participated in the broader economic system. Many participants from both PITU and the Bishop Paiute Tribe moved to larger cities in their regions, Salt Lake City and Los Angeles respectively, following jobs and education opportunities. Most younger participants I interviewed finished high school and experienced greater opportunities as a result, in contrast to their parents. While there were greater opportunities for younger participants, they spoke of obtaining working class jobs rather than following well-paid careers.

Moving to larger cities and accepting different jobs and lifestyles brought about changes in Native people's access to heritage foods due to location and economic status. In larger cities, it became more difficult for participants to hunt and gather heritage foods because they lived far from heritage food-related resources such as forests where they could gather pine nuts or rivers where they could fish. Due to low economic status and the cost of travel, it was difficult for participants to visit tribal lands or other rural areas. In addition, participants had less time to obtain or prepare heritage foods due to the time requirements of new jobs. Finally, moving to cities for new jobs dramatically changed Native lifestyles in that Native people were suddenly much more sedentary as they adjusted to life in cities and were increasingly unable to continue heritage foods practices, such as hunting and gathering, which protected Native people's health through the regular, sustained exercise that was necessary to harvest and prepare heritage foods in traditional ways. 


\section{Social Changes}

Social changes such as women entering the workforce, economic opportunities, and resulting time constraints had effects on food selection and preparation. Many of the participants I interviewed were women, and they described changes in their economic status and food habits that were very similar to what Sidney Mintz outlines in his political economic study of the history of sugar and its place in people's lives. Key to the discussion here, Mintz suggests that changes in food choices after the rise of the industrial complex in England, such as eating store-brought bread and factory-made jam instead of wholesome oatmeal, were interrelated with a host of other changes, including "the decline of home-prepared food" and "the place of a higher value on women's labor" (1997:365-366). Not only did sugar become available on a larger scale due to the rise of industrial production, the price of such foods as bread and jam dropped. Greater numbers of women entered the workforce, and fewer meals were made at home. Men and women began to view the routine of the day, including food consumption, in ways that centered on the workplace and ingestibles quickly consumable during work breaks, such as coffee, tea, and of course, sugar. Changes in consumption practices led to diet-related health problems and tooth decay (Mintz 1997:366). Mintz clearly outlines how systemic economic change caused widespread health issues.

Similarly, in contrast to their grandmothers and often their mothers, PITU and Bishop Paiute Tribe women I interviewed reported taking jobs outside the home to make ends meet at some point during their adult lives, either through part-time work during their children's early years or through full-time work after their children were in school. 
Some of the older women I interviewed, along with the mothers of many women I interviewed, had traveled in their younger years for seasonal migrant work. The structure of their daily lives shifted, as did their food choices. Along with women in the rest of American society, Native women worked more and increasingly opted in favor of cheaper and quicker meals. Some participants described having only one day now set aside for "Indian breakfast," usually a Saturday when the family can relax and enjoy the meal and its meaning together. The women I interviewed reported making fewer and fewer traditional meals during their adult lives, or reported only eating heritage foods regularly during their childhoods. As one participant phrased it: "It's a totally different way of life now. Everything is different." Social changes such as women entering the workforce had dramatic effects on everyday choices concerning food. These shifts also created disadvantageous health consequences, as I discuss in more detail in the following chapter.

The ability to purchase "American" foods, according to participants' responses, ensured greater flexibility in feeding one's family. They just made sense for a busy family. For example, Margie discussed the ease of feeding her children with general American foods like pasta and casseroles rather than the traditional foods with which she grew up. "I had eight kids. Nowadays my kids only have one each. And I think, 'How did I do it?' she said. 'It wasn't that hard to feed my family back then because... what I used to do was lay out a menu for a week and I'd follow that. I would buy and stock, and the food wasn't so expensive back then. I used to plan my food for a week." Processed foods were seen in a positive light and signified development or advancement. 
Ellen, a PITU participant, distilled the influence of the larger society on diet over time in several vivid stories from her childhood. She described an LDS leader in Cedar City that helped her family:

"Will Palmer was the one that talked to the Paiute people... He did a lot for the Paiute people. We would go to his house. My grandmother would take her gloves and baskets to sell, and Will Palmer would buy them. She would tell me, 'You can't go in there. You might break something.' This little old lady would come out with a glass of milk and a piece of bread with jelly on it. That was the best treat! Oh, I thought I'd died and gone to heaven. It was so good! I mean, she made her bread, and she would do the goat's milk. She would tell me they came from her goats. I drank it - oh. I'd never tasted milk. That was where I first tasted milk, and that's the first time I tasted homemade bread and jelly, so good. Every time I went to her house, I was looking forward to it. She was very nice."

LDS members introduced participants like Ellen to new foods like jelly and milk. "And we thought it was the agency man [Indian agency representative], and he lived in a white house. And he brought candy like Christmas candy, and they had curls in them."

Non-Native people introduced Native people to unhealthy foods like candy and sugared foods.

"That was the first time I seen Santa Claus, the ugliest thing I've ever seen. He had all this stuff for us. I got my gift, and I started thinking, 'What is this anyway?' There was a lot of goodies, and I went home. I ran home, and I told my grandma, 'Gosh, look! Look what that old man gave me!' 'What? Old man!' I 
dumped it on our little floor, the whole sack in there, and out popped all this orange and apple."

Ellen had probably eaten fruits like this before, but the gift represented something special for her. Non-Native foods in contexts such as this one were associated with positive aspects of non-Native identity and were incorporated into participants' diets. In the case of candy and processed food, non-Native foods negatively affected Native people's health once they incorporated them into their diets. In the case of unfamiliar fruits and vegetables, non-Native foods positively affected Native people's diet-related health.

\section{Time and Transportation}

According to participants, even people who live in rural areas find that it is no longer feasible or even possible to gather heritage foods or hunt or fish in the exact manner and timeframe Native people in their area did in the past, due in part to economic reasons such as the cost of gas to travel to gather foods. For example, the trip from Bishop to the NTTR, former ancestral lands, is roughly 95 miles, a two-hour drive via a pass through the White Mountains. PITU and Bishop Paiute Tribe members asserted that while they still highly value and praise traditional knowledge of foods and continue to put that knowledge into practice, depending on the individual or family, the living and working conditions, the entire lifestyle that hosted that knowledge and practice has changed.

For example, rather than going for a month at a time to gather pine nuts, participants reported going out for one day at a time to gather. Rather than walking (or riding in wagons) to gather as they used to, older participants I interviewed said it just 
makes sense to drive to where one needs to go now. Glenn, a Bishop Paiute Tribe participant, age 75, engaged in the interview with enthusiasm and spoke at length about hunting, fishing, and gathering heritage foods during his childhood and at times with his own children. "We went pine nut picking [with my kids] too, but not like they used to do it," he said. "We just went for a day and got some pine nuts. And that's how it is today. I don't know anyone who goes out and camps anymore." Distances from tribal lands, cost of travel, and time needed to participate in heritage food practices provide barriers to participation and sharing foraging knowledge with subsequent generations.

Moving to urban areas forced many participants away from their extended families and support networks and away from open lands where they had been accustomed to gathering and learning about heritage foods as children. "When we lived at Moapa, [Nevada, a town 120 miles from Cedar City,] my grandpa used to go hunting all the time," Julia said. "And after he died, we moved down to the town, and couldn't just go out and hunt wherever, restricted [due to land ownership]." The place of heritage foods in participants' daily lives has changed over time as Native people increasingly fit into the American economic system and as access to heritage food-related resources and lands diminished. Work schedules, travel costs, and moving to urban areas all worked together to restrict the time Native families spend hunting, gathering, camping, and teaching the next generation about heritage foods firsthand.

\section{Barriers to Access}

Federal government agencies like the United States Forest Service (USFS) and the Bureau of Land Management (BLM) manage large quantities of land in the Cedar 
City and Bishop areas today and restrict to some degree the activities of all people on the land. Government agencies like USFS and BLM in some ways work to protect resources, and they restrict and monitor activity on the land, including Native American land management and heritage foods practices. Agencies vary in their management of the land. In the Bishop area specifically, the Los Angeles Department of Water and Power owns and manages a significant amount of land and resources. LADWP restricts activity on the land it manages in order to protect the water resources and inadvertently protects other resources, though not through an explicit mission of protecting environmental resources.

While it was not a specific part of my interview schedule, participants offered commentary concerning whether or not Native people could access the land and resources necessary for gathering and what permits were required for foraging, if any. Carla revealed that most Native people are not aware that they may obtain permits from USFS or other government agency specifically to gather and are allowed to gather on public lands as Native people. Perhaps one of the reasons for participants' lack of awareness is the sometimes inadequate communication between Native people and government agencies. Some participants said there were not places to gather anymore because the land had been bought and is now private. Some participants said they could access the land to gather just as much as in times past, if they wanted to, but that only some families still carry on the traditions.

A few participants described nearby roads they used in the past on national lands, such as those managed by USFS or BLM, being closed or blocked off certain times of the year due to conservation efforts. Some roads in Owens Valley for instance are very near 100 
populated areas and easily accessible to any visitor. ATV (all-terrain vehicle)

recreationists often abuse their access to these roads, using them to create still more trails and paths, and the high rate of recreation tourism in the area exacerbates this problem, causing government agencies to monitor local roads with care and at times to limit access to high-profile roads into the forest. "Now of course they've closed off a lot of the roads where you can't drive in there anymore. They've blocked them off so you can't just pull your trailer up there and unload your stuff and camp. It was done so those areas would be preserved because if people see a trail they get off the road and make another road," Glenn explained. Restrictions put into place to protect the landscape can also affect Native people's access to heritage foods.

Participants discussed other boundaries to foraging practices. Glennine spoke of fishing in Owens Valley now. "They' re not as easy to catch now... we used to get a sackful, I remember, when I was little. Now they go out fishing...it's not as easy now...you have to go out and get a license." Kimberly said of the barriers: "You have to have a fishing license, and that's 60 bucks. I think you can apply for one through the tribe, but it takes a while." Even relatively small barriers such as license regulations prevent some Native people from accessing heritage-food related resources. Participants revealed issues of environmental degradation and limited access to public lands and resources that currently work to limit Native people's access to heritage food-related resources.

\section{Environmental Health}

Changes in environmental policy and resulting changes in the environment itself influenced food choices and selection of heritage foods. Without the prompting of a 101 
particular interview question, the participants all believed that the food gathered today is tainted with chemicals sprayed on the fields and by the general environmental degradation that has occurred in past centuries and more recently. I noticed a difference between what PITU participants and Bishop Paiute Tribe participants experienced firsthand of environmental changes affecting heritage foods and gathering due to historical factors. While PITU members related changes in agricultural practices that happened within their own lifetimes, Bishop Paiute Tribe members talked about changes that began more than a century ago, of which they are still feeling the effects today.

I found a common explanation among PITU participants regarding the environmental health of the land used for food-gathering purposes. All of the PITU participants I asked about access commented on the overall poor environmental health of the region, the impact of farming and ranching and the use of chemicals on the environment due to agricultural practices in particular, and the unhealthy status of the land and plants used for gathering in past generations. "They [traditional foods] used to be good a long time ago, but they're not anymore," said Jenny, with Paul nodding in agreement. "We went way into the field and got us a rabbit and cleaned it and cooked it. I can't remember what was wrong with it...I think it made someone sick, didn't feel good after he ate it." Carla, a PITU participant who continues to gather heritage foods, distinguished between purchased foods and gathered foods in terms of health. "Today whatever you buy has pesticides, chemicals on it," she said. "Eating healthy, even when you're trying to eat healthy, is very hard to do. Unless you're out picking your own plants, eating from nature, that's as healthy as you can get. So for me eating healthy is trying to eat as much greens as you can and I try to go out and pick some of the native 102 
plants." From the perspective of participants like Carla, some heritage foods were still healthy to eat and were much healthier than foods sold in the supermarket and thus directly contaminated by pesticides. Ethel described a similar situation: "We go now and can't have it. I can't remember it was a good 10, 15 years ago, somebody went to get onions and nearly died from it. Because of the chemicals that was on it. They sprayed." Ethel described the effects of the use of pesticides in modern agricultural practices on the whole ecological system, including native plants growing in nearby fields. Modern agricultural practices have negatively affected the health of most foods available to participants and the health of participants.

In contrast, Bishop Paiute Tribe participants voiced concerns about the loss of water in their area rather than the poisoning of the landscape. Owens Valley is a special case of environmental change in the last century due to the control the Los Angeles Department of Water and Power (LADWP) has taken in the region through its ownership and management of an immense amount of land (and thus water) in Owens Valley. Since the early years of the twentieth century, LADWP has literally drained the valley of water for the City of Los Angeles (Cragen and Schumacher 1962:198). Bitter disputes over water rights and water use between locals and Los Angeles continue to this day.

All of the Bishop Paiute Tribe participants remarked on how green and fertile the Owens Valley used to be and how much more abundant the plants and foods important to Indian people were when they were younger. They testified to the dramatic changes in the environment in their area. "It's drying everything up because my grandmother used to say it used to be so green. And my aunt said it was really green and pretty and now it's just dried up," said Kimberly. "We used to irrigate, pulling water out of the creeks, until 103 
DWP started taking the water," she said, when discussing gardening on the Bishop Paiute Tribe Reservation. "There's a creek down here...used to be a lot more water in there and now there's not much water and you can tell it's never been like it was 40 years ago or even 45 years ago," said Glennine. However, she and other Bishop Paiute Tribe participants expressed some ambivalence about LADWP's involvement in the valley, as there has been and continues to be little development in the area due to LADWP's ownership of a significant portion of the valley. "Most of this land here is owned by DWP, and I think if they didn't own the land, I think there would be businesses all over the place. It's kinda twofold, I guess. It's good and bad," she said. Participants agreed that the influence of LADWP is good in the sense that there has been less development in the area and more land preserved than there would have been without LADWP ownership. However, all on its own, LADWP has caused monumental environmental changes in the area simply by taking so much water from Owens Valley, drying up Owens Lake and changing the habitat of numerous species of animals and plants. In addition, the gold and silver mining industry fueled many environmental changes in Owens Valley in the nineteenth century, representing a continuum that began with a large influx of miners and settlers and continued into the $20^{\text {th }}$ century (Cragen and Schumacher 1962). Miners felled thousands of Pinon and Jeffrey pines. Cattle and sheep herds overgrazed grasslands and devastated food sources such as tubers, roots, and seeds in the most flourishing parts of the valley along the Owens River. Persistent hunting by settlers nearly wiped out populations of game and fowl. By 1870, Native ways of life had been radically altered, and most Native Americans in the area worked on ranches or 
farms because they could not hunt or gather as effectively as they had before the arrival of Euro-Americans (Cragen and Schumacher 1962:180).

In general, participants from both tribes believed the land is no longer treated well. Many described the ways Indian people treat the land when gathering, saying prayers and leaving offerings, and said that there are no longer enough prayers and offerings. "We always have some cedar with us so we can pray," said Renee, voicing great respect and appreciation for the traditions. "We always get some cedar and put it on the fire and bless ourselves. Anytime we're out camping we really believe the old ones are there or have been there, and it's respect for them also." PITU and Bishop Paiute Tribe participants alike discussed the importance of honoring traditions that respect the land and keep the environment whole and well, and they asserted that in many cases the land is not being respected due to commercialization, such as companies harvesting pine nuts with machines in a harsh manner. Native traditions that respect the land include prayers, offerings, and land management practices such as pruning dead limbs from pinyon trees during the gathering of pine nuts (Anderson 2006:284). Environmental degradation as well as the loss of indigenous land management practices have contributed to the diminishment of food-related resources.

Pine Nuts

Participants from both tribes described changes in the availability and taste of different heritage foods, and in particular, pine nuts. For Native people east of the Sierra Nevada Mountains, the singleleaf pinyon pine's nuts have been an important food resource for millennia (Anderson 2006:283). The pine nut is the seed found inside a pine 105 
cone. The singleleaf pinyon pine nut is a large nut and may be orange to chocolate brown in color (Anderson 2006:283). It is an excellent source of protein, unsaturated fatty acids, and carbohydrates (Anderson 2006:280). Pine nuts can be gathered in large quantities and stored for long time periods (Anderson 2006:280). PITU and Bishop Paiute Tribe members continue to gather pine nuts today. Native people traditionally use either hooked sticks to bring the limbs toward the gatherer who snaps off the green cones or large poles to whip the trees and knock down the cones or the mature seeds out of the cones (Anderson 2006:284). The pine nuts may be eaten raw or roasted or cooked in a variety of dishes. Participants in my research provided details about the process of gathering pine nuts and roasting them. Many participants described pine nut gravy and Indian bread or potatoes as a favorite heritage foods meal. Pine nuts for purchase today are very expensive. For example, a 1-lb. bag of pine nuts for purchase at Manor Market in Bishop costs \$12.00.

Participants remembered going camping and gathering pine nuts in the hills as children. "People had their places where they would go to camp and pick pine nuts. Maybe there would be a group, a family, that kind of thing," described Glenn. They recalled their parents and grandparents visiting particular locations every year to gather, locations which are now devoid of the plants for gathering or lacking a bountiful crop of pine nuts. "Everybody had pine nuts, you know. It seemed like at that time when we were growing up that there was more pine nuts. I don't remember any years that there wasn't some pine nuts. Now it seems like some areas have them, sometimes they don't," said Glenn of the pine nut crops. Although the amount of pine nuts in a particular location varies from year to year, they noted an exceptionally low amount year after year in recent 106 
decades. Participants also noticed a difference in the taste and quality of pine nuts gathered now, but they did not know what had caused the difference, except to say that environmental damage to one part of the ecological system affects the whole system.

Participants provided the important distinction between pine nuts gathered by people and those gathered by an industrial process, which involves the use of large machines, is detrimental to plants, and is often carried out illegally. From participants' perspectives, illegal gathering contributes to the lower amounts of pine nuts present every year. Several participants agreed that they would rather not eat any pine nuts at all than to eat low quality pine nuts available now, either given to them by someone else who still gathers or bought at the roadside or in the store. Some participants believed pine nuts bought in the store and not gathered in the traditional way were not traditional food. "Pine nuts, that's become, you've gotta beat all the companies that go out and shake the trees and beat the non-Indians," said Kimberly. "They shake the trees. There are big tire tracks, and there aren't any pine nuts. Or they're all over the ground, and none in the trees." Glenn and others described a similar mechanical process non-Indian people use for gathering pine nuts. "They say they have these machines, I've never seen them, that just shake the tree," he said. "Of course if you shake it that hard, you've gonna get every pine nut on that tree off. The commercial pickers sell their product. I don't know if they sell in this area, but I know Manor Market has pine nuts for sale. But I don't know who they buy them from. It could be someone on the reservation." Competition with commercial pickers as well as non-Native people makes it difficult for Native people to obtain a good harvest of pine nuts, when they are able to go out and pick pine nuts. 


\section{Conclusions}

While Native participants have some access to gathering places, the access is limited. Due to participants jobs' and integration into the economy, it is difficult for them to find time to get to the land to gather. In addition, many participants did not learn about heritage foods from their parents and may not have adequate heritage foods knowledge or access to elders who could teach them about heritage foods. Finally, once they go out to gather or hunt, participants may find the landscape degraded or the resources already harvested. As a result, many Native people have shifted to urban, sedentary lifestyles and eat processed foods. In light of political economy with the added perspective of Critical Medical Anthropology, perhaps society, rather than spending millions of dollars on genetic studies and focusing on individual nutrition education, would best benefit Native American health through changing overarching policy in order to foster an environment that encourages the consumption of heritage foods. This would include creating and reinforcing policy that that facilitates access to healthy lands and foods for Native people.

The latter part of the last century brought changes in social conditions, often what appeared to be improvements in social conditions, among Native individuals, families, and communities, such as access to abundant food, media, education, greater economic opportunities, and integration into the larger society. However, some of those changes contributed to devastating health effects in the form of diabetes and other diet-related health problems due to increased acculturation and access to processed and fast foods. What then do equal social conditions, or conditions that promote health equity and the highest attainable standard of health, for Native people look like today? If access to healthy heritage foods and a meaningful return to a traditional diet gain Native people 
better health, policies and social conditions necessary to promote heritage foods as well as continued economic and education development would promote health equity among Native communities. 


\section{Chapter 6: Diet-Related Health and Diabetes}

\section{Introduction: Human Rights and Health Equity}

It is a bright, sunny morning on the reservation. Sunlight pours through the open windows as Vernon and I sit together in his front room, Vernon in a wheelchair and I on the worn couch. We can hear his grandkids playing in one of the back rooms, and they peek at us with curiosity from time to time. With a serene expression, perhaps even a bit of a resigned look, Vernon agrees to do an interview with me. Vernon is 67 and has lost the lower half of his legs due to his diabetic condition.

Vernon is cautious to share information, perhaps due to past experiences with interviewers and perhaps due to the personal nature of what he is sharing. A lot has changed on the reservation in his lifetime. He recalls gathering fruit from orchards and vegetables from gardens that no longer exist. He remembers eating wild foods and attending traditional gatherings where Native people shared traditional foods with one another. He tells me about struggles that people he knew had with alcohol and his own drinking problem during his younger years. Now, he says, most people do not eat their traditional foods like they used to, or as often as they did in the past. But it isn't as simple as making a conscious choice about foods and drink. According to Vernon and other participants, the entire pattern of Native people's lives changed in the latter half of the last century, and many structural forces that operate outside of individuals' control affected their consumption choices.

Not only changes in the reservation environment, but also changes in the US food supply have affected Native people's food choices. In general, obesity and type 2 
diabetes are closely linked (CDC 2012). However, I observed during my research that many participants I interviewed who said that they had type 2 diabetes did not appear obese. Vernon, for example, was not obese. More than half of the participants I interviewed had type 2 diabetes, a fact not necessarily reflected by participants' body size or body type. Instead, I found that the quality of foods participants ate was often more important than the quantity of foods in terms of diet's contribution to a diagnosis of diabetes.

Diabetes is a group of diseases (including type 1, type 2, and gestational diabetes) characterized by high blood glucose levels, which is a result of the body's inability to produce or use insulin (ADA 2012). Glucose is obtained from food, and insulin is necessary for the body to use glucose for energy (ADA 2012). If glucose builds up in the blood, the cells are starved for energy, and over time the eyes, nerves, kidney, and heart can be damaged (ADA 2012). Risks for the disease include having impaired glucose tolerance, having a family history of the disease, being overweight, being over 45 , and having high blood pressure (ADA 2012). Type 1 diabetes, also known as juvenile diabetes, is usually diagnosed in children and young adults. People diagnosed with Type 1 diabetes must take insulin to control the effects of the disease because their bodies do not produce insulin. Type 2 diabetes, also called adult-onset diabetes, usually appears later in life. People with type 2 diabetes can control the effects of the disease through proper diet and exercise. Type 2 diabetes patients are instructed in ways to monitor their blood sugar levels and to maintain healthy levels through diet and exercise.

Vaughn M. Bryant points to two important events that have contributed to the prevalence of type 2 diabetes in the US and the prevalence of overweight and obesity 111 
(2003: 89). Current Center for Disease Control (CDC) statistics reflect that more than one-third of American adults are overweight and more than one-third are obese (CDC 2012). Even more sobering, almost $17 \%$ of American children and adolescents are obese, three times the rate of a generation ago (CDC 2012). Obesity-related conditions, including heart disease and diabetes, are among the leading causes of death in the US (CDC 2012). The CDC often highlights the relationship between socioeconomic status and obesity, suggesting that poorer people eat less healthy diets, but between 2007 and 2008 the prevalence of obesity increased among adults at all income and education levels (CDC 2012). The first important event contributing to this trend according to Bryant was the series of farm support bills that led to the heavily subsidized agricultural industry and thus abundant and inexpensive food and food products that are harmful to people's health, like high-fructose corn syrup and soy bean oil. The second was the growth (and appeal) of the fast food industry. Both events contributed to the creation of a toxic food environment and the prevalence of obesity and diabetes among all people in the US and among Native Americans in particular.

First, an overabundance of food in the US, in combination with the development of long-distance shipping of foods, aggressive advertising by the food industry, and increased demand for nonlocal foods, led to major shifts in the availability of food to even the poorest Americans and the makeup of most meals in the typical American household in the latter part of the last century. Academic nutritionist Marion Nestle, in her book Food Politics: How the Food Industry Influences Nutrition and Health, reports that the most important shift in food habits in the $19^{\text {th }}$ century was from not getting enough of some nutrients, which led to nutrition deficiencies and diseases, to eating too 
much food, from all major food groups (2002:9), which led to a different set of problems. In part, the abundance of inexpensive food was the result of the rise of industrial farms and distribution centers, subsidies for gasoline and interstate highways, and advances in food processing and long-term storage of foods, all of which pushed the decline of smallscale and local farming (Halweil 2004:7; Hendrickson and Heffernan 2002; Nabhan, Walker, and Moreno 2010). As recently as the 1950s, almost all of the fruits and vegetables people consumed in most American cities and towns were grown on nearby farms (Halweil 2004:7). But in 2000, according to a study in Chicago, the average kilogram of produce in the US traveled more than 2,400 kilometers from farm to plate, nearly 25 percent farther than in 1980 (Halweil 2004:7). The value of trade in international food has tripled since 1961 (Halweil 2004:8). "Far-flung food" has become the norm (Halweil 2004; Hendrickson and Heffernan 2002).

Nowhere is far-flung food more evident than in the remote desert regions of the American Southwest and the Great Basin, including the Owens Valley, where a great amount of fresh foods are acquired from distant locations. The City of Bishop in Owens Valley, for example, has only one chain supermarket, Vons, a division of Safeway, Inc. According to local "factoids," apart from Catalina Island stores and the Mammoth Lakes store, located 30 miles north of Bishop, the Bishop store is rated the most expensive out of the hundreds of Vons grocery stores in California; shipping costs cause the markup (Kessler 2011). In my own experience of living in Owens Valley, I took note that the prices of grocery items were similar in Bishop stores and in the Yosemite Store in Yosemite National Park - a shop with a captive audience and a considerable markup. The closest major cities to Bishop where one might find reasonably priced groceries are 
Carson City and Reno, Nevada, 171 and 203 miles north of Bishop respectively, roughly a $3 \frac{1}{2} 2$ to 4 -hour drive. Las Vegas, Nevada, is 270 miles away, roughly a 5-hour drive. Some Owens Valley residents drive south to shop on a regular basis. For example, Ridgecrest, California, a $2 \frac{1}{2} 2$ hour drive from Bishop, has a Wal-Mart. "I hear a lot of people saying it's too expensive to buy fruits and vegetables at the store. Everything is expensive here," Kimberly, a Bishop Paiute Tribe participant, said. "We'll go north or south and buy our meats at Costco and stuff like that." Although Bishop has several small alternative grocery stores that sell local produce, such as Manor Market, participants residing in the relative food desert of Owens Valley described traveling to one of the distant cities, perhaps once a month, to shop in bulk at cheaper prices.

This large-scale change in the food supply along with its infrastructure has deeply affected people's food choices in the US due to the artificial cheapness of processed, "globe-trotting" foods (Halweil 2004:6; also see Hendrickson and Heffernan 2002). Halweil asserts that there are a number of hidden costs in the long-distance food system, such as loss of farmland to subdivisions and asphalt, contamination of groundwater, and hazards to human health (2004:14).

Second, in addition to the availability of processed food, both the Cedar City, Utah, and the Bishop, California, areas provide ample evidence of the availability of fast food and its proximity to Native populations. Both cities offer a host of amenities and especially fast food restaurants that cater to travelers passing through the cities on Interstate 15 and US Route 395, respectively. For example, the primary businesses in Bishop are located along a $1 \frac{1}{2}$ mile stretch of US-395, and along that section of highway in 2012 one can find the following major chains: Jack in the Box, McDonald's, Carl's Jr., 
Taco Bell, KFC, Denny's, and Little Caesars. Glenna Jean, the participant with a lovely backyard garden, compared her childhood food habits to current practices: "We didn't eat out. We didn't have those fast foods like they do now. It's so easy. I think that's really bad," she said. Participants from both areas talked with me about the ease of fast food and the frequency with which Native people now eat at those restaurants, taking them away from heritage foods and home-cooked meals. Less access to local food and greater access to fast food and processed food, along with large-scale economic dynamics, create not only a food desert, but a toxic food environment for local people, including Native people. The toxic food environment constrains people's food choices and is manifested in food-related health issues like diabetes and obesity. Changes in diet were unique to the situation of Native peoples in that they were much more rapid than among most people in the US.

Uniting theory from public health and human rights, health equity is a concept that underlies a commitment to reduce inequalities in health through distributive justice, or through modifying determinants of health beyond medical care and personal behavior (Braveman 2010). Human rights principles of non-discrimination and equality are key parts of the conceptual foundation for health equity. These principles help identify groups among whom inequalities in health status and social conditions exist, whether through intentional or unintentional discrimination (Braveman 2010). Health equity has a strong connection to human rights and the ethical principle that all people should possess the right to a standard of living adequate for health, which includes access to not only enough food but quality food from quality sources (Braveman 2010). In this chapter, I utilize the 
concept of health equity to analyze the efficacy of both individual and collective efforts to reduce inequalities and improve Native American access to quality foods.

\section{Food Policy and Health}

Interrelated social and political factors influence food choices among all Americans, and particularly Native Americans. Scholars from multiple disciplines offer insights into the politics of food and critique the role of the food industry in influencing the modern food system and the health of the public. Marion Nestle discusses the actions of food companies in our political system, from advertising to youth to lobbying Congress and to swaying nutrition experts $(2002: 2,95,175)$.

Nestle likens large food companies to big tobacco, which tried to influence people to smoke a lot even though tobacco companies knew tar caused cancer (Nestle 2002:175). Americans may believe that choices in diet are less harmful than the effects of cigarette smoking, but each contributes to about one-fifth of annual deaths related to chronic diseases (Nestle 2002:3). The food industry's tactics may be legal, but Nestle questions whether their actions to encourage people to "eat more", in direct opposition to nutrition advice to "eat less," are ethical (2002:3). Nestle asserts that the goal of the food industry, like the tobacco industry, is not to promote the health or well-being of the public but, quite simply, to sell products (2002:2).

In the marketing environment of food choice, food companies are willing to spend billions of dollars to make nutrition advice appear confusing and eating healthfully appear impossible (Nestle 2002:29). From her secure academic position, Nestle takes advantage of the opportunity to speak out against the questionable ethics of the food 
industry and nutritionists who support it through ambiguous messages about food and nutrition (2002:111). Despite the economic harm they may cause to food producers, she offers solutions through modifications to public policies which "change the social environment of food choice" (Nestle 2002:360). She suggests requiring food advertisements and fast food restaurants to disclose calories, taxing junk food, or banning commercials and the sale of soft drinks in schools (Nestle 2002:367). In agreement with the perspective of political economy and Critical Medical Anthropology, Nestle encourages taking the emphasis off personal responsibility and individual education and instead focusing on the larger political forces and societal structures in place that could, if changed, "make it easier for everyone" to take personal responsibility for their diet and health (2002:360).

Larger political-economic forces and the wider system in great part determine that people will eat poorly and are just as important as, if not more important than, individual choices concerning eating and health. Native Americans I interviewed believed strongly in personal responsibility and personal action to protect and maintain health and many had received invaluable dietary guidance from various sources. Nevertheless, these influences on food choices do not fully depict the story of diet and diet-related health among Indian people. I turn to Gary Nabhan (an ethnoecologist) and Lauri Monti (a nurse practitioner and medical anthropologist), who worked among the Seri Indians of Mexico, to understand both genetic influences on and environmental determinants of diet-related health and diabetes (2004:164).

Modern genetic medicine has shown the complicated nature of genetic susceptibilities and that there is no single gene that confers susceptibility to type 2 
diabetes (Nabhan 2004:177-178). Instead, Nabhan and other medical anthropologists focus on other forces that impinge on diet-related health. Nabhan notes four political and social circumstances that have contributed to diet-related ill health among Native Americans. Specifically, Nabhan addresses factors behind the rapid increase in the incidence of type 2 diabetes among all populations and disproportionately among indigenous peoples. First, secondary plant compounds, particularly those found in desert plants, protect people from impaired glucose tolerance and are lost when a population shifts to an agricultural diet (Nabhan 2004:179). Second, restrictive livestock management practices and breeding select out the remaining beneficial compounds from people's diets (Nabhan 2004:179). Third, milling processes that were instigated during the Industrial Revolution rid most of the quality fiber from grains (Nabhan 2004:180). Fourth, highly industrialized foods produced in the last fifty years have additives such as trans-fatty acids and sugary syrups that make fast foods "fast-release" foods in contrast with the slow-release foods of traditional diets (Nabhan 2004:180). European societies have experienced these changes over thousands of years, and scientists believe their genetic makeup may have had time to shift. In contrast, some Native American populations have had less than fifty years to accommodate these changes in their communities and bodies. All of these factors contribute to Native American food-related health status.

Gary Nabhan discusses at length particular genes scientists have isolated that are known to influence an individual's susceptibility to the effects of alcohol and to diabetes and other nutrition-related diseases. However, his breakthrough in studying the genealogical histories of indigenous peoples and the prevalence of diabetes among their 
communities was finding that, more than the percentage of their ancestry, their distance from their traditional diet and the degree of their acculturation and acceptance of a modern diet was indicative of a high probability of diabetes (Nabhan 2004:167).

This finding supports the structural explanation for certain kinds of diet-related health issues like type 2 diabetes. Nabhan found that groups of Native Seri people in Mexico who lived traditional lifestyles in remote areas by the sea had a lower incidence of diabetes, despite weighing more than their counterparts in villages who had easy access to nearby towns, to fast food restaurants and grocery stores with Pan Bimbo bread and Coke (Nabhan 2004:167). Nabhan found that the regular consumption of native foods among the traditional people tended to hold diabetes more in check, which could be true of all traditional diets to some extent (Nabhan 2004:167). Greater weight does not necessarily mean greater incidence of diabetes. Rather than the sheer quantity of food, the quality of foods in modern diets many of the Seri now eat on a regular basis, especially store-bought fats, alcohol, and simple sugars, triggers diabetes (Nabhan 2004:167). The point is that Native individuals, regardless of weight, receive some measure of protection from diabetes if they continue to consume traditional foods on a regular basis rather than rapidly change to a diet of processed foods.

With scientist and nutrition analyst Jennie Brand-Miller, Nabhan found that native desert foods, traditionally consumed by Native Americans and Australian aborigines, were so slowly digested and absorbed (due to the foods' high content of soluble fiber, tannins, and complex carbohydrates) that blood-sugar levels remained in sync with insulin production and provided protection against diabetes among indigenous peoples (2004:169). On the other hand, fast foods spiked blood sugar and had glycemic values 
two to four times higher than native desert foods (Nabhan 2004:169). Regrettably, the US National Institutes of Health (NIH), in collaboration with Pima communities in the Sonoran Desert on a diabetes project spanning four decades, has ignored this key distinction between quantitative and qualitative differences in Native American diets and has instead focused on genetic predisposition (Nabhan 2004:167).

As Nabhan's own collaboration with Seri, Papago, and Pima indigenous people with diabetes has shown, insulin sensitivity and glucose tolerance can be improved among Native populations through a return to a diverse diet of traditional foods and healthy foods rich in soluble fiber and secondary plant compounds (Nabhan 2004:182). After accomplishing a 220-mile pilgrimage, along with Nabhan, fueled only by traditional food sources, Native American participants reported a renewal of their cultural pride and spiritual identity as well as motivation to improve their own health (Nabhan 2004:184). Returning to traditional diets provided Indian people not only motivation, but also a holistic way to keep their bodies, communities, and the environment healthy, a way that blended modern and traditional means and undergirded the beliefs and pride of the community (Nabhan 2004:184-185). In my research, I followed Nabhan's example of including participants in a collective effort to encourage both healthy eating and a sense of identity connected with food.

Although participants did not address the structural side of the question of dietrelated health, they understood in many ways the consequences of the toxic food environment. Participants' emphasis on individual responsibility for diet and health stems in part from changing social conditions, as Native people have increasingly integrated into American society and this perspective reflects an American ethic of free choice. At 
the same time, the Native diabetes prevention program coordinator and Native diabetes patients cited examples of collective efforts, like health education to the public, which, along with individual motivation and actions, helped improve Native people's dietrelated health. In some ways, collective efforts at the tribal level like the ones Nabhan describes provide an answer to diet-related health problems that are caused by structural forces. In particular, participants realized the importance of heritage foods not only to identity, but to Native health, and believed collective efforts would be more effective if heritage foods were incorporated into Native health education programs, classes, and activities. Collective efforts like Native health education programs, especially those that are coordinated by Native professionals and supported by the community at large, work against structural forces and work toward health equity for Native people through encouraging a diet optimal for health.

Although society cannot alter genetic realities for individuals, it can work to provide health equity and improve social conditions and access to social, political, and economic resources. The concept of health equity is particularly relevant in areas which could be described as food deserts, such as Owens Valley, where economics, location, transportation, and shipping costs restrict food choices among the local population.

\section{Rapid Changes in Social Conditions}

A very moving finding during my research was the realization that some participants I interviewed were outliving both their parents and their children due to rapid changes in social conditions within their lifetimes. For example, one female participant raised seven children and had lost six of them. At the same time, she and other 
participants had experienced the death of their parents much earlier in their lives, despite the fact that many of them reported that their grandparents lived to be 100 or close to 100 years of age.

In terms of changing social conditions, this situation recalls what Melissa Fay Greene writes of the experience of the AIDS epidemic in Ethiopia in her book There Is No Me Without You (2007). In Ethiopia in 2007, people were outliving their parents or grandparents who had died from diseases like typhoid as well as their children who were dying from HIV/AIDS. Scientists have found that development and improved conditions, in this case new technology and the dramatic increase in the accessibility of vaccinations in Africa in the 1950s, actually fostered the environment that allowed the mutation of viruses and the creation of HIV. Medical improvements (use of the syringe) led to the immunization of the majority against common preventable diseases like tuberculosis, but vaccinations at that time in Africa were not properly managed; more often than not, needles were not sterilized. Simultaneously, due to social conditions, Africans were much less likely to be aware of the existence of HIV and its prevention and to have adequate healthcare and treatment. Increased access to life-saving vaccinations and abundant foods, often seen as improvements in social conditions, in this case worked against younger generations.

Native American participants experienced rapid changes in social conditions and health related to two ingestible substances, alcohol and processed food. Participants reported that some of their children had diabetes or were on dialysis. More than half of the participants I interviewed volunteered the information that they had type 2 diabetes. Many of those who did not say they had diabetes reported that diabetes was present in 
their families. Some participants also talked about the effects of alcoholism on their families. As I have already discussed economic and political factors at length, I will focus in this section on the social or modifiable characteristics of people's environment and their impact on health.

\section{Diabetes}

Participants revealed that their food choices changed over their lifetimes as their access to abundant, processed food increased and their access to heritage foods and gathering places became limited. People commented on the public health statistics that reveal rampant diabetes, high blood pressure, and other health problems related to diet among Native American populations. "Everyone is getting diabetes nowadays," said one male participant, as we sat outside his home on the Shivwitz Reservation watching a rainstorm build over the red rock cliffs in the distance. "Not just Indians." Participants asserted that these effects are seen throughout the US population, especially among poor populations in this country. According to Native elders, it is only obvious among Native Americans because the changes occurred so rapidly. "Everyone here has got a family member with diabetes," Kimberly, a nurse and nutrition counselor, explained, as she described how as an occupation she educates Native individuals on diabetes and its management. "It's all diet and exercise." Participants pointed to exercising less and gaining weight, in addition to eating less healthy foods, as changes Native people experienced in a relatively short time and contributed to the prevalence of diabetes. As they lamented the changes, Native people reported that they wanted to learn ways to live a healthier lifestyle, including eating healthier foods and getting enough exercise. 
A greater number of younger participants (less than 60 years old) than older participants (more than 60 years old) mentioned that they had been diagnosed with type 2 diabetes. Older participants discussed experiencing the illnesses of their children due to preventable chronic diseases, such as diabetes, while younger participants described their siblings', cousins', or their own experiences of diabetes. "She [my mom] doesn't have diabetes," Kimberly, a younger participant, said. “They didn't have diabetes...now I see our generation, my cousins, having diabetes." These problems stemmed from changes in Native people's diets due to changing social conditions and the incorporation of unhealthy foods from the dominant culture.

For many participants who experienced changing social conditions within their lifetimes, American foods signified better lifestyles and diets. Kimberly discussed the ways Native people viewed processed foods in contrast with traditional foods when she was growing up. "I remember my mom saying we didn't have to hunt. We didn't have to eat deer meat," Kimberly remarked. "My mom would eat traditional foods, I guess. She would eat headcheese, menudo [a soup made with cow stomach], things I wouldn't eat." Many participants described changes during their lifetimes in a similar way: Improved social conditions, which included shopping at supermarkets and buying processed foods, were seen as better than past conditions, even if diets were healthier in the past when participants were more likely to eaten fresh, local produce from their own gardens or with wild foods that their families gathered.

Embracing the larger economic system and gaining greater economic stability and mobility were seen as positive by participants and participants' parents or grandparents. As participants experienced greater education and economic opportunity, the structure of 
daily routines changed to accommodate school schedules and jobs. In addition, participants had greater access to easier, more desirable purchased foods for their children and processed foods that fit into busier lifestyles. For many participants and their families, trends toward more sedentary lifestyles and less healthy diets, due to integration into the economic system and increased purchasing of lower quality foods as opposed to gathering and preparing traditional foods, created negative health outcomes for younger generations.

Alcohol

Most of the older participants experienced the loss of their parents years ago, sometimes from alcohol-related illnesses or alcohol-related accidents. Kelley, a 44 year old woman who was half-Paiute and half-Navajo, was a mother of 3 children, one of whom was still at home. She shared with me in a very open, congenial way during the interview, and her pride for her heritage was obvious in both her outlook and her home. "I was raised by my father's mother, me and my four sisters and my one cousin. My grandmother did a lot of raising children," she said. "In Indian country, I see that there's a lot of broken homes. That [alcohol] is what separated my mother and father. My father tried to do his best, but my mother was an alcoholic. And from what I understand, she was an alcoholic from 12 years old, and she still made it through school in Brigham City, where all the Indian kids went." Participants like Kelley made it clear that they stayed away from alcohol, and many had embraced the church's ban on alcohol.

The literature on alcohol among Native American populations abounds. Spicer encourages an anthropology of alcohol that takes into consideration the profound 
ambivalence among individuals toward alcohol use, as Native Americans comprehend the destructive effects of alcohol abuse, but also value it as part of important social relationships (Spicer 1997:307). While it was not a major focus of my work, I found that it came up frequently in conversations with participants.

Lenora also described the influence of alcohol on her parents' lives. "My sister is 11 years younger than me. I took care of her a lot because my parents were alcoholics," she said. "She was born with a cleft palate. She couldn't even suck on a regular sized nipple. Her mouth was too tiny. So we fed her with a syringe. My mother showed me how to feed her like that, so I more or less took care of her, when I got home from school." Alcoholism and changing family structures often kept participants from learning traditional foods knowledge from their parents or grandparents as they were sent as children to non-Native foster families or were forced to care for other members of the family at a young age. Poor social conditions, often exacerbated by alcoholism or other social problems, affected participants' lives. Broken families have fewer economic opportunities, less money, and poorer health.

\section{Let's Make Woopadabonah: Individual and Collective Efforts to Make Healthy Food}

\section{Choices}

Participants offered examples of individual efforts to improve diet-related health. "I watch my diet. I eat everything. I just don't eat that much. I try to keep my weight down. If I get full, I'm full," Margie said. Renee emphasized individual responsibility for health. "But we're adults, and you have to learn to choose what to eat," she said. Although changes in social conditions produced some negative effects, changes also 
included increased access to nutrition education and media, which helped participants learn about healthy foods. Some participants said they learned a lot about nutrition, food enrichment, and food labeling on their own and through tribal diabetes prevention or nutrition programs due to their concern over the rampant diabetes problem in their tribe and community. Although eating well is not easy in the current environment of food choice, participants believed individual efforts to eat healthier foods and exercise were still important.

Participants identified the importance of exercise, in combination with a healthy diet, in maintaining overall health and preventing diet-related health problems. Margie, an energetic woman of 73 who watches her grandchildren on a regular basis, emphasized staying active to maintain health. "I do a lot of walking, chase after my grandkids. I keep busy that way. I like to be involved, like to do a lot of things. I don't just sit and watch TV." Margie also believed being active in the community is important to health. She goes to craft classes that tribal members offer and continues to learn from other elders. Kimberly described the changes in lifestyle that led Native people in Owens Valley to gain weight and led to more diagnoses of diabetes. "I was trying to put a flyer together where we had all our parents when they were active," she said. "If you look at photos of the 1930s on up you start to see where we're putting on weight, but before that they were thin because they always walked and hunted. They worked. They had to get their food. Now we don't have to walk, just go to McDonald's in your car and come home with food." The sudden changes in the $20^{\text {th }}$ century that led to less exercise among all people, including PITU and Bishop Paiute Tribe participants, contributed to the prevalence of obesity and diabetes among Native people. 
In addition to discussing individual initiatives, participants gave examples of ways the tribe influenced their diet-related knowledge and ways tribal members worked together to improve the health of their community, such as preparing food for gatherings in healthy ways. Randee, a participant who now lives in Cedar City, talked about taking care of her husband's family in Nebraska for part of her life and about what she learned from her husband's tribe, the Winnebago Tribe. "I was there to help his grandfather who had diabetes, and his mom had it. Back here [Cedar City] we didn't have health services, so we never knew all that. We never had those services [before restoration of the tribe]," Randee said. "I never knew about diabetes when I was here. It was when I went back there that I learned. They ate healthy - fruits, vegetables." One participant described a program one of the tribes offered that helped her: "Actually, the tribe had a 'lose weight' program, a supplement program. I'm big now, but back then I thought I was bigger. I was able to lose 50 pounds in 11 weeks. I never did catch on to the food that they had. There were vitamins, stuff like that. I was drinking Diet Coke for 20 years, and when I went back to regular Coke this last year, that's where I gained my weight. When I was on Diet Coke, I never gained and never lost, just stayed the same.” Renee discussed human health and how tribal members encouraged healthier preparations of traditional foods at gatherings. "And the human health, it means everything to us," Renee said. "With fry bread, I try to make tortilla instead of frying it too much. And at the gatherings we have, we pass it on to everyone: 'Let's make woopadabonah, [also known as] tortillas, instead of fry bread because we have a lot of elders [meaning people 50 years old and older] who have diabetes. Give them a range of choice." Tribal efforts to improve health proved helpful to participants. Participants expressed a desire to eat healthier and to learn 
healthier ways to cook foods they cherish. They also wanted to learn completely new and healthy recipes in order to improve the health of their families, tribe, and community.

\section{Traditional Foods Cookbook}

The traditional foods cookbook was an applied part of my project that complemented my research and was a group effort. Several Native leaders I consulted during my research and traditional foods cookbook project were pleased with the idea of sharing traditional foods recipes to promote a healthy, traditional diet. I shared my plan to create a traditional foods cookbook with the Paiute Indian Tribe of Utah tribal council, and they endorsed my project. Through posing questions about the project to tribal members I interviewed and listening to their feedback, however, I found that they wanted to take the idea of a cookbook a step further. They encouraged the idea of having participants share demonstrations of recipes, but rather than sharing the traditional recipe only, participants should share a "healthy version" alongside the traditional one, such as steaming potatoes instead of frying them.

As I interviewed participants, I asked them if they wanted to contribute a favorite traditional foods recipe to the cookbook. A majority of participants were enthusiastic about the traditional foods cookbook and were helpful in contributing recipes that reflected both old and new ways of cooking healthfully and traditionally. Fry bread, for example, was not included in the cookbook. Instead, healthier versions of bread, baked instead of fried, such as Indian bread, oven bread, or tortilla (different from Mexican version), were included in the cookbook. 
Under the supervision of the PITU tribal council, I created the format for the cookbook and compiled traditional foods recipes gathered during research into a simple spiral-bound book with 20 pages. I consulted the tribal council concerning the style of the cookbook cover and key recipes to include. For example, the tribal council instructed me to include recipes for fish, rock chuck, Indian bread, deer, and pine nut gravy. The front cover was printed in color and featured the PITU logo. Images of prairie dogs and Indian corn, at the request of the tribal council, as well as photographs from the traditional foods dinner added visuals alongside the recipes within the cookbook. I ordered over 100 copies of the cookbook printed for participants and their families and for tribal council members.

Participants talked about traditional foods that are unhealthy and ways to prepare them in healthier ways. "I was in a family where they prepared healthy food. I should have just learned from that, but going back to my reservation, you go back to the fried potatoes," Eliza said. "I imagine some families prepare different from others, where it's not so greasy, but I think some of the traditional foods have gotten better. I hear some ladies say, 'I drain the grease out of the hamburger before I cook the potatoes.' I think that's good." Julia, who remembered catching frogs to eat as a child, also talked about cooking potatoes in a healthier way. She chose to add a recipe for steamed potatoes to the cookbook. For some participants, hamburger, when cooked with potatoes or other traditional foods, is considered traditional. Even if foods were not considered heritage foods, but had become a regular part of the diet, participants wanted to incorporate healthy ways of cooking them. Foods connected with their identity and cooked in healthy 
ways as well as incorporated foods cooked in healthy ways were important to participants in improving diet for health.

The larger influences of environmental policy, the politics of food, and the current social environment of food choices play key roles in the diets and health of Americans today, including Native Americans. In addition, individual experiences of food choices and health are significant. Despite larger social and political forces, Native people seek to protect and maintain their health and their closely related identity, which supports their health in a holistic way, through individual and collective means. Modifications to environmental policy and food policy as well as attempts to provide and encourage access to healthy, heritage foods are things for which our society could take responsibility for the benefit and health of the public, and in particular, the health of Native Americans.

\section{Diabetes Prevention/Health Education}

Kimberly, a nurse, nutrition and diabetes counselor, and coordinator of a diabetes prevention program for Native people, discussed her efforts to help people monitor and control diabetes. "This is a diet everyone should be on, not just your spouse or child [with diabetes]," she said. "Everyone should be on this type of meal plan." While she focused on the role of the individual in maintaining their diet-related health, she also provided evidence of individual success that occurs in partnership with collective efforts to improve health, such as program support and education.

Kimberly described the diabetes prevention program the Toiyabe Indian Health Project in Bishop, California, offers. "When they come in and they want help with either weight loss or if I have a newly acquired diabetes patient, I try to get them right away to 
get them education. Education first. I help them make goals; we talk over goals. I'll tell them how diabetes works, anatomy and physiology kind of thing. How and when to test their blood sugars. Why they're testing. It's not just numbers - it's really information about your body." Kimberly explained the difference education makes, through both individual counseling and group classes as part of the program. "They don't know why they're putting up that number [when monitoring their blood sugar]," she said. "But somebody told them. So I try to get people to understand why those numbers are important to them. So if I tell a person if you go and take your blood sugar before you exercise, come back and take it again. You'll see how it's dropped. Once they see that on themselves, that it's tangible, their blood, their finger, then it makes a difference." Individual counseling helps patients understand the disease and motivates patients to change dietary habits for the sake of health.

The program offers patients various classes on diabetes and diet, even a class in which students are invited to pick produce at a local orchard, and encourages patients to attend free exercise classes like swimming and aerobics, which are offered through different Health Project programs. "Our last class was very successful," Kimberly said. "They want a support group, and maybe somebody has got a hint that will help you lower your blood sugar." Group classes offer patients collective support and enhance education. In addition, alternatives to delocalized food are integrated into education and are accessible to tribal members and the community at large, such as Saturday farmer's markets and home gardens. "A lot of people have gardens. They used to have gardens. They're trying to bring that back, with canning," she said. "They have a canning class that starts tomorrow. I want to have a canning class for my diabetic patients. I remember 
my grandmother having a root cellar because they had peaches, apples, they canned all their vegetables and fruits." In addition to farmer's markets, gardens, and changes in commodities programs, such as offering fruits and vegetables, Kimberly discussed the advantages to encouraging a return to some of the traditional foods. "I would like to bring them back, lean cuts of meat, whole grains, fruits, vegetables," she said. "Indian tacos is not a traditional food. But there is a recipe with whole wheat." Alternatives to processed, delocalized food, especially in the form of heritage foods, and alternatives to unhealthy heritage foods like fry bread are keys to improving the diet-related health of Native people through collective means.

As access to health information and education has increased to the general public, stigma connected with diabetes and social attitudes related to diabetes and nutrition have changed for the better. "When I first got this job, very few people would talk about diabetes. Nobody wanted to take a class because they didn't want anybody to know they had diabetes," she said. "Today it's not as bad. People that used to say that are now coming to the classes." As attitudes have changed along with public efforts, program participation and health outcomes have improved. Programs like the one Kimberly manages are good examples of collective ways to improve individual health in that they represent publicly funded efforts to address health issues, are a collective means of working against structural forces like the toxic food environment, and are integrated into a particular community.

As Kimberly explained the program, examples of program support as well as of patient self-efficacy were evident. "You can have a candy every now and then, but you have to remember what it does to your body," she said. "And try to get activity in. It's 
hard to change. It's not an easy thing. They'll say, 'I don't want to go to the doctor because I know they're gonna tell me to lose weight.' I'll have someone come in, and all they've heard is they have diabetes. So I try to get them here and explain what it is. It's not their fault. We just have more risks, and we can change it." Often individuals are so overwhelmed by their diagnosis that they feel helpless to change their food habits. "If someone wants to have case management, they can set it up with me," she said. "It's up to them. Some people don't want that much, they're not ready. Some are in denial." Kimberly feels the role of the program is to motivate patients, and patients must be motivated for change to occur. Individual responsibility is thus emphasized, as program advocates and patients alike believe long-lasting change to a healthy diet and exercise requires the initiative of the patient. The collaboration of collective efforts and individual initiative working against structural forces equals success.

Participants from both tribes expressed some satisfaction in what they had already learned about nutrition from multiple sources. Before nutrition education programs, they said, they didn't read food labels. Eliza, a younger PITU participant who has high blood sugar, but is trying to prevent the onset of type 2 diabetes, described taking a non-tribal nutrition class and the difference it made in her choices. "I would love a nutrition class where you taste," she said. "For myself, I took a nutrition class. Here in Cedar. It was like a year ago. I always want to know about the foods, and it just kinda taught me about what like carbs, all that. I never knew that before. I was glad I took it. I never read the box, now I do. I used to get whatever, what tastes good. The reason I took this class was my blood sugar was going high.” Participants, including Kimberly, believed nutrition education makes a difference in people's food choices and thus their diet-related health, 
empowering them to maintain a healthy diet. In this way, collective efforts, from program support to exercise classes and to alternative food networks, help individuals make choices that are counter to structural forces.

\section{American Ethic of Individual Responsibility}

Despite evidence of collective efforts to improve health such as the diabetes prevention program and public nutrition education programs, participants, even the coordinator of the diabetes prevention program, possessed the common perspective that it is ultimately up to the individual to "take care of her/his health," that health is a responsibility one has for oneself. While several participants believed that nutrition education programs offered to the tribe would have been more effective if leaders of the nutrition classes had taken into account the importance of Native foods and had used Native foods in demonstrations and examples, participants believed that there is ample nutrition and health information available today through multiple sources, including websites, to help people be healthy if they choose to access that information. Due to changing social conditions, fragmentation, variation among individuals and families, and intensely personal aspects of food and eating, participants' responses in general reflected the American ethic of free choice and individual responsibility.

If structural forces like the toxic food environment are beyond individuals' control, why does the emphasis remain on individual responsibility for health consequences? And, how feasible is it to expect individuals to succeed in a toxic food environment that remains the same? Interestingly, participants did not often address large-scale issues around food, except to comment on the expense of particular healthy 
foods like fruits and vegetables and traditional foods like pine nuts and to discuss the negative effects of large-scale agriculture on the environment and traditional foods. Overwhelmingly, participants focused on self-efficacy related to diet and physical activity, even in programs that provided some social support, and individual responsibility for health knowledge and healthy eating.

\section{Conclusions}

The manner in which diet-related health problems are addressed in our society at times does not adequately encompass the variety of individual experiences of health or the social conditions of particular communities. It is not a problem that can be simplified with success for the ease of health interventions. Why does diabetes continue to affect Native people despite the implementation of countless health programs "targeting" at-risk populations over the last several decades? Although quantity is part of it, it is not only a matter of the quantity of food, but also the quality of food. It is not only a matter of personal choice, but also a matter of public policy.

My collaborators also believed it would be best to focus on the actual demonstrations rather than the printed cookbooks. Many of those I interviewed, particularly participants with diabetes, had been handed printed information and told to cook healthier, but had not been shown how to do it. Or, if they had been shown, it was with foods that were not traditional or familiar. In learning traditional food preparations and other skills, participants reported learning by doing and continuously learning from elders by watching and then applying knowledge, by participating. For example, Ellen taught traditional skills like cradle or basket making in tribal classes where participants 
watched and created as they learned. According to participants, many Native people were intimidated by the prospect of cooking with new foods or in unfamiliar ways. They thought hands-on training would be invaluable. As a result, I coordinated, along with my collaborators, a traditional foods dinner, an event where PITU participants shared traditional food dishes with one another and discussed traditional food preparations.

The traditional foods cookbook and dinner projects revealed that many tribal members were willing to adopt new ways of cooking while still striving to preserve knowledge of their heritage and foods they have long considered traditional and culturally significant. From what I gathered in interviews, Native people value both traditional foods and nutrition. They value the old and the new. They hope to "take care of their health," and economic status, food policy, social conditions, personal experiences of health, and other factors play into this endeavor. 


\section{Chapter 7: Conclusion}

\section{Main Arguments}

In this thesis, I have argued that many participants believed that there is a way to blend the old way of preparing heritage foods with the new. Cultural practices are closely tied to cultural identity, and food practices are of particular relevance to identity. Shifts in traditional food practices that incorporated new foods and nontraditional methods demonstrate changes in concepts of identity among participants. In addition, contrasts between PITU and Bishop Paiute Tribe members reflect the unique history of each tribe and differences in their relationships with the dominant culture. Regardless of definitions or current use, participants from both tribes identified several key heritage foods as important to their culture and related to their ethnic identity. While foodways and concepts of "tradition" have changed, participants of all ages clearly defined themselves as "Paiute" or "Native". Whether or not they still ate deer, for example, they still connected their self-understanding with symbols like deer meat that have persisted over time.

I found evidence of gender divisions in past heritage food practices in the ways I found during preliminary research. With one exception, all participants stated that women did the gathering and cooking and men did the hunting and sometimes the cleaning of the animals. However, some participants believed that the gender division they described was reflective of past roles and no longer necessarily applied. For PITU and Bishop Paiute Tribe female participants, obtaining and cooking foods the "American way" or the "white man way" became an important part of providing for children and taking care of the 
health and future of their families as women and "good mothers." Female participants performed their ethnic and gender identity through food.

I found that participants did not romanticize the past in their discussion of changing tastes, instead admitting that in the case of some heritage foods they never liked the taste or they would not like it now. A majority of all participants reported favoring "plain food," such as stew with little seasoning added or plain beans or potatoes, because such foods were associated with heritage in the way they were prepared and the way they tasted, as in familiar and wholesome. Changing tastes hold implications for identity among Native people, as participants came to view wild foods like rock chuck as a symbol of identity rather than a food regularly consumed to maintain identity. The fact that their ancestors ate rock chuck or that they themselves ate rock chuck when they were younger was enough to form identity around that food. In addition, as tastes changed, children of participants were less exposed to heritage foods firsthand and identified less with foods their parents may have recognized as part of their identity. It became important to participants to navigate multiple worlds with appreciation for all of them and to configure self-understanding in terms of gathering values and traits central to the different cultures with which they were raised as children, which they hoped to preserve in their own children.

While people from the dominant culture may romanticize Indian cultures and map static identities onto Native peoples, I found that participants did not romanticize their Native American identity and self-understanding in the sense that they simultaneously discussed the importance of foods symbolic of their ethnic identity and the everyday nature of choices about adopting new traditions, carrying on old traditions, and tossing 139 
out others. While participants acknowledged some "white food," whether pioneer food, LDS food, or general American food, as traditional and familiar, they were careful to separate key symbolic foods like deer, pine nuts, Indian bread, rock chuck or prairie dog (now protected), and fry bread from other traditional foods and to articulate the importance of these symbolic foods to their ethnic identity.

Through the traditional foods dinner, I found evidence of group cohesion and membership through the sharing of foods symbolic of group and ethnic identity. According to Jones, Giuliano, and Krell concerning foodways, once food is associated with social experience and social identity, food becomes symbolic (1983:41-42). Sharing food with others reinforces the experience of preparing or serving food as valuable and meaningful. The dinner allowed participants to define their community, to appreciate being a part of that community, and to assert their collective identity and groupness, or individual sense of belonging in the group.

In addition, I have argued in the thesis that the larger forces of economics and policy constrain Native people's access to heritage foods and have worked to diminish heritage foods knowledge and to erode diet-related health. Ironically, participants as children often had optimal health outcomes due to plentiful exercise and access to wild foods, despite low economic status. However, low economic status later worked against the diet-related health of participants as they entered the wage economy and were more likely to consume easier, quicker, more processed foods. The effects of colonization and increased urbanization on indigenous health have been far-reaching due to changes in social conditions, or modifiable characteristics of a person's environment, such as decreased access to heritage food-related resources and loss of time to gather or hunt 
heritage foods. I have argued that the structure of participants' lives has changed to accommodate the dominance of capitalism in American society. I found that participants, through no fault of their own, were in many ways disadvantaged in working within and against wider systems that directly affected their health.

Finally, I have argued in the thesis for a structural explanation for diet-related health issues like diabetes rather than for individual responsibility for health. I found that a majority of participants had diabetes in their families or had diabetes themselves. I also noted dramatic changes within their lifetimes that affected their diet-related health, namely rapid changes in the quality of foods from heritage foods hunted or gathered from the landscape to processed foods purchased in the supermarket. I found that among many participants changes in social conditions that disrupted family structure inhibited heritage foods knowledge transmission and thus incorporation of heritage foods in diets later in life. While participants varied in their individual situations, I found that rapid changes in lifestyle from gathering and eating heritage foods and getting plenty of exercise to entering the wage economy and becoming more sedentary to be the most indicative of a risk for the onset of diabetes among Native people. However, I noted numerous examples of individual and collective efforts to address diet-related issues and improve diet-related health, including nutrition education and diabetes prevention counseling and classes. Collective efforts, especially at the level of the tribe, provide an important bridge between individual initiative and structural forces. 


\section{Implications of Research}

Implications of my research include a confirmation of the role of wider politicaleconomic forces at work in determining people's diet-related health and an increased understanding of ethnic identity in terms of food and in terms of self-understanding and groupness. Within the larger scope of political-economic theory and Critical Medical Anthropology, my research contributes to understanding of several larger forces that apply to the case of heritage foods and human health. In addition, my research contributes to understandings of ethnic identity through discussion of food-related identity and the performance of identity and to understandings of self-understanding and groupness specific to multicultural contexts and tribal or ethnic group contexts.

My research contributes to the body of theory called political economy in that my research found that aspects of economics and policy have affected Native people's dietrelated health by diminishing Native access to heritage foods and thus knowledge of heritage foods. Through understandings of the role of economic status and economic factors like the expense of heritage foods for purchase and the expense of travel and time to hunt and gather heritage foods, my research confirms the constraints economics places on people's food choices. Further, my research confirms the role policy has played and continues to play in affecting Native people's access to heritage foods, through environmental policy that changed landscapes and ecosystems critical to heritage foodrelated resources, through government-mandated boarding schools that diminished heritage foods knowledge transmission from parent to child, and through current barriers to heritage foods practices, from hunting licenses to federal land regulations. In sum, 
research involving heritage foods access is a good example of wider systems in place that disadvantage people.

My work also contributes to Critical Medical Anthropology by supporting a structural explanation for diet-related health issues like diabetes and by demonstrating that social conditions dramatically affect people's health outcomes and are critical to health equity. In the case of PITU and Bishop Paiute Tribe members, social conditions as well as rapid changes in conditions contributed directly to Native American diet-related health through decreased access to heritage foods and increased access to processed foods. At the same time, participants in my research offered good examples of collective efforts that counter structural forces like the toxic food environment and partner with individual initiative to improve diet-related health. Efforts at the tribal and community levels are especially relevant to Critical Medical Anthropology in that they work to support and maintain health equity, or optimize conditions for positive health outcomes for individuals.

Finally, my research contributes to the anthropology of food and ethnic identity through articulating definitions of traditional and heritage foods and through exploring the role of food in self-understanding and groupness. Within the broader framework of ethnic identity, my research revealed multicultural aspects of participants' selfunderstanding as Native, LDS, and/or Paiute. Through the traditional foods dinner, my work explored the role of food, and sharing of food, in maintaining social cohesion and demonstrating group membership and groupness, or an individual's understanding of self in relation to the group. My research contributes to understandings of the performance of food-related identity as female participants performed their gender identity through food, 
food choices, and heritage foods practices and as participants resisted the delocalized food system through traditional and familiar food practices like gardening and canning. In sum, my work engaged with ethnic identity and political-economic theory to increase understanding of food-related identity, diet-related health, and health equity.

\section{Avenues for Further Research}

Possible avenues for future research on this topic include investigation of the specific effects of environmental degradation on heritage food-related resources and knowledge and the specific benefits of policy and public efforts that facilitate and encourage heritage foods access, practices, consumption, and knowledge transmission. Future research may prove fruitful if it includes a detailed look at particular heritage foods and the state of related resources and offers recommendations to improve access. In addition, interesting findings may result from a detailed evaluation of the benefits of policy that has been put in place, such as greater environmental protection of heritage food-related resources, or collective efforts that have been attempted, such as alternatives to delocalized food, in terms of facilitating Native people's heritage foods access and practices.

Finally, in terms of the applied nature of this research, I recommend in future research working with tribal leaders to elect a Native participant to gather heritage foods recipes and to provide leadership in creating a cookbook. The leadership of a Native person in this aspect of the research project would be most fruitful due to the investment of the person in long-term relationships with other participants and the contribution a 
Native person would make in the manner of collecting healthy, heritage foods recipes from a Native perspective and in the aesthetics of the cookbook itself.

Ellen and other participants shared with me intensely personal stories that demonstrated the nature of rapidly changing social conditions and the influence of changes on specific aspects of life, such as food practices and choices. "I had a good life with my grandmother," she said. "I had a different kind of life with her." Ellen enjoyed a traditional life with her grandmother and learned heritage foods practices from her, some of which she shared with her children.

However, participants like Ellen did not romanticize the changes they experienced from eating mostly heritage foods when they were younger to incorporating new foods as they grew older and increasingly integrated into the larger society. Participants recognized that rapid changes in diet and physical activity contributed to diet-related health issues, and through individual and collective efforts, worked to improve dietrelated health in their families and tribe.

In addition, participants did not romanticize their ethnic identity. While they clearly understood themselves to be Native or Paiute and associated particular foods with their heritage and identity, they recognized themselves as functioning in multiple worlds and came to value foods representing multiple aspects of their identity. 


\section{Bibliography}

Ahearn, Laura M.

1999 Agency. Journal of Linguistic Anthropology 9(1-2):12-15.

American Diabetes Association (ADA)

2012 Diabetes Basics. ADA. http://www.diabetes.org/diabetes-basics/.

Anderson, M. Kat

2006 Tending the Wild: Native American Knowledge and the Management of California's Natural Resources. Berkeley: University of California Press.

Appadurai, A.

1988 How to Make a National Cuisine: Cookbooks in Contemporary Indian Comparative Studies in Society and History 30:3-24.

Axelson, M. L.

1986 The Impact of Culture on Food-Related Behavior. Ann Rev. Nutr. 6:345363.

Baer, Hans, Singer, Merrill, and Ida Susser

2003 Medical Anthropology and the World System. $2^{\text {nd }}$ Edition. Westport, CT: Praeger Publishers.

Bailey, C.

2007 We Are What We Eat: Feminist Vegetarianism and the Reproduction of Racial Identity. Hypatia 22(2):39-59.

Beaulac, Julie, Kristjansson, Elizabeth, and Steven Cummins

2009 A Systematic Review of Food Deserts, 1966-2007. Prev. Chronic Dis. $6(3)$.

Berkes, Fikret and Nancy J. Turner

2006 Knowledge, Learning, and the Evolution of Conservation Practice for Social-Ecological System Resilience. Human Ecology 34(4):479-494.

Bernard, Russell H.

2002 Research Methods in Anthropology: Qualitative and Quantitative Methods. Walnut Creek, California: AltaMira Press.

Bigfoot, Dolores S., and Susan R. Schmidt

2010 Honoring Children, Mending the Circle: Cultural Adaptation of TraumaFocused Cognitive-Behavioral Therapy for American Indian and Alaska Native Children. Journal of Clinical Psychology 66(8):847-856. 
Biolsi, Thomas

2007 Race Technologies. In A Companion to the Anthropology of Politics.

David Nugent and Joan Vincent, eds. Pp. 19-41. Durham: Duke University Press.

Bishop Paiute Tribe

2012 About Us and Our History. A Sovereign Tribal Nation. Bishop Paiute Tribe. http://www.bishoppaiutetribe.com/aboutus.html.

Blackhawk, Ned

1997 Julian Steward and the Politics of Representation: A Critique of Anthropologist Julian Steward's Ethnographic Portrayals of American Indians in the Great Basin. American Indian Culture and Research Journal 21(2):61-81.

Bolton, Herbert E.

1950 Pageant in the Wilderness. Salt Lake City: Utah State Historical Society.

Braveman, Paula

2010 Social Conditions, Health Equity, and Human Rights. Health and Human Rights: An International Journal 12(2):31-48.

Brooks, Juanita

1972 The Southern Indian Mission. In Under the Dixie Sun: A History of Washington County by Those Who Loved their Forebears. Daughters of Utah Pioneers, eds. Pp. 23-33. Washington County Chapter, Utah.

Brubaker, Rogers and Frederick Cooper

2000 Beyond "Identity." Theory and Society 29:1-47.

Bryant, Vaughn M.

2003 Eating Right: Lessons Learned from Our Prehistoric Ancestors. In Reflections on Anthropology: A Four-Field Reader. Katherine A. Dettwyler and Vaughn M. Bryant, eds. Pp. 82-99. New York: McGraw Hill.

Bureau of Indian Affairs (BIA)

2013 Western Region - Tribes Served. Indian Affairs, US Department of the Interior. http://bia.gov/WhoWeAre/RegionalOffices/Western/WeAre/Tribes/index. htm

2013 Pacific Region - Tribes Served. Indian Affairs, US Department of the Interior. 
http://bia.gov/WhoWeAre/RegionalOffices/Pacific/WeAre/Tribes/index.ht $\mathrm{m}$

Calorie Count

2013 Calories in Bread, Indian (Navajo) Fry. Bread. About, Inc. http://caloriecount.about.com/calories-bread-indian-navajo-fry-i18031.

Centers for Disease Control and Prevention (CDC)

2012 Overweight and Obesity. Division of Nutrition, Physical Activity, and Obesity, National Center for Chronic Disease Prevention and Health Promotion. http://www.cdc.gov/obesity/data/adult.html.

Cheney, Brock

2012 Plain But Wholesome: Foodways of the Mormon Pioneers. Salt Lake City: University of Utah Press.

Clark, Lauren

1998 Gender and Generation in Poor Women's Household Health Production Experiences. In Understanding and Applying Medical Anthropology. Peter J. Brown, ed. Pp. 158-168. Mountain View, California: Mayfield Publishing Company.

Cook, Sherburne F.

1976 The Conflict between the California Indian and White Civilization. University of California Press: Berkeley and Los Angeles, California.

Cook, I.

2008 Geographies of Food: Mixing. Progress in Human Geography. 32(6):821833.

Cook, I., and M. Harrison

2003 Cross Over Food: Rematerializing Postcolonial Geographies. Transactions of the Institute of British Geographers 28:296-317.

Counihan, Carole

1999 Anthropology of Food and Body: Gender, Meaning and Power. New York: Routledge.

2004 Around the Tuscan Table: Food, Family and Gender in Twentieth Century Florence. New York: Routledge.

Cragen, Dorothy, and Genny Schumacher

1962 History. In Deepest Valley: Guide to Owens Valley and its Mountain Lakes, Roadsides, and Trails. Genny Schumacher, ed. San Francisco: Sierra Club. 
Dietler, Michael

2006 Alcohol: Anthropological/Archaeological Perspectives. Annual Review of Anthropology 35:229-249.

Douglas, Mary, ed.

1984 Food in the Social Order: Studies of Food and Festivities in Three American Communities. New York: Russell Sage Foundation.

Duruz, J.

2005 Eating at the Borders: Culinary Journeys. Environment and Planning D:

Society and Space 23:51-69.

Ervin, Alexander M.

2005 Applied Anthropology: Tools and Perspectives for Contemporary Practice. 2nd Edition. Boston: Pearson.

Euler, Robert C.

1966. Southern Paiute Ethnohistory. Salt Lake City: University of Utah Press.

Farmer, Paul

2001 Infections and Inequalities: The Modern Plagues. Berkeley: University of California Press.

2004 An Anthropology of Structural Violence. Current Anthropology 45(3):305-325.

Forrest, S. Cuch, ed.

2000 A History of Utah's American Indians. Logan, Utah: Utah State University Press.

Fowler, Catherine $\mathrm{S}$.

1994 Owens Valley Paiute. In Native America in the Twentieth Century: An Encyclopedia. Edited by Mary B. Davis. New York: Garland Publishing.

Gamburd, Michele

2008 Breaking the Ashes: The Culture of Illicit Liquor in Sri Lanka. New York: Cornell University Press.

Goody, Jack

1982 Cooking, Cuisine, and Class: A Study in Comparative Sociology. Cambridge: Cambridge University Press.

Greene, Melissa F. 
2007 There Is No Me Without You: One Woman's Odyssey to Save Het Country's Children. USA: Bloomsbury.

Gutierrez, R. A.

1991 When Jesus Came, the Corn Mothers Went Away. Stanford: Stanford University Press.

Halweil, Brian

2004 Eat Here: Reclaiming Homegrown Pleasures in a Global Supermarket. Washington, DC: Worldwatch Institute.

Hanrahan, Maura

2008 Tracing Social Change among the Labrador Inuit and Inuit-Metis. Food, Culture, \& Society 11(3):316-333.

Hanes, Richard, and Laurie Collier Hillstrom

2013 Paiutes. Countries and Their Cultures. Advameg, Inc. http://www.everyculture.com/multi/Le-Pa/Paiutes.html.

Hendrickson, Mary K., and William D. Heffernan

2002 Opening Spaces through Relocalization: Locating Potential Resistance in the Weaknesses of the Global Food System. Sociologia Ruralis 42(4):347369.

Herrick, C.

2008 To the West and East of Interstate-35: Obesity, Philanthropic Entrepreneurialism, and the Delineation of Risk in Austin, Texas. Environment and Planning 40:2715-2733.

Holt, Ronald L.

1992 Beneath These Red Cliffs. Albuquerque: University of New Mexico Press.

Holtzman, Jon D.

2006 Food and Memory. Annu. Rev. Anthropol. 36:361-378.

Humphrey, Lin T.

1988 "Soup Night": Community Creation Through Foodways. In We Gather Together: Food and Festival in American Life. Theodore C. Humphrey and Lin T. Humphrey, eds. Pp. 249-261. Logan, UT: Utah State University Press.

Jew, Stephanie, Abumweis, Suhad S., and Peter J. H. Jones

2009 Evolution of the Human Diet: Linking Our Ancestral Diet to Modern Functional Foods as a Means of Chronic Disease Prevention. Journal of Medicinal Food 12(5):925-934. 
Jones, Michael O., Giuliano, Bruce S., and Roberta Krell

1983 Foodways and Eating Habits: Directions for Research. Los Angeles, CA:

California Folklore Society 40(1).

Julier, Alice

2008 The Political Economy of Obesity: The Fat Pay All. In Food and Culture. Carole Counihan and Penny Van Esterik, eds. Pp. 482-499. New York:

Routledge.

Karr, Steven M.

2009 The Warner's Ranch Indian Removal: Cultural Adaptation,

Accommodation, and Continuity. California History 86(4):24-84.

Kahrl, William

1983 Water and Power: The Conflict over Los Angeles Water Supply in Owens Valley. Berkeley: University of California Press.

Kelly, Isabel T.

1934 Southern Paiute Bands. American Anthropologist 36(4):548-560.

Kelly, Isabel T. and Catherine S. Fowler

1986 Southern Paiute. In Handbook of North American Indians: Volume 11, Great Basin. William C. Sturtevant and Warren L. D'Azevedo, eds. Pp. 368-397. Washington: Smithsonian Institution.

Kessler, Bennett

2011 Vons Union Reaches Tentative Deal with Stores. Sierra Wave Media. http://www.sierrawave.net/8210/vons-union-deal/.

Kidder, Tracy

2004 Mountains Beyond Mountains: The Quest of Dr. Paul Farmer, A Man

Who Would Cure the World. New York: Random House.

Kleinman, Arthur

1988 The Illness Narratives: Suffering, Healing, and the Human Condition. USA: Basic Books.

1995 Writing at the Margin: Discourse Between Anthropology and Medicine. Berkeley, CA: University of California Press.

Kleinman, Arthur, Das, Veena, and Margaret Lock, Eds.

1997 Social Suffering. Berkeley, CA: University of California Press.

Knack, Martha C. 
1989 Contemporary Southern Paiute Women and the Measurement of Women's Economic and Political Status. Ethnology 28(3):233-248.

1997 Church and State in the History of Southern Paiutes in Cedar City, Utah. Journal of California and Great Basin Anthropology 19(2):159-178.

2001 Boundaries Between: The Southern Paiutes, 1775-1995. Lincoln: University of Nebraska Press.

Kuhnlein, Harriet V., and Olivier Receveur

1996 Dietary Change and Traditional Food Systems of Indigenous Peoples. Annu. Rev. Nutr. 16:417-42.

Kumanyika, Shiriki K.

2005 Social Change Implies Dietary Change. Social and Preventive Medicine 50:131-132.

Kuper, Adam

2003 The Return of the Native. Current Anthropology 44(3): 389-402.

Lawton, Harry W., Wilke, Philip J., DeDecker, Mary, and William M. Mason

1976. Agriculture Among the Paiute of Owens Valley. Journal of California Anthropology 3(1):14-16.

Liljeblad and Catherine S. Fowler

1986 Owens Valley Paiute. In Handbook of North American Indians: Volume 11, Great Basin. William C. Sturtevant and Warren L. D'Azevedo, eds. Pp. 416-427. Washington: Smithsonian Institution.

Lorber, Judith

1994 Paradoxes of Gender. New Haven: Yale University Press.

Mankekar, P.

2005 'India Shopping': Indian Grocery Stores and Transnational Configurations of Belonging. In The Cultural Politics of Food and Eating. J. L. Watson and M. L. Caldwell, eds. Pp. 197-214. Oxford: Blackwell.

Massey, D.

1994 Space, Place and Gender. Minneapolis, MN: University of Minnesota Press.

Mintz, Sidney W.

1996 Tasting Food, Tasting Freedom: Excursions into Eating, Culture, and the Past. Boston: Beacon Press. 
1997 Time, Sugar, and Sweetness. In Food and Culture: A Reader. Carole Counihan and Penny Van Esterik, eds. Pp. 357-369. Routledge, New York.

Mintz, Sidney W., and Christine M. Du Bois

2002 The Anthropology of Food and Eating. Annu. Rev. Anthropol. 31:99-119.

Nabhan, Gary P.

1985 Native Crop Diversity in Aridoamerica: Conservation of Regional Gene Pools. Economic Botany 39(4):387-399.

1998 Food, Health, and Native-American Farming and Gathering. In Eating Culture. Ron Scapp and Brian Seitz, eds. Pp. 169-180. Albany: State University of New York Press.

2004 Why Some Like It Hot: Food, Genes, and Cultural Diversity. Washington, DC: Island Press.

2008 Rooting Out the Causes of Disease: Why Diabetes is so Common among Desert Dwellers. In Food and Culture. Carole Counihan and Penny Van Esterik, eds. Pp. 369-380. 2nd Edition. Routledge, New York.

Nabhan, Gary P., Pynes, Patrick, and Tony Joe

2002 Safeguarding Species, Languages, and Cultures in the Time of Diversity Loss: From the Colorado Plateau to Global Hotspots. Annals of the Missouri Botanical Garden 89(2):164-175.

Nabhan, Gary P., Walker, DeJa, and Alberto M. Moreno

2010 Biocultural and Ecogastronomic Restoration: The Renewing America's Food Traditions Alliance. Ecological Restoration 28(3):266-278.

Nadeau, Remi A.

1950 The Water Seekers. New York: Doubleday.

Nellis Air Force Base (NAFB)

2012 Nevada Test and Training Range. Nellis Air Force Base, US Air Force. http://www.nellis.af.mil/library/factsheets/factsheet.asp?id=18506

Nestle, Marion

2002 Food Politics: How the Food Industry Influences Nutrition and Health. Berkeley, CA: University of California Press.

Nye, William 
1886 A Winter among the Piutes. Overland Monthly (second series) 7(39):293298.

Ortner, Sherry

1996 Making Gender: Toward a Feminist, Minority, Postcolonial, Subaltern, etc., Theory of Practice. In Making Gender: The Politics and Erotics of Culture. Pp. 1-20. Boston: Beacon Press.

2006 Reading America: Preliminary Notes on Class and Culture. In Anthropology and Social Theory. Pp. 19-41. Durham: Duke University Press.

Paiute Indian Tribe of Utah

2012 Paiute Indian Tribe of Utah: History. http://www.utahpaiutes.org/about/history/.

Pelto, Gretel H., and Perrti J. Pelto

1983 Diet and Delocalization: Dietary Changes since 1750. Journal of Interdisciplinary History XIV(2):507-528.

Perry, Cynthia, and Barbara Hoffman

2010 Assessing Tribal Youth Physical Activity and Programming Using a Community-Based Participatory Research Approach. Public Health Nursing: 24(2):104-114.

Phelan, Jo C., Link, Bruce G., and Parisa Tehranifar

2010 Social Conditions as Fundamental Causes of Health Inequalities. Journal of Health and Social Behavior 51(1):28-40.

Pilcher, J.

2008 Who Chased out the 'Chili Queens'? Gender, Race and Urban Reform in San Antonio, Texas, 1880-1943. Food and Foodways: History and Culture of Human Nourishment 16(3):173-200.

Prindeville, Diane-Michele

2004 "Feminist Nations? A Study of Native American Women in Southwestern Tribal Politics". Political Research Quarterly (Formerly WPQ) 57(1):101112.

Pritzker, Barry

2000 A Native American Encyclopedia: History, Cultures, and Peoples. Oxford University Press.

Reisner, Marc 
1993 Cadillac Desert: The American West and Its Disappearing Water, Revised Edition. New York: Penguin Books USA, Inc.

Ribot J., and N. L. Peluso

2003 A Theory of Access. Rural Sociology 68(2):153-181.

Rouse, Carolyn, and Janet Hoskins

2004 Purity, Soul Food, and Sunni Islam: Explorations at the Intersection of Consumption and Resistance. Cultural Anthropology 19(2):226-249.

Scheper-Hughes, Nancy

1994 Embodied Knowledge: Thinking with the Body in Critical Medical Anthropology. In Assessing Cultural Anthropology. Rob Borofsky, ed. Pp. 229-242. New York: McGraw-Hill.

Singer, Merrill

1995 Beyond the Ivory Tower: Critical Praxis in Medical Anthropology. Medical Anthropology Quarterly 9(1):80-106.

2001 Toward a bio-cultural and political economic integration of alcohol, tobacco and drug studies in the coming century. Social Science \& Medicine 53:199-213.

2007 Poverty, Welfare Reform, and the "Culture of Wealth.” Practicing Anthropology 29(4):43-45.

Singer, M. and S. Clair

2003 Syndemics and Public Health: Reconceptualizing Disease in Bio-Social Context. Medical Anthropology Quarterly, 17: 423-441.

Slocum, Rachel

2010 Race in the Study of Food. Progress in Human Geography 35(3):303-327.

Spicer, Paul

1997 Toward a (Dys)functional Anthropology of Drinking: Ambivalence and the American Indian Experience with Alcohol. Medical Anthropology Quarterly 11(3):306-323.

Spoon, Jeremy and Richard Arnold

2012 Collaborative Research and Co-Learning: Integrating Nuwuvi (Southern Paiute) Ecological Knowledge and Spirituality to Revitalize a Fragmented Land. Journal for the Study of Nature, Religion and Culture.

Spoon, Jeremy, Arnold, Richard, and the Nuwuvi Working Group 
2011 Nuwu Kanee, Nuwu Tooveenup (Our Home, Our Story): Nuwuvi (Southern Paiute) and the Spring Mountains. Prepared for Spring Mountains Recreation Area, Humbolt-Toiyabe National Forest, and U.S. Forest Service.

Steward, Julian

1933 Ethnography of the Owens Valley Paiute. Berkeley: University of California Publications of American Archaeology and Ethnology 33(3).

1938 Basin-Plateau Aboriginal Sociopolitical Groups. Bureau of American Ethnology Bulletin 120. Washington, D.C.: Government Printing Office.

1955 Theory of Culture Change: The Methodology of Multilinear Evolution. Urbana: University of Illinois Press.

1970 Basin-Plateau Aboriginal Sociopolitical Groups. Smithsonian Institution, Bureau of American Ethnology, No. 120. Reprint. Salt Lake City: University of Utah Press, 1970.

Stoffle, Richard W., and Maria N. Zedeno

2001 Historical Memory and Ethnographic Perspectives on the Southern Paiute Homeland. Journal of California and Great Basin Anthropology 23(2):229-248.

Tierney, R. Kenji, and Emiko Ohnuki-Tierney

2012 Anthropology of Food. In The Oxford Handbook of Food History. Jeffrey M. Pilcher, ed. Pp. 117-134. London: Oxford University Press.

Toiyabe Indian Health Project

2012 Elders. Health Services. Toiyabe Indian Health Project, Inc. http://www.toiyabe.us/elders.html.

Tom, Gary, and Ronald Holt

2000 The Paiute Indian Tribe of Utah. In A History of Utah's American Indians. Forrest S. Cuch, ed. Chapter 4. Logan, Utah: Utah State University Press.

Trimble, Joseph E.

2000 Social psychological perspectives on changing self-identification among American Indians and Alaska Natives. In Handbook of Cross-Cultural and Multicultural Personality Assessment. R. H. Dana, ed. Pp. 197-222. Mahwah, NJ: Lawrence Erlbaum Associates.

Turner, Katherine L., and Nancy J. Turner 
2008 "Where Our Women Used to Get the Food": Cumulative Effects and Loss of Ethnobotanical Knowledge and Practice. Canadian Journal of Botany 86(2):103.

Wilk, R.

2006 Home Cooking in the Global Village: Caribbean Food from Buccaneers to Ecotourists. Oxford: Berg.

Zafar, R.

1999 The Signifying Dish: Autobiography and History in Two Black Women's Cookbooks. Feminist Studies 25(2):449-469. 


\section{Appendix A: Interview Schedule for Native American Participants}

\section{Demographic Questions:}

1. What is your age?

2. With what Nation/ethnic group do you identify?

3. What language(s) do you speak?

4. Where were you born? Where did you grow up? Where have you lived during your life?

5. What place do you call home now? How long have you lived there?

6. Can you please tell me a little bit about your family? What is the education level of members of your family? Where do they live now?

7. Where did you go to school? How many years of school did you complete?

8. If you would like to share this information, what is your religion/spiritual affiliation?

9. What is your occupation?

\section{Food Questions:}

1. How do you define traditional foods? Please list traditional foods that you know/are familiar with.

2. Which foods are most important to your culture/traditions?

3. In the past, were there important social aspects to the ways in which these foods were gathered and prepared?

4. How do women obtain and prepare traditional foods? How do men obtain and prepare traditional foods? Was farming divided by gender? Why/why not?

5. Are current gathering practices new since the loss of access to ancestral lands? How have practices changed, if at all?

6. How did you learn about traditional foods? Who taught you about traditional foods? How did they teach you?

7. What traditional foods are available to you now? Can any of these foods now be purchased?

8. Do you prepare traditional foods? If you could prepare/eat any traditional foods for yourself or your family, what would they be?

9. How do you define human health? What does health mean to you?

10. In your opinion, how are traditional foods related to health?

11. Do you know of any recipes or food preparations that include traditional foods? Would you like to describe or demonstrate how to prepare traditional foods? Would you like to participate in a traditional foods potluck and cookbook with other participants in this project? (Recipes will be shared with other participants only and not with anyone else. Only participants will receive copies of the cookbook and will have ownership of the cookbook.) 


\section{Appendix B: Exhaustive List of Heritage Foods}

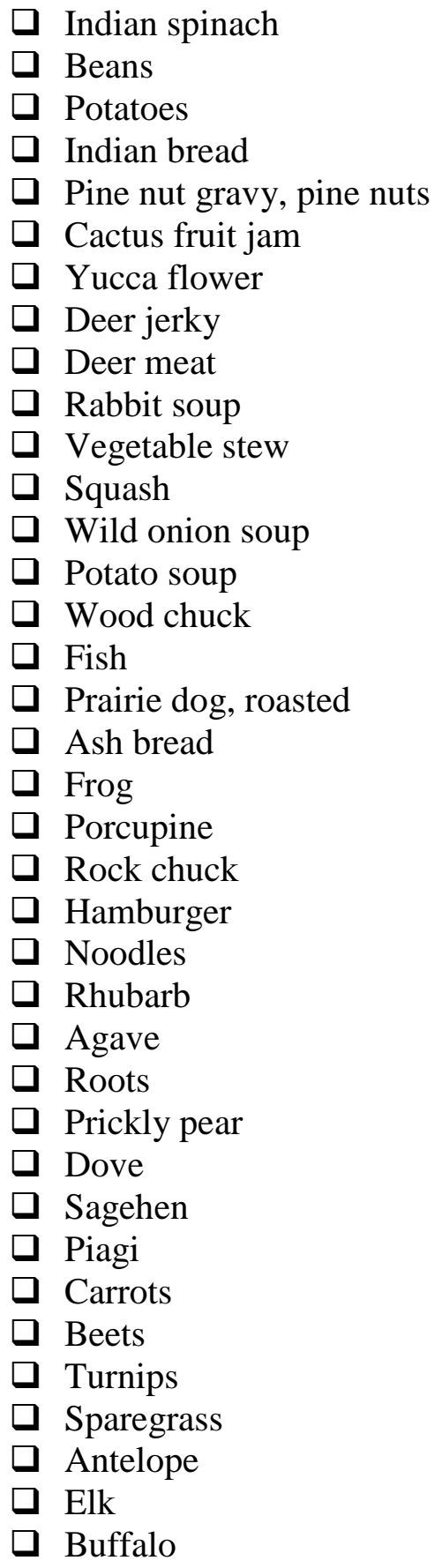

\begin{tabular}{|c|}
\hline $\begin{array}{l}\text { Chuckawalla } \\
\text { Strawberries } \\
\text { Chokecherries } \\
\text { Turtle soup } \\
\text { Bacon } \\
\text { Eggs } \\
\text { Jam } \\
\text { Peaches } \\
\text { Cherries } \\
\text { Plums } \\
\text { Green beans } \\
\text { Corn } \\
\text { Sunflowers } \\
\text { Acorn soup } \\
\text { Acorn flour } \\
\text { Cabbage } \\
\text { Cornbread } \\
\text { Watercress } \\
\text { Squirrel } \\
\text { Water fowl } \\
\text { Geese } \\
\text { Ducks } \\
\text { Squaw berry } \\
\text { Buffalo berry } \\
\text { Anderson wolf berry } \\
\text { Snake } \\
\text { Oven bread } \\
\text { Karate bread } \\
\text { Cowboy bread } \\
\text { Acorn porridge } \\
\text { Lettuce } \\
\text { Tomatoes } \\
\text { Watermelon } \\
\text { Stew beans } \\
\text { Celery } \\
\text { Onion }\end{array}$ \\
\hline
\end{tabular}




\section{Tribal Affiliation}

$$
\begin{aligned}
& \text { PITU }=21 \quad 68 \% \\
& \text { Bishop }=10 \quad 32 \% \\
& \text { Total }=31
\end{aligned}
$$

Gender

$$
\begin{array}{rlr}
\text { Female } & =24 & 77 \% \\
\text { Male } & =7 & 23 \% \\
\text { Total } & =31 &
\end{array}
$$$$
\text { Age }
$$
Older than $60=17$
$55 \%$

Younger than $60=14$

$45 \%$

\section{Average Age $=60$}


Appendix D: Map of the Research Area

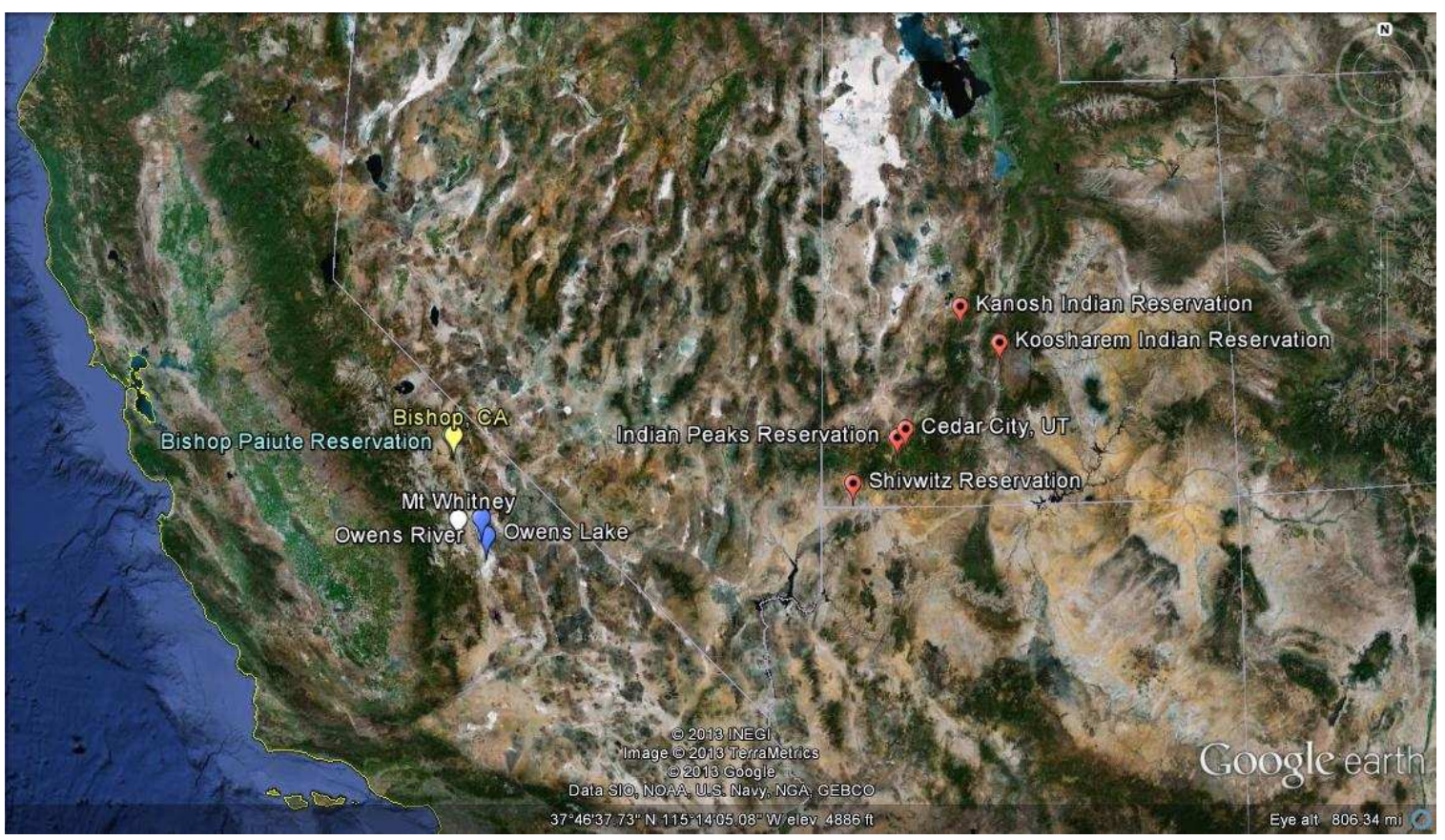




\section{Appendix E: Map of Owens Valley}

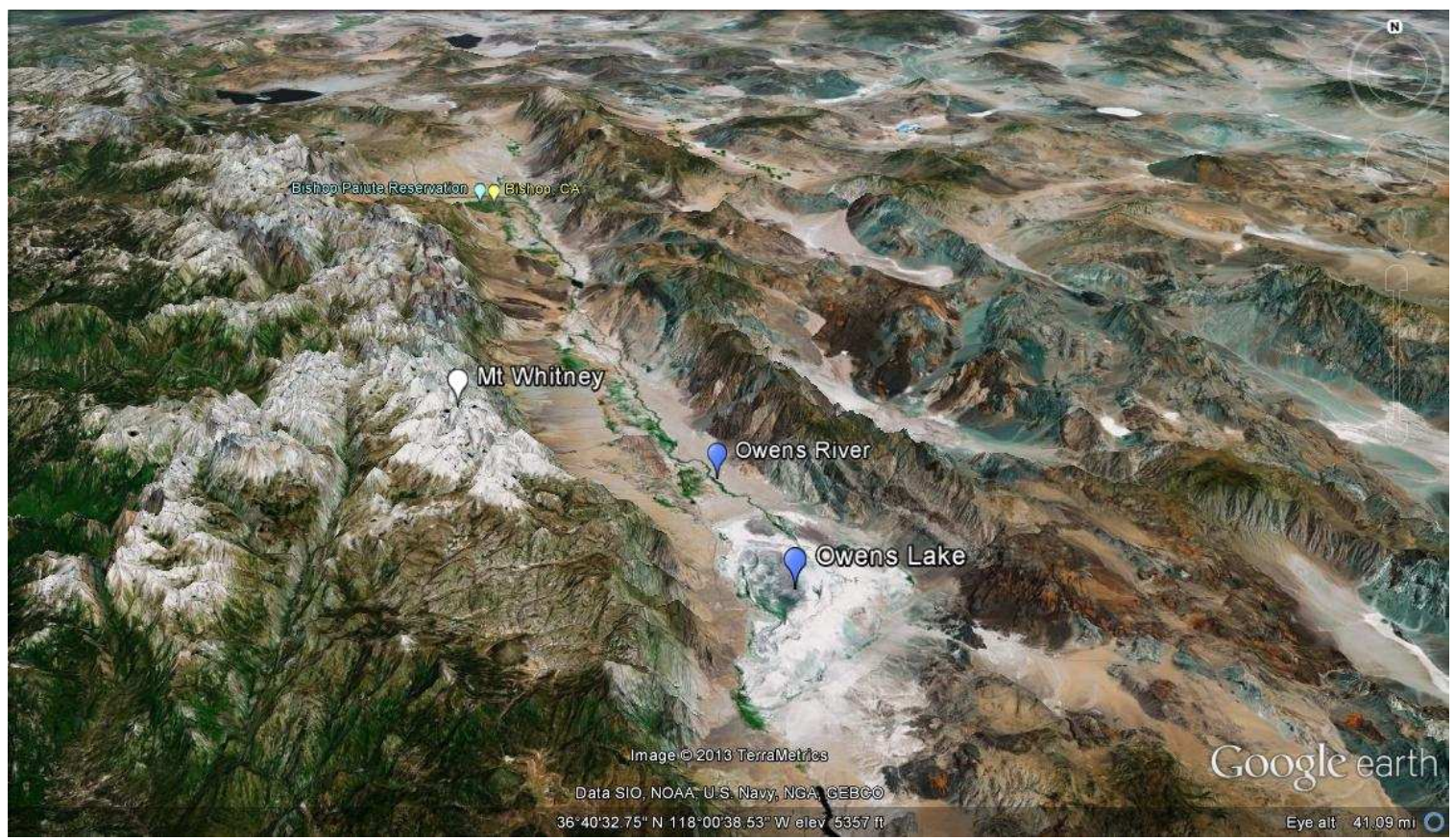

